\title{
Interactions of Polymers with Fillers and Nanocomposites, NIST, June 18-19, 1998: A Workshop Report
}

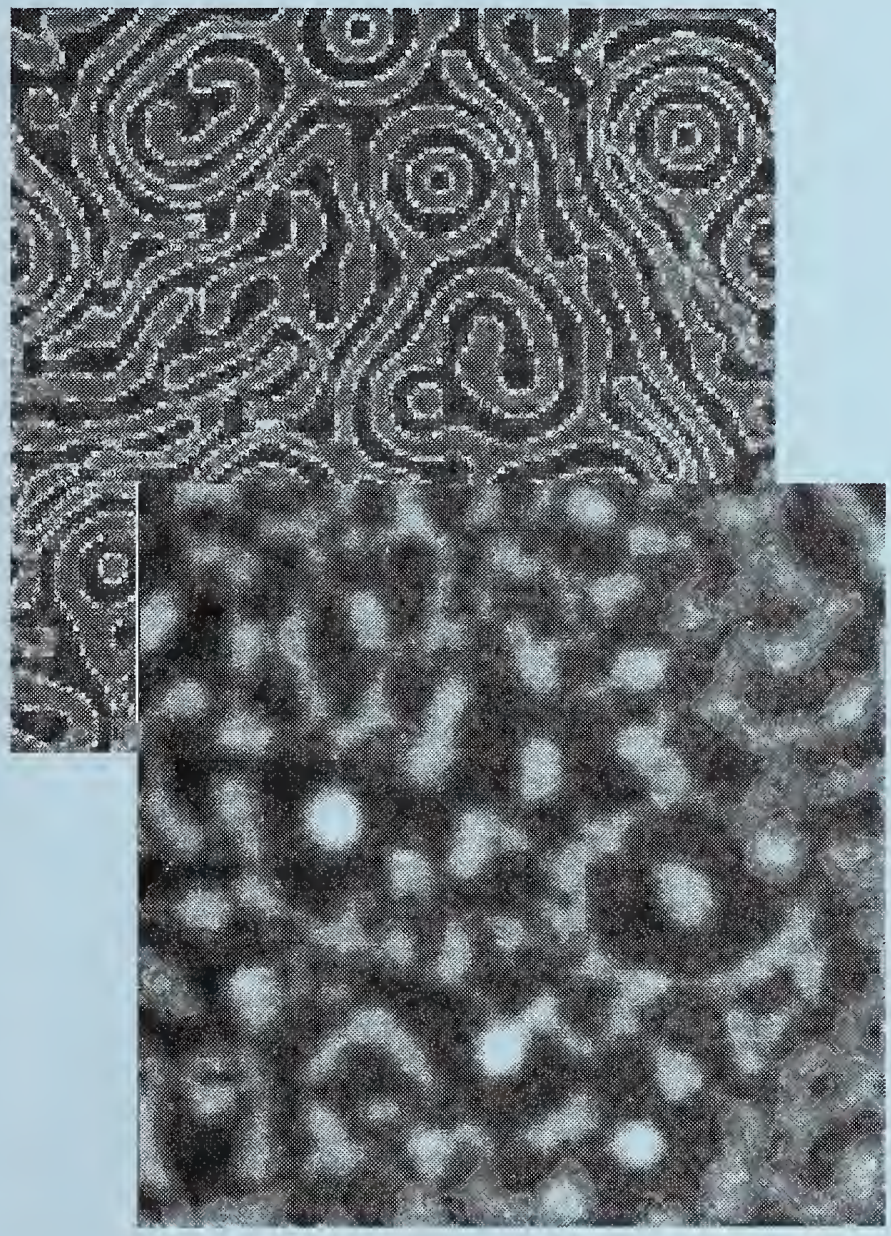

QC 100

.056

NO. 6312
Alamgir Karim

Acknowledgments

Alan Nakatani

Kathy Barnes

Brett Ermi

Jack Douglas

Erik Hobbie

\section{Eric Amis}

U.S. DEPARTMENT OF COMMERCE

Technology Administration

National Institute of Standards

and Technology

Gaithersburg, MD 20899 



\title{
Interactions of Polymers with Fillers and Nanocomposites, NIST, June 18-19, 1998: A Workshop Report
}

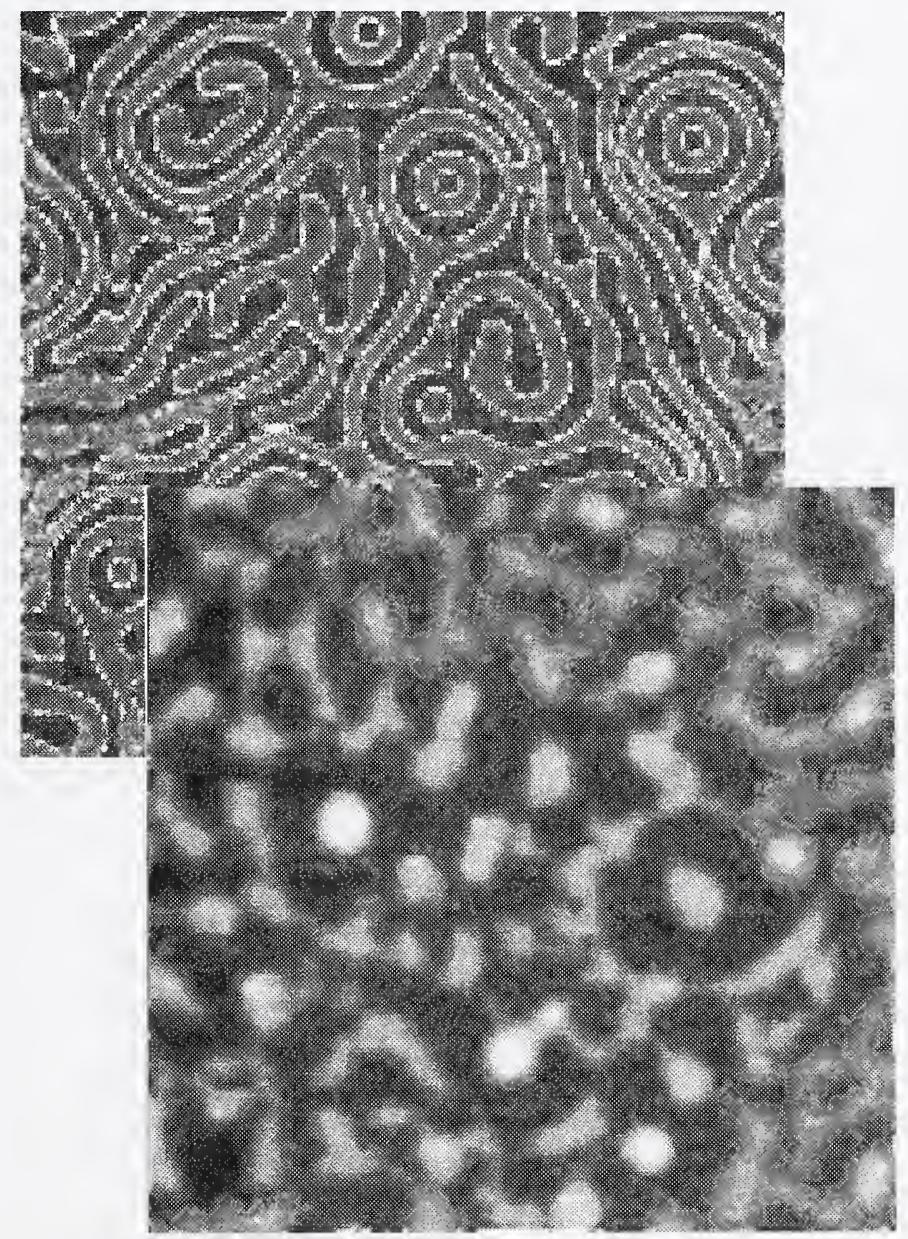

\author{
Alamgir Karim \\ Acknowledgments \\ Alan Nakatani \\ Kathy Barnes \\ Brett Ermi \\ Jack Douglas \\ Erik Hobbie \\ Eric Amis
}

U.S. DEPARTMENT OF COMMERCE

Technology Administration

National Institute of Standards and Technology

Gaithersburg, MD 20899

March 1999

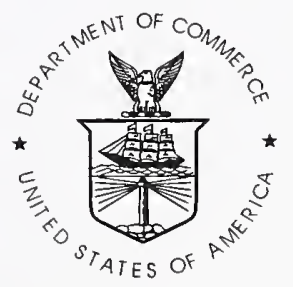

U.S. DEPARTMENT OF COMMERCE William M. Daley, Secretary

TECHNOLOGY ADMINISTRATION

Gary R. Bachula, Acting Under Secretary for Technology

NATIONAL INSTITUTE OF STANDARDS AND TECHNOLOGY

Raymond G. Kammer, Director 



\section{Table of Contents}

\section{Page}

INTRODUCTION

1.1 Workshop Objective 3

1.2 Executive Summary 3

1.3 Acknowledgements 4

1.4 Disclaimer 4

\section{PRESENTATIONS SUMMARY}

2.1 Opening Remarks 5

2.2 Compounding, Reinforcement and Toughening (I) 5

2.3 Compounding, Reinforcement and Toughening (II) 20

2.4 Nanocomposites 29

2.5 Theory and Modeling $\quad 44$

ATTENDEES RESPONSE

3.1 Results of Survey $\quad 54$

\section{CONCLUSIONS}

4.1 Research and Technology Needs 62

4.2 Summary and Future Outlook $\quad 65$

\section{APPENDICES}

Appendix I : Workshop Agenda 66

Appendix II: Attendee List $\quad 68$ 


\section{INTRODUCTION}

Filled polymers and nanocomposites represent a significant share of the world plastic market, competing strongly with costly high performance plastics. Yet, a major limitation to the potential growth and development of this industry has been a lack of understanding of the interactions between fillers and the polymer matrix and of measurements quantifying such interactions. This limitation has forced the filled polymers industry to adopt empirical approaches for product development, a procedure that necessarily delays product development cycles. Recently, renewed interest in the area of clay nanocomposite materials has spurred a number of industries to initiate research programs for developing applications of these materials. A long term plan for successful application of nanocomposites as materials with unique properties also requires fundamental characterization measurements. Thus, the need to identify critical technology development and state of the art measurement techniques to support the rapid growth of the filled polymers industry is generally recognized as being important.

\subsection{Workshop Objective}

\section{Problems, Opportunities and Challenges in Filled Polymers}

The NIST workshop entitled "Interactions of Polymers with Fillers and Nanocomposites" sought to gather experts on filled polymers and nanocomposites from industry and academia to identify the most critical issues hindering progress on filled polymer technology. Over two days the workshop participants highlighted important scientific and technical problems with the aim of identifying critical measurement techniques and modeling which can improve the performance, manufacture, and applications of filled polymers and nanocomposites. The recommendations of the workshop were used to better define the research efforts of the Polymer Blends and Processing Group in the area of filled polymers and nanocomposites, in addition to laying the foundation for collaborations with industry.

\subsection{Executive Summary}

Control of molecular-level interactions and measurement of polymer dynamics at the filler interface were identified by participants at a recent NIST sponsored workshop as the most critical issues in filled polymers and nanocomposites. Although filled polymers already represent a substantial fraction of polymer materials, recent developments in nanocomposites have attracted renewed interest in developing the science and technology base to optimize performance. The workshop focused on identifying the most critical issues hindering improvements in applications of filled polymers and nanocomposites. Of the 75 external participants, 50 were from industry, mostly experts in the area of filled polymer technology. Through productive discussions, the workshop participants highlighted and prioritized a range of future research and measurement needs for filled materials.

The discussions also laid the foundation for future research in this area, and collaborations between NIST, industry, and academia. The Polymer Blends and 
Processing Group of the Polymers Division, MSEL initiated research on polymer-filler interactions in 1997 using X-ray, neutron and light scattering in combination with microscopy techniques, and concepts that had been previously applied with great success on polymer blends. The results of the workshop will be used to plan future directions of the NIST work.

\subsection{Acknowledgements}

The authors would like to thank the speakers for their valuable presentations, and the session coordinators for conducting the meetings of the workshop. In addition, we would like to thank the participants for attending and contributing to the discussion sessions. Furthermore, we would like to express our appreciation to the Conference Facilities Group at NIST for providing the arrangements and organization that made the workshop possible.

\subsection{Disclaimer}

Commercial equipment, instruments, software, materials or services are identified to adequately report the presentations and discussions that took place. Such identification does not constitute nor imply recommendation, endorsement, or criticism by the National Institute of Standards and Technology (NIST). Nor does NIST take responsibility for the accuracy or source of the various non-NIST numerical values reported in this document, or the use of units other than those of the International System by non NIST authors. 


\section{PRESENTATIONS SUMMARY}

\subsection{Opening Remarks}

Dr. Leslie Smith (MSEL Director)

The Materials Science and Engineering Laboratory (MSEL) director, Dr. Leslie Smith emphasized the importance of fillers and nanocomposites to the polymer industry and the need for fundamental measurements in the area. Dr. Smith described the laboratories structure under MSEL and also the different NIST programs, placing emphasis on the Advanced Technology Program and the Measurements and Standards Laboratories. The ways by which NIST identifies needs were summarized: 1) Visits to and by industrial researchers; 2) Through workshops organized by NIST; and 3) Through industrial roadmaps.

Dr. Eric Amis (Group Leader, Polymer Blends and Processing Group)

Dr. Eric Amis described the goals of the Polymer Blends and Processing Group and emphasized that the area of filled polymers and nanocomposites was becoming a high priority area for research by this group at NIST. He iterated the purpose of the workshop as gathering the experts in the area of filled polymer technology to highlight the key areas and critical issues hindering progress in the area. The ideas generated through the Workshop would be used guide the blends research efforts at NIST and potentially establish long term collaborations with industry in some critical areas.

Dr. Alamgir Karim (Physicist, Polymers Blends and Processing Group)

Dr. Karim discussed the Blends and Processing Group research program in the area of filled polymers to study fundamental aspects related to measurements of filled polymers and nanocomposites. He described the nature of research being conducted by the group in the area of filled polymers and nanocomposites that take advantage of some unique measurement capabilities at NIST.

\subsection{Compounding, Reinforcement and Toughening Session (I)}

"Concepts in Rubber Chemistry: The Role of the Filler particle", Gary T. Burns, Dow Corning Corp., Pare Industriel-Zone C, Seneffe B-7180, Belgium

Dr. Burns gave an overview of filled polymer processing technology and discussed properties of fillers that impact material characteristics. One of the problems with elastomers is that they change during compounding so that the initial and final state elastomers are quite different. He emphasized that while much has been done to characterize fillers prior to processing, the state of the filler in the final product is poorly characterized. Also discussed were the two main features controlling properties of the filled materials: Filler structure/geometry and the surface energy.

Regarding filler structure/geometry the primary particle size is the most important contribution to the surface area. The size of typical primary particles is in the range of ( 3 to 50$) \mathrm{nm}$. In this regard, the measured surface area by gas adsorption may not be the true surface area. The aggregation of the primary particles and packing control porosity, 
and hence spatial arrangements of particles within aggregates and of the agglomerates are important. However, while the role of aggregation is important, there is no well defined measure of its reinforcement properties. Additionally, the density makes a difference and is important.

Surface area can be measured by BET $\left(\mathrm{N}_{2}\right.$ adsorption) and CTAB adsorption. The relevant formulas for obtaining the surface area of spheres and rods were discussed. Pore volume can be measured by $\mathrm{BJH}$ analysis, mercury porosimetry, and dibutyl phthalate absorption. The role of surface roughness is system specific, which implies that there are surface energy effects, so that the measured surface area may not be related to the true surface area.

Concepts of bound and occluded rubber were introduced as measures of polymerfiller interaction. The bound rubber are the rubber molecules which are strongly adhered to the filler surface, while the occluded rubber are the polymer chains trapped in voids of aggregates and are shielded from the applied stress. The bound rubber has a layer of directly attached chains and a second layer of entangled chains. Shape factor could be related to occluded rubber. Bound rubber fraction can be measured by NMR techniques as well as by extraction. All such measurements seem to provide satisfactory results.

On the theoretical side, Dr. Burns discussed the Modified Smallwood-Guth-Gold Equation for predicting the modulus of a filled material as a function of filler volume fraction only.

In his concluding remarks, he stated the following needs for advancing the understanding of filled polymers: 1) Development of a generalized equation with welldefined variables such as filler shape, filler porosity, filler-filler and filler-polymer interactions; 2) Accepted techniques to measure these variables; 3) Characterization of the state of the filler not only before but after mixing as well.

Discussion- The point was raised that occluded and bound rubber are related to hysteresis behavior and that rheological effects often differ from observed mechanical behavior.

\section{Select Figures}

\section{Factors Contributing to Reinforcement}

Fig. 1

- Surface Area of Filler

- Aggregate Structure

Porosity (inherent and in-situ generated)

Shape (probability of filler-filler contact)

- Surface Energy

Polymer-Filler Interactions

Filler-Filler Interactions 

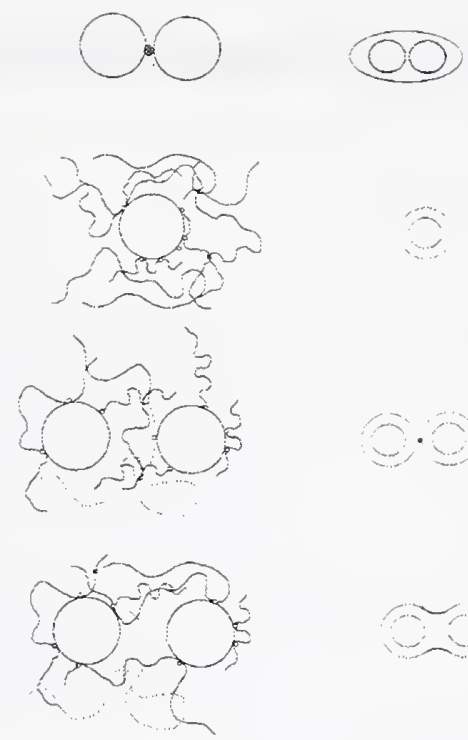

Individua Panticles Interacting with Each Other

Individual Particles Interacting with

Polymer Matrix

Particles adhering through entanglements of adsorbed polymer

Paricles adhering through sharing of adsorbed polyner

\section{Fig. 2}

\section{TLLERS}

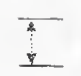

8
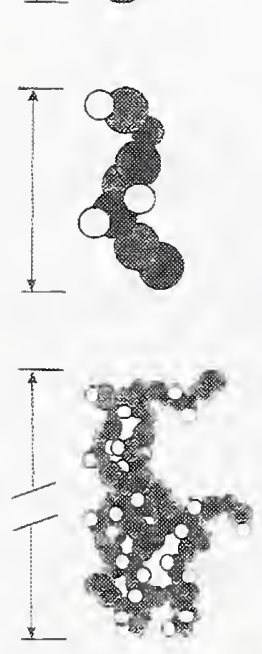

Primary Particle

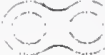

Dow Coming $(3-50 \mathrm{~nm})$

POLYMER CHAINS

Polymer Cross-section

$\left(-2-10 \mathrm{~nm}^{2}\right)$

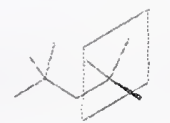

\section{Aggregate $(100-200 \mathrm{~mm})$}

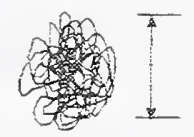

Random Coil ( $10-50 \mathrm{~mm})$

Agglomerate $\left(10^{4}-10^{5} \mathrm{~nm}\right)$

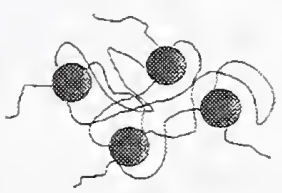

Block Copolymer

(10-100 mo donains)

Dow Coming

Fig. 3 


\section{Primary Particle Size Versus Surface Area for Silica Particles}

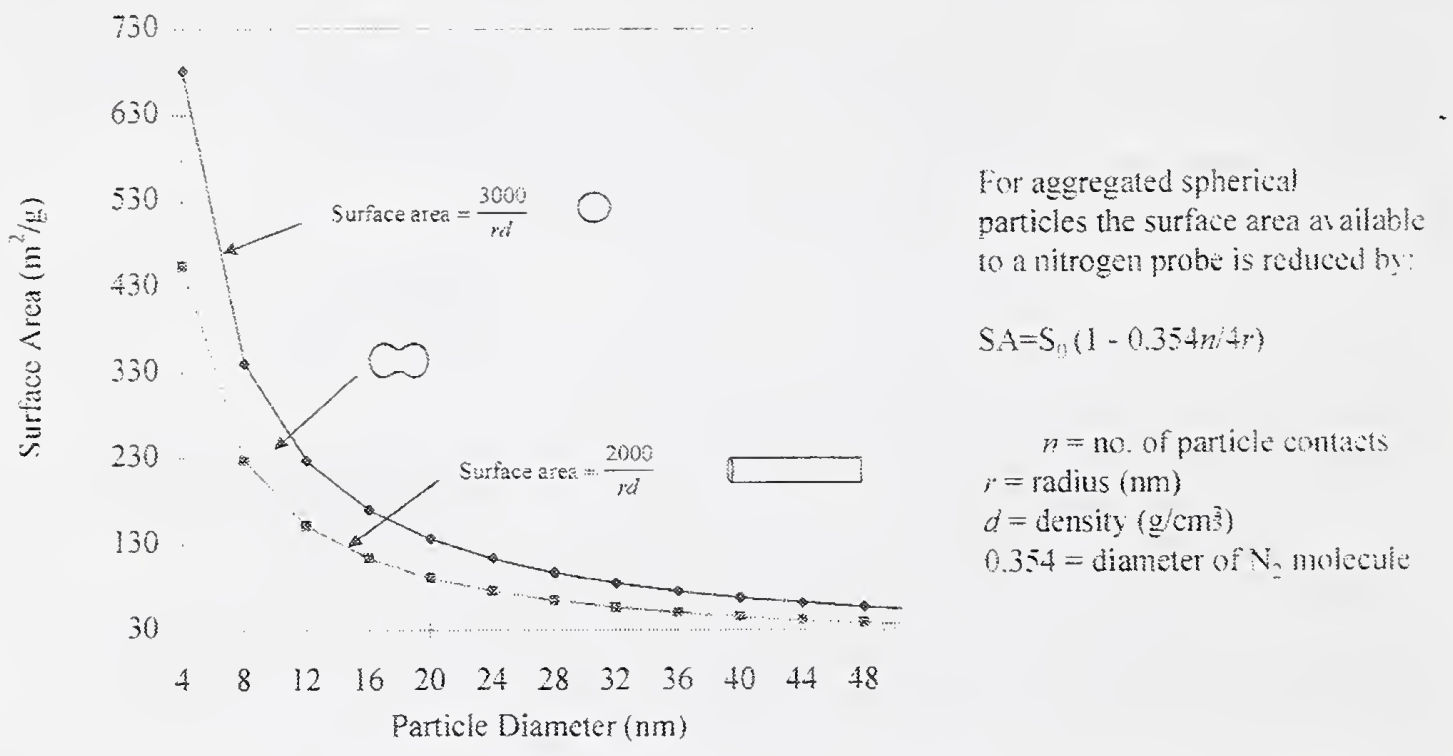

Fig. 4

\section{Filler / Aggregate Structure}

\section{Structure or Geometric Parameters:}

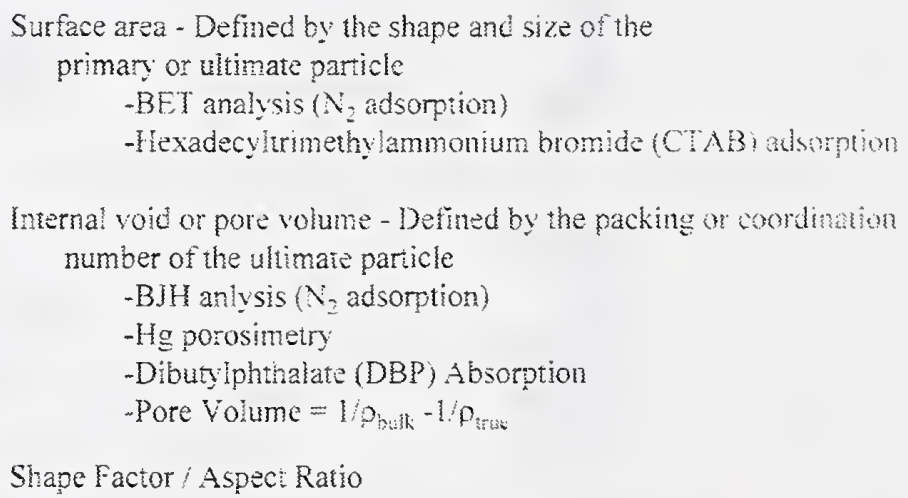

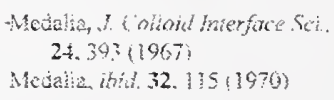

OCCLUDED RUBRER - Rubber whicls is situated within the irregular contours of an aggregate and is thas shielded from an applied strexs. The presence of occluded nubber increuses the effective volume fraction of 3 iller. For carbon blacks,

$$
\phi=0.5 \phi\left[1-\left(\frac{1+02139(D B P .4)}{1.6}\right)\right.
$$

\section{Fig. 5}




\section{Surface Differences between Silicas and Carbon Black}

\section{Silica}<smiles>C[SiH2][SiH](O)[SiH](O)[SiH2]O</smiles>

Carbon Black

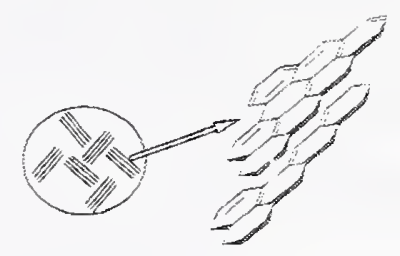

Functionality at edge of

graphite plane

-Fumed $(30-40 \%$ isolated / $60-70 \%$ vicinal $)$

-Precipitated (predominantly vicinal)

Fig. 6

\section{Needs}

General Equation with clearly defined, measurable variables

- filler shape (probability /perculation factor)

- filler porosity (effect of pore volume, pore shape and pore size distribution)

- filler-filler interactions $\left(y^{* \prime \prime}\right)$

- filler-polymer interactions $\left(\gamma_{s}^{*}\right)$

Accepted/Standardized Techniques to measure variables

State of Filler Before and After Mixing

Fig. 7

"Dynamic Studies of Compounds-Latest Results", Henry Yang, M. Gerspacher and C.P.O' Farrell, Sid Richardson Carbon Co., Fort Worth, TX

Dr. Yang discussed the role of filler distribution on high and low frequency rheological behavior. He stated that carbon black has no porosity or surface groups and that the crystal edges in the particles are the active sites. Nevertheless, there are a 
number of different interactions, which need to be identified and quantified, and the relevance of each interaction needs to be determined.

The high frequency behavior is dominated by the polymer while the low frequency behavior is dominated by the filler properties. Increasing filler dispersion lowers reinforcement while it increases the attenuation coefficient. Low strain, low frequency behavior can be related to the filler-filler interactions and low strain, high frequency behavior can be related to the filler-polymer interactions.

Discussion- Questions were raised concerning the lack of surface groups and porosity in carbon blacks.

\title{
Select Figures
}

\section{Dynamics of Tread Compounds}

Tire treads undergo periodic deformations

Two Domains of Strain Energy Input
A. Wheel Assembly
- Frequency $<40 \mathrm{~Hz}$
- Tread deformation (strain)
between .1 and $20 \%$
B. Tire/Road Contact
- Very small tread volume involved
- Very small strain
- Very high frequency $(\mathrm{MHz}+)$

Strain and Frequency are Essential Parameters

\section{Fig. 1}

\section{Tire Tread Requirements}

\author{
Good Rolling Resistance \\ Low Heat Generation in (A) \\ Good Traction \\ High Energy Adsorption in (B) \\ Good Wear \\ Complex Mechanism
}

Low Hysteresis at Low Frequency

High "Hysteresis" at High Frequency

Ideal Tread Compound

$806 \mathrm{~F} 004 \mathrm{~F}$

Fig. 2 


\section{Tire Tread Compounds}

\section{Main Components}

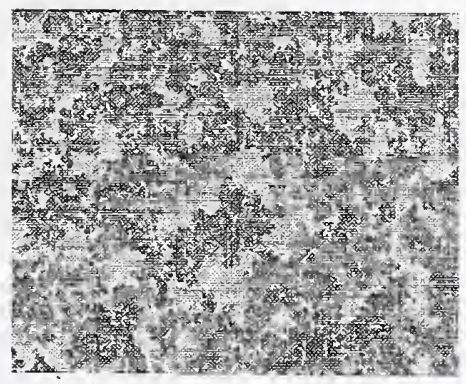

* Elastomers

Crosslinked Networks

Polymer Chain Mobility

* Filler (Carbon Black)

(Percolated) Network

Ridgid Filler Aggregate

\section{Materials Interactions}

Fig. 3

\section{Interactions}

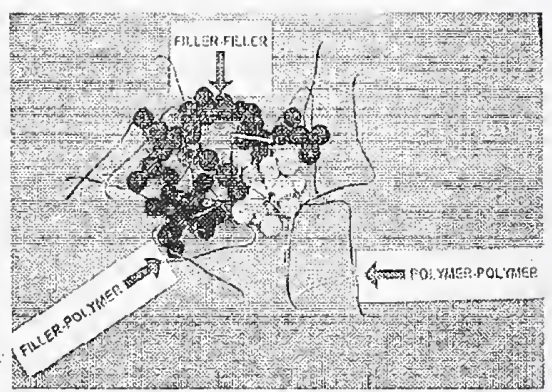

Type of Interaction

* Van der Waals

$\rightarrow$ Carbon Black Network Carbon Black - Polymer

* Chemical/Covalant $\rightarrow$ Surface Crosslink

* Electrostatic

$$
\rightarrow \text { Polymer Chains }
$$$$
\text { Carbon Black - Polymer (?) }
$$

Amount of Interaction * Filler Morphology and Dispersion

* Crosslinking Density

* Polymer Type

\section{Interactions Relevancy?}

Fig. 4 


\section{Strain Energy and Interactions \\ * Low Frequency \\ * Strain Range below 30\%}

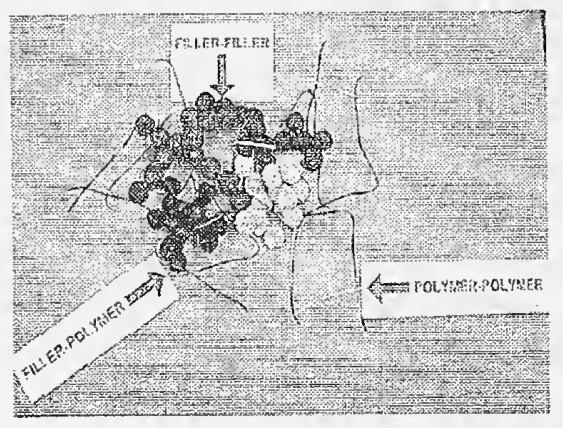

- Carbon Black Network

- Polymer Chains

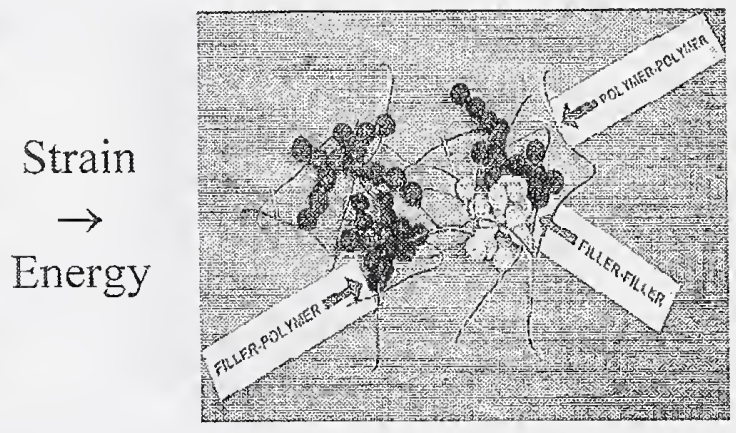

$\rightarrow$ subnetworks

$\rightarrow \quad\left(t_{R} \sim t_{E}\right)$ relaxation

Carbon Black Network Dominates

Fig. 5

\section{Strain Energy and Interactions (Cont'd)}

* High Frequency $(\mathrm{MHz})$

* Very Low Strain

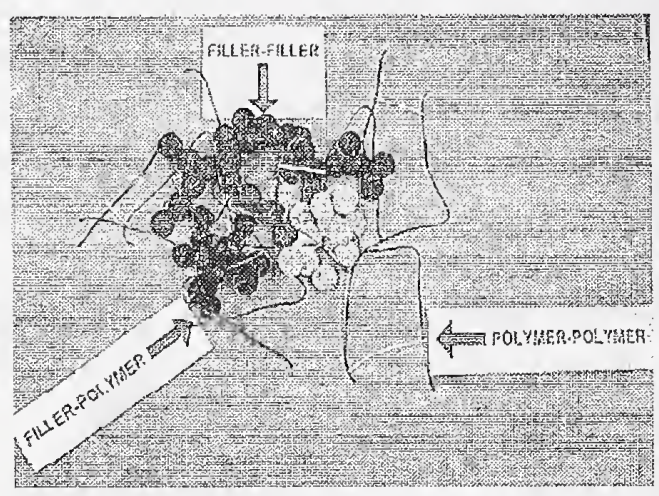

- Carbon black network not disrupted

- Only short polymer chains segment relax

Fig. 6 


\section{Future Evaluations}

* Effect of shear rate

* Effect of temperature

* Effect of substrate

- nature

- roughness

- dry / wet

Fig. 7

Develop Meaningful Testing

(6) Parameters

"Flow-induced Microstructural Changes in Filled Polymeric Liquids", Saad A. Khan, Srinivasa R. Raghavan, Department of Chemical Engineering, North Carolina State University, Raleigh, NC 27695-7905

One of the aspects of interest in filled systems is to elucidate microstructural changes caused by flow fields, and to evaluate whether these changes persist over long periods of time. This point becomes particularly relevant in non-traditional composite systems where the particle/filler interactions can lead to a wide range of rheological behavior, such as in fumed silica systems in low molecular weight polymers. In fumed silica systems, the surface characteristics can be tailored to give rise to two different classes of filled materials: (a) colloidal gels (networks); and (b) colloidal (stabilized) suspensions. In the case for gels, a three-dimensional network of colloidal (fumed silica) particles extends throughout the volume of the system. Under the action of oscillatory pre-shear at large deformations, the microstructure is disrupted into distinct entities. The critical variable is not the shearing time but the strain amplitude. The equilibrium microstructure can be changed with pre-shear and shows anomalous behavior in terms of the existence

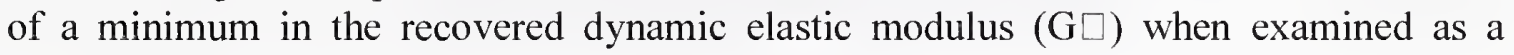
function of pre-shear strain amplitude. To better understand the changes occurring during shear, the concept of fractal dimension was introduced. Changes in the power law behavior of $\mathrm{G} \square$ and the critical strain amplitude versus filler volume fraction was observed following preshear. This could be related to changes in fractal dimension from 1.75 before shear to 2.02 following moderate preshear. While the fractal dimension before shear was experimentally obtained, that following shear was obtained using the model of Potanin et al. and requires further experimental verification.

In the case of stabilized suspensions, a dramatic increase in steady-shear viscosity was observed at high shear-rates (shear-thickening). Likewise, a dramatic enhancement in the dynamic properties (complex modulus $G^{*}$ or complex viscosity $\eta^{*}$ ) was also observed under large oscillatory deformations and high frequencies - a phenomenon 
referred to as strain-thickening. A unique correlation between steady shear-thickening and dynamic strain-thickening was established utilizing a "modified Cox-Merz rule." While these shear and strain thickening behavior are consistent with the formation of hydrodynamic clusters, direct evidence of microstructural rearrangements during shear would be highly desirable.

Discussion- The role of particle and orientation and utility of techniques such as rheooptics was raised. Since the structures are not anisotropic, it was doubtful there would be much orientation, hence the rheo-optical techniques would not be very useful.

\section{Select Figures}

Fig. 1

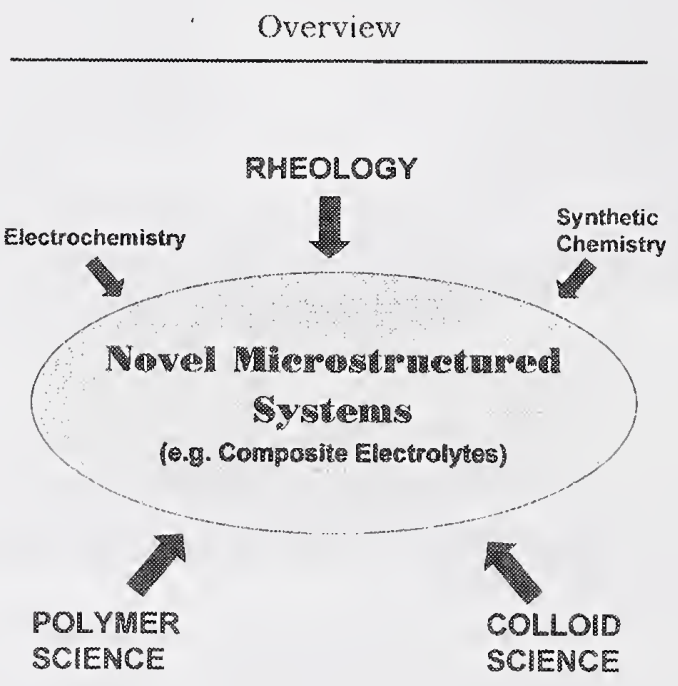

\section{Polymer Electrolytes for Lithium Batteries}

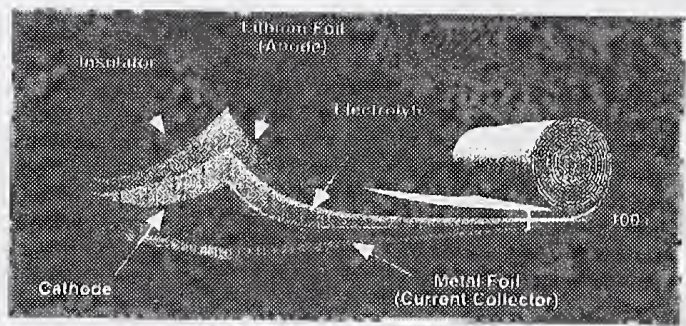

Material Requirements

- Acceptable ionic conductivity $\left(>10^{-3} \mathrm{~S} / \mathrm{cm}\right.$ at $\left.298 \mathrm{~K}\right)$

- Chemically and electrochemically stable

- Mechanically stable (solid-like at end-use conditions)

- Processable

\section{Fig. 2}




\section{Composite Polymer Electrolytes (CPEs)}

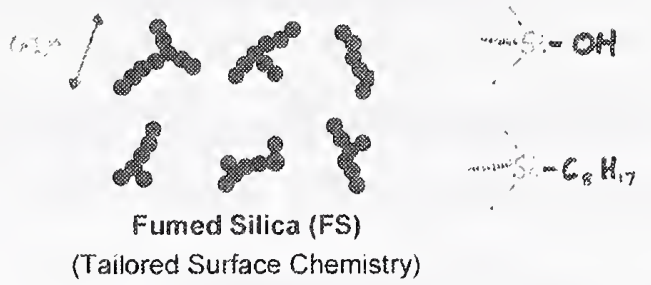

$\$$

Poly(ethylene glycol) (PEG-dm), Lithium salt

(low molvt; end-capped) (e.g. Li imíde)

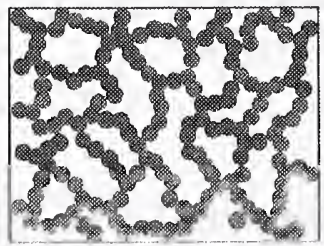

GEL (Physical)

Fig. 3

(Mechanically Stable, yet processable)

\section{Fundamental Issues}

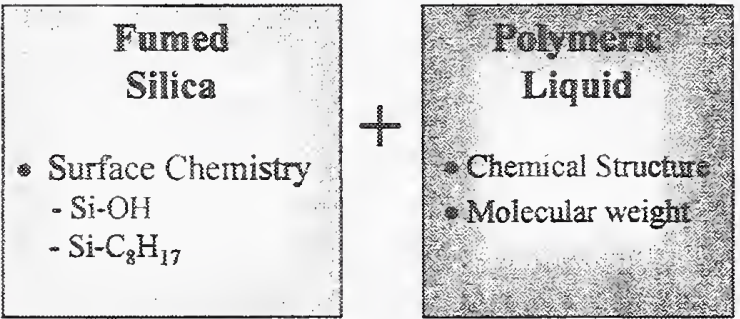

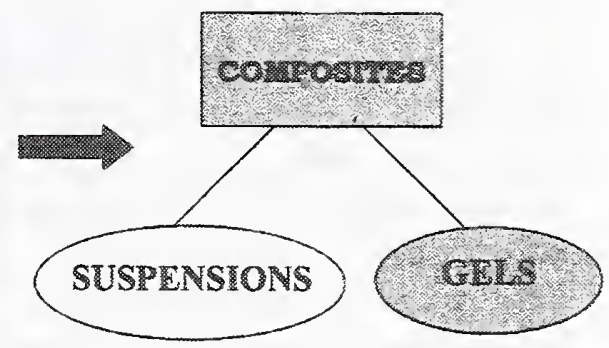

Fig. 4

\section{Obiectives}

- Equilibrium Microseructure \&

- Behavior Under Shear $\$$ 


\section{COLLOIDAL GELS}

- Show anomalous recovery behavior on being subjected to oscillatory shear at moderate strains.

- Attributed to changes in fractal dimension due to shear

\section{COLLOIDAL SUSPENSIONS}

- Show shear-thickening under steady shear and strain-thickening under oscillatory shear. The two phenomena can be correlated by an extended Cox-Merz rule.

- Both phenomena are attributed to hydrodynamic forces which induce cluster formation

Above hypotheses need to be experimentally verified.

Fig. 5

"Recent Industrial Developments: From Anti-Static Polymers to Artificial Marble", Moshe Narkis, Dept. of Chemical Engineering, Technion, Israel Institute of Technology, Haifa, Israel

Dr. Narkis commented that while compression molding studies are available in the literature they are of little interest to industry. This is because injection molding is typically used in industry and so these types of studies are preferred by industry. He stated the need for new anti-static injection moldable composites since most current materials become insulating when they are injection molded. He illustrated these ideas with carbon black, glass fibers, and polypropylene (PP) with 3 other component fillers. Finally, he urged the need to better understand multicomponent (greater than 3) immiscible systems and stated the need for better conductivity definitions.

Discussion- Question was raised concerning the possibility of measuring the conductivity during and after processing. Another question was raised concerning the effect of carbon black structure on its capacity to migrate.

\section{Select Figures (Next page)}




\section{CARMELSTAT ${ }^{\text {TM }}$}

\section{The Unique $10^{6}-10^{9} \mathrm{ohms} / \mathrm{sq}$ ESD Material with Only $1 \%$ Carbon Black -}

About $1 \%$ carbon back provides permanent, controllable, consistent resistivity

Controlled sitfiness! impact balance

High Heat Deflection Temperature

Low-sloughing, ciean room compatible

Cost - effective

Fig. 1

THE BEHAVIOR OF CARBON BLACK / MISCIBLE

POLYMER BLENDS IS SIMILAR TO CARBON

BLACK / SINGLE POLYMER SYSTEMS, IN

CONTRAST THE DISTRIBUTION OF BLACK

PARTICLES IN AN IMMISCIBLE POLYMER

BLEND IS MUCH MORE COMPLEX.

Fig. 2

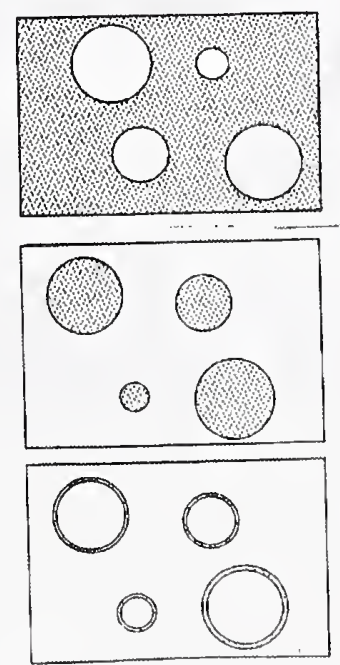


FOR A GTVEN POLYMER, THE TRANSITION

DEPENDS ON THE TYPE OF CARBON BLACK

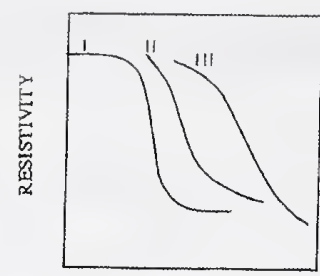

$$
D B P_{1}>D B P_{I I}>D B P_{I I I}
$$

CONCENTRATION

POR A GIVEN CARBON BLACK, THE

TRANSITION DEPENDS ON THE POLYMER

TYPE. THE CRITICAL PERCOLATION

CONCENTRATION CAN BE CORRELATED WITH

THE POLYMER SURFACE - TENSION

Carmona - 1993 Sumita - 1982

Fig. 3
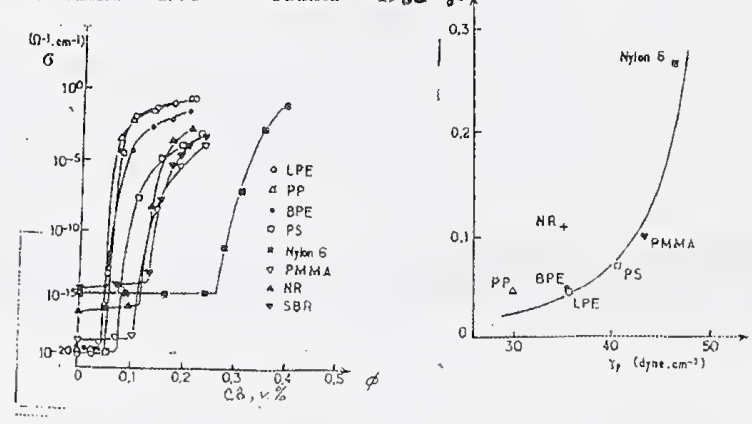

\section{Resistivity vs. Carbon Black Loading --}

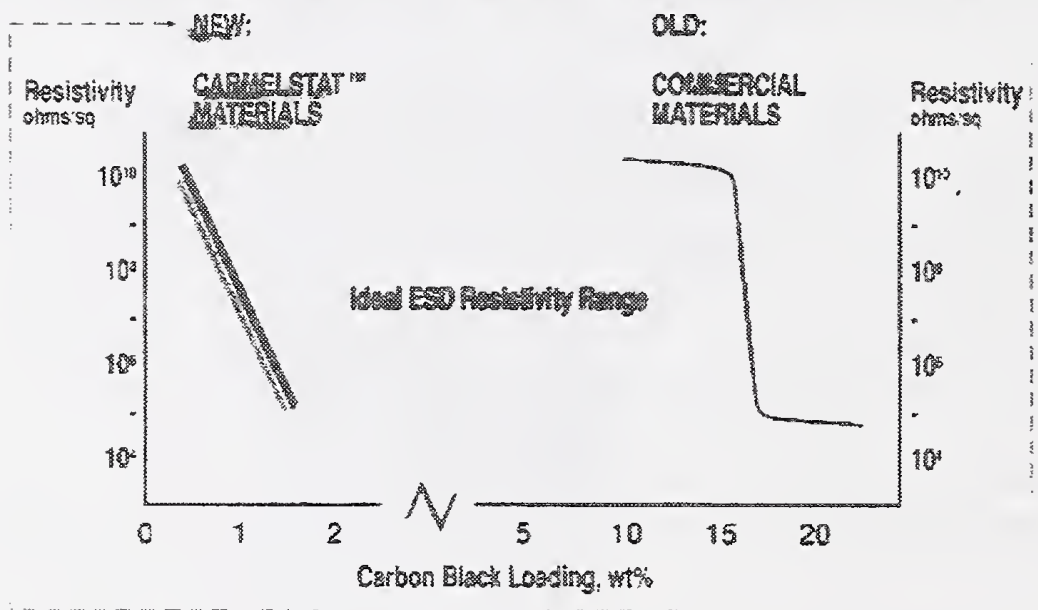

Fig. 4

(9) CALIMEL ULEFINS 


\begin{tabular}{|c|c|c|c|c|c|c|}
\hline Property & $\mathrm{PP} / \mathrm{GF} / \mathrm{CB}$ & $\mathrm{PP} / \mathrm{CB}$ & $\mathrm{PH} / \mathrm{CF}$ & $\mathrm{PP} / \mathrm{CF}$ & $\begin{array}{c}\mathrm{PP} / \mathrm{CK} \\
\text { Commercial }\end{array}$ & $\begin{array}{c}P \mathrm{P} / \mathrm{CF} \\
\text { Compercial }\end{array}$ \\
\hline Concuctive Filler, \% & 1.2 & 6 & 11) & 15 & $\geq 15$ & $>15$ \\
\hline Tensile Strength, MPa & 55 & 38 & 38 & +1 & 22 & +1 \\
\hline Flexural Modulus, MPa & 3300 & 2910 & 3279 & 6908 & $124 i)$ & $\$ 300$ \\
\hline Ixod Impact, notched, $/ / \mathrm{m} 23^{\circ} \mathrm{C}$ & 57 & 13 & 43 & 50 & 180 & 54 \\
\hline Heat Distortion Temperruture, ${ }^{\circ} \mathrm{C}$ & 161 & 95 & $1+3$ & $1+7$ & 115 & 132 \\
\hline Volume Resistivity, obsu-con & $10^{6}-10^{7}$ & $<10^{3}$ & $10^{2}$ & $\angle 10^{3}$ & $10^{8} \cdot 10^{6}$ & $10^{2}-10^{5}$ \\
\hline Surface Resistivity, olim/sg & $10^{6}-10^{7}$ & $<10$ & $10^{5}$ & $<10^{3}$ & $10^{2}-10^{6}$ & $10^{2}-10^{6}$ \\
\hline
\end{tabular}

POLYCARBONATE

\begin{tabular}{|c|c|c|c|c|c|}
\hline Property & $\mathrm{PC} / \mathrm{GF} / \mathrm{CB}$ & PC/CA & $\mathrm{PC} / \mathrm{Cr}$ & $\begin{array}{l}\mathrm{PC} / \mathrm{CH} \\
\text { Commercial }\end{array}$ & $\begin{array}{l}\mathrm{PC} / \mathrm{CF} \\
\text { Conmercial }\end{array}$ \\
\hline Conducuve Fller, \% & 2 & 6 & 15 & $\geq 15$ & $\geq 15$ \\
\hline Tenslle Strength, $\mathrm{MPa}$ & 96 & 32 & 136 & 65 & $1+5$ \\
\hline Flexural Modulus $\mathrm{MPa}$ & 5150 & 2888 & 8715 & 3100 & 8960 \\
\hline Irod Impact, notched, $1 / \mathrm{m} 23^{\circ} \mathrm{C}$ & 45 & 50 & 58 & 33 & 150 \\
\hline Heat Distortion Temperature, ${ }^{\circ} \mathrm{C}$ & $1+4$ & & $1+0$ & 132 & 150 \\
\hline Volume Resistivity, ohm-cra & $10^{6}-10^{7}$ & $\leq 10^{3}$ & $<10^{3}$ & $10^{2}-11^{6}$ & $10^{6}-10^{5}$ \\
\hline Surface Resistivity, olim/sg & $10^{6}+10^{7}$ & $<10^{3}$ & $<10^{3}$ & $10^{2}-10^{6}$ & $10^{-}-10^{6}$ \\
\hline
\end{tabular}

PHT

\begin{tabular}{|c|c|c|c|c|c|}
\hline Property & $\mathrm{PH} / \mathrm{CH} / \mathrm{CB}$ & $\mathrm{PBT} / \mathrm{CB}$ & $\mathrm{PBT} / \mathrm{CH}$ & $\begin{array}{l}\mathrm{PB} T / \mathrm{CB} \\
\text { Consonercial }\end{array}$ & $\begin{array}{l}\mathrm{PB} \mathrm{I} / \mathrm{CF} \\
\text { Comnercial }\end{array}$ \\
\hline Conductive Filler, $\%$ & 1.5 & 6 & 15 & $>15$ & $>15$ \\
\hline Tersile Strenghh, MPa & 61 & 56 & 126 & 5t & 103 \\
\hline Fiexural Modulus, MPa & 6120 & 3130 & 89.40 & $\$(1) 64$ & 9635 \\
\hline Lood Inpact, notched I/m $23^{\circ} \mathrm{C}$ & 70 & 30 & 31 & 110 & 18 \\
\hline Heat Distortion Temperanire ${ }^{\circ} \mathrm{C}$ & 227 & 19.4 & 224 & 202 & 225 \\
\hline Volunie Resistivity, ohrn $\mathrm{cm}$ & $10^{6}-10^{2}$ & $<10^{5}$ & $\angle i)^{3}$ & $-110^{3}$ & $10^{2}-10^{6}$ \\
\hline Surface Resistivily. ohin/sg & $10^{8}-10^{\frac{7}{2}}$ & $<10^{2}$ & $<10^{1}$ & $<10^{5}$ & $10^{2} \cdot 10^{12}$ \\
\hline
\end{tabular}

\section{WHAT IS NEEDED?}

- A BETTER UNDERSTANDING OF THE GENERAL BEHAVIOR OF IMMISCIBLE MULTI-COMPONENT SYSTEMS.

- betTER definITIONS OF CONDUCTIVITY LEVELS FOR THE VARIETY APPLICATIONS OF CONDUCTIVE MATERIALS

Fig. 6

- A GOOD BACKGIROUND IN POLYMER BLENDING. RHEOLOGY AND PROCESSING OF SHORT-FIBER COMPOSITE MATERIALS AND ABOVE ALL. IMAGINATION!!! 


\subsection{Compounding, Reinforcement and Toughening Session (II)}

"A comparative study of microstructure and fracture behavior of a conventional filled polymer and a nanocomposite", Albert F. Yee, J.P.Harcup, J. Du, and J. Lee, Dept. Materials Science \& Engineering, The University of Michigan, Ann Arbor

This talk focussed on fracture and toughening mechanisms in macro and nanocomposite materials. One of the goals of this research work on fracture and toughening was to explore the size scale of interfacial properties. Dr. Yee mentioned that there was a lack of theoretical models for satisfactorily explaining toughening of filled materials. This is a different approach than what most traditional filled systems entail. Instead of a rigid particle in a rubbery matrix to get enhanced modulus (amongst other properties), one has a rigid matrix filled with rubbery particles to get improved fracture resistance. He elaborated on crack shielding and crack pinning in this context. The idea of bound rubber becomes important as well for toughening. It was also noted that better dispersion does not necessarily lead to better properties and he stated the need to examine the dynamics of processes to get an understanding of the mechanics involved. In this regard, measure of the morphology alone is insufficient to understand fracture and toughening in filled materials.

Discussion- Questions on the effect of orientation (A: Hasn't been looked at) and the effect of aggregation on the interface (A: Not sure).

\section{Select Figures}

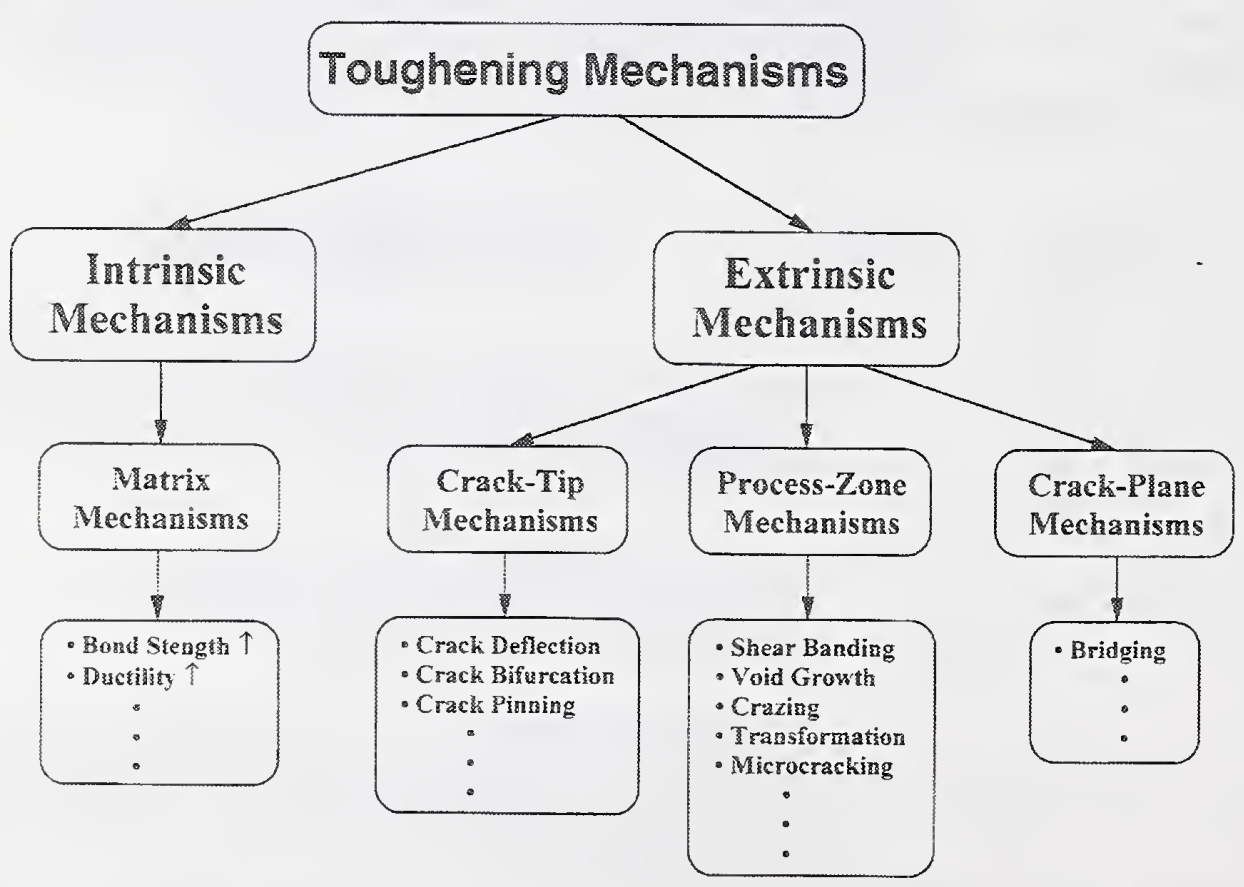

Fig. 1 


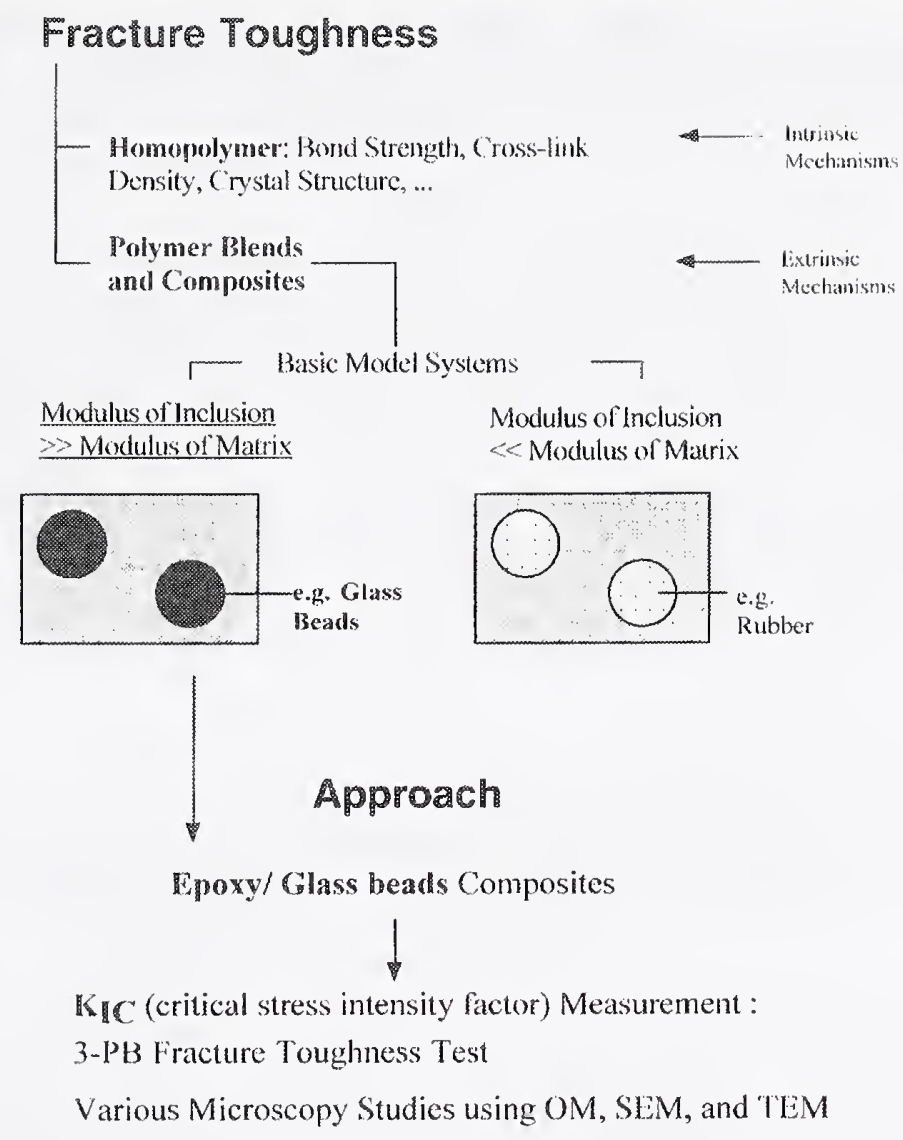

Fig. 2

\section{Modeling for Steady-State Toughening}

- This model is for toughening by shear yielding of the matrix.

- The constituitive behavior (power-law hardening) is for toughened material, NOT for pure matrix.

- A large n (strain-hardening exponent) corresponds to a low hardening material.

- Plane-strain crack-tip field for a power-law hardening material can be described by HRR fomulation.

- Steady-state toughening can be evaluated by an energy-balance approach.

\section{Steady-State Toughening Efficiency}

- A significant toughening effect can be obtained only when the ratio of cohesive strength to yield stress $\left(\sigma_{d} / \sigma_{0}\right)$ exceeds a certain value. This can be achieved by decreasing the plastic-flow stress $\left(\sigma_{0}\right)$ and/or increasing the cohesive strength $\left(\sigma_{c}\right)$.

- Steady-state toughening efficiency $\left(\Delta J_{5 s} / J_{0}\right)$ increases with increasing the ratio of Fig. 3 cohesive strength $\left(\sigma_{c}\right)$ to yield stress $\left(\sigma_{0}\right)$ and/or strain-hardening exponent $(n)$. 
"Metallocene Impact Modifiers: Influence of TPO Paintability and Cohesive Strength", Rose A. Ryntz, Visteon Automotive Systems, Dearborn, MI

Dr. Ryntz talked about crystallization in the presence of fillers. As in the previous toughening problem, the filler particles here are elastomers as well. It was also of interest to study effects of metallocene impact modifiers on cohesive strength of thermoplastic olefins (TPOs). The study involved stability and structure of coatings and the influence of the skin-sublayer interface. Typical measurements involved utilizing compressive shear tests. Also of interest was the effect of having a filler in the presence of twopolymeric components. In Dr. Ryntz's view, for the fillers and nanocomposites area to develop significantly, a knowledge of the mechanical behavior of multicomponent (more than 2) systems was deemed critical. Dr. Ryntz also stated that the needs for the area are interphase characterization and crystallization effects.

\section{Select Figures}

Fig. 1

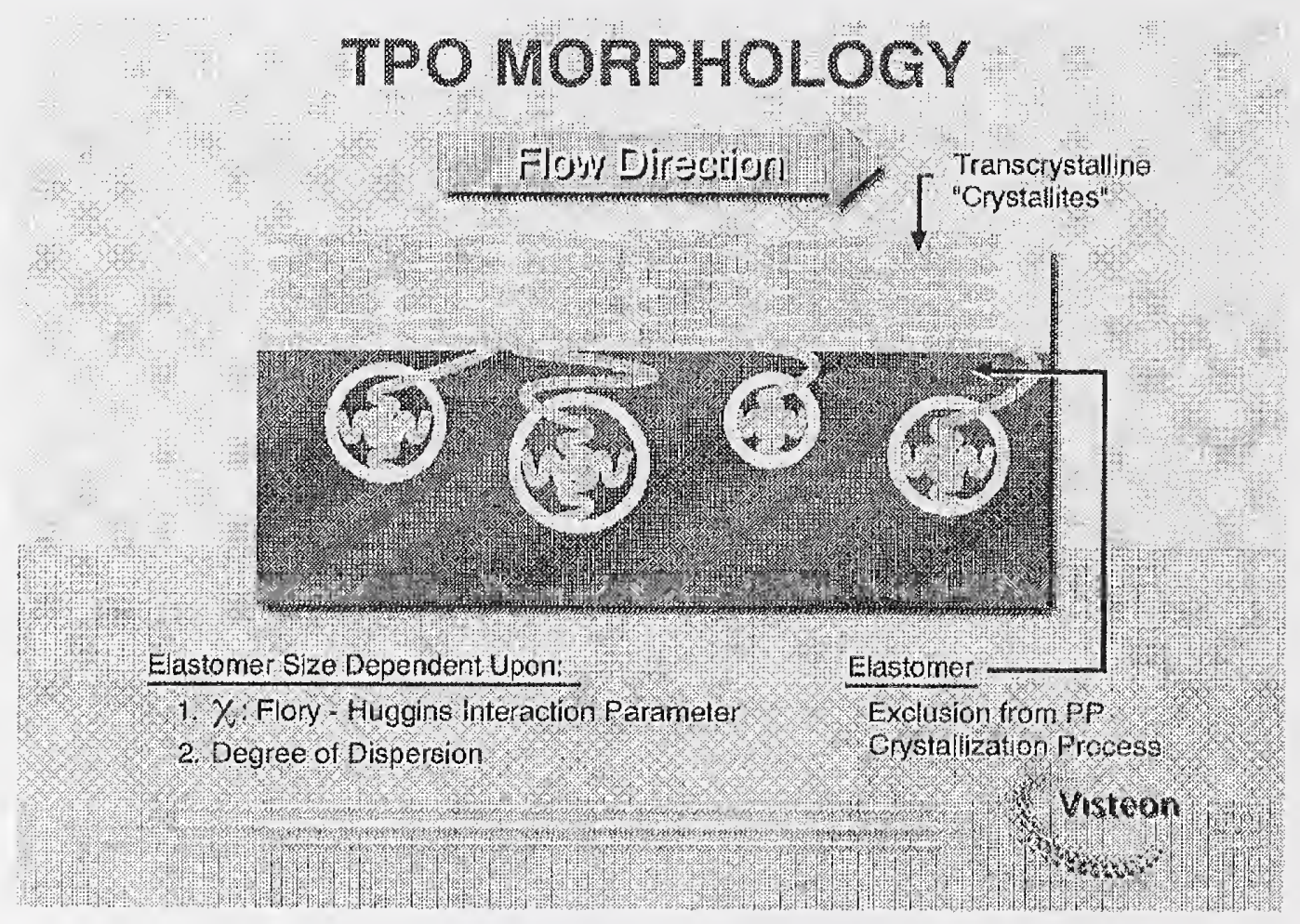




\section{FACTORS INFLUENCING MISCIBILITY}

- Molecular Weight, Molecular Weight Distríbution, and Isotacticity Level of Matrix

- Molecular Weight and Molecular Weight Distribution of Elastomer Phase

- Copolymer Ratio in Elastomer Phase

- Concentration of Crystalline/Amorphous Sequences in Elastomer Phase

Fig. 2

\section{FACTORS INFLUENCING MISCIBILITY}

- Size and Uniformity of Elastomer Dispersion Domains

- Melt Viscosity Ration of Matrix/Elastomer

- Stiffness Disparity, at Meltlike Densities, Between Matrix and Elastomer Phase

- Degree of Entanglement Between Elastomer/Matrix Phase

Fig. 3 


\section{FACTORS GOVERNNG DISPERSION SIZE*}

From Melt Blend:

- Rejection of Dispersed Elastomer Particles from Crystalizing Front, Occlusion in Intraspherulitic Regions

Deformation of Occluded Particles and Rejection Into Newly Formed Boundaries

- Coalescence of Occluded Particles

- Rejection of Particles in Interspherulitic Regions

Fig. 4

Wartuscell, E. Thefmoplastlo Elastomers from Bubber plastig Blends

S.K. De at al Editore, Ellia Hanvood, NY, NY 1990 p.ag

\section{FLORY-HUGGINS INTERACTION PARAMETER POLY(PROPYLENE) PLASTOMER BLENDS}

$X<0.002$ Indicative of Miscibility at Mw 100,000

$\chi>0.002$ Made Compatible by Increasing Mw of Dispersed Phase or Partial Crosslinking of Dispersed Phase

$x>>0.03$ More Likely for Dispersed Phase to Migrate to Surface

Fig. 5 


\section{FLORY-HUGGINS INTERACTION PARAMETER*}

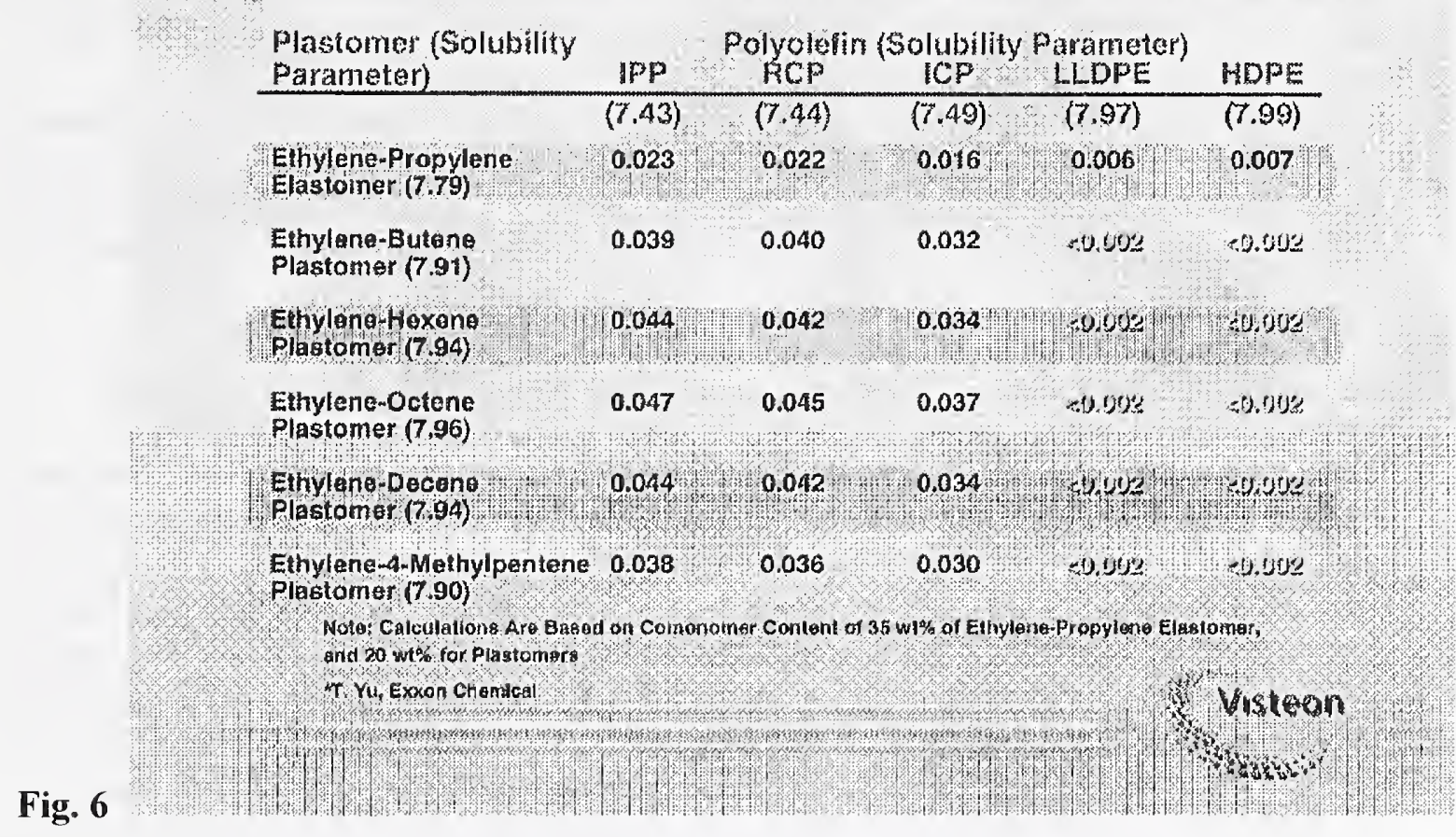

\section{Interphase Characterization Needs}

Fig. 7

Develop models with polymer alloys

- Determine effects of processing variations

I Depth dependence

- Compatibility measurement

1 Interphase characterization

7 crystallization effects

"Blends of Brominated Isobutylene Paramethylstyrene Copolymer (BIMS) and carbon Black", Mun Fu Tse, K.O. McElrath, H.-C. Wang, Exxon Chemical Co., Baytown, TX

In his talk, Dr. Tse discussed the determination of polymer-filler interactions from bound rubber fraction measurements. In these measurements involving carbon black fillers, there is a surface area and concentration dependence. Solvent extractions methods are used to determine the bound rubber content. It was found that the amount of bound rubber is a function of the filler concentration. Blends of a number of different brominated isobutylene paramethylstyrene copolymers (BIMS elastomers) with different types of carbon black were studied. The BIMS elastomers have different levels of BrPMS (bromo-paramethylstyrene) and PMS structure levels. These polymer/filler blends are characterized by solvent extraction at different temperatures (bound rubber fraction), viscoelasticity and stress-strain behavior. It has been found that BIMS elastomer interacts strongly with carbon black, as indicated by bound rubber 
measurements. These interactions increase approximately with the specific area of the carbon black, and with the BrPMS and/or PMS content in the BMS elastomer. In some cases, the structure level of the carbon black produces some subtle effects on the stressstrain behavior of the BIMS/carbon black blends.

Discussion- Question concerning whether studies of small molecule model compounds have been done to correlate bound rubber and adsorption / desorption behavior. Also whether calorimetric studies have been done to look at polymer-surface interactions; the need to determine the nature of the binding - whether it is chemical (covalent) or physical.

\section{"Investigations of Filler - Polymer Interactions" A.J. Dias, Exxon Chemical Co., Baytown, TX}

Dr. Dias stated that $85 \%$ of elastomers produced are used in tires. Therefore, any incremental improvement impacts a major market segment. In their studies, the driving force behind migration of fillers was investigated. Does the filler move to a specific polymer phase or does the polymer move to the filler were some of the questions being asked. Apparently the filler particles migrated rapidly within and between viscous media, but it was unclear on what the mechanism and driving forces were. In his talk Dr. Dias stressed the importance of studying multicomponent polymer mixtures with filler. He explained that it was not possible to predict properties of networks from structural knowledge because of the range and effects of fluctuations. As an alternate technique to the bound rubber extraction, it was possible to follow adsorption of polymer to filler surfaces from polymer solutions using NMR. The order of addition of the polymers was important, implying the binding may be covalent. Further, he expressed the need to understand the diffusion behavior of polymers near surfaces. In their thin film studies they found that the polymer chains slowed down dramatically in thin films of thickness $20 \mathrm{~nm}$. Additionally, he stated the need to understand the mechanics of deformed filled elastomers. Presently, a model by Lipizzera exists but further extensions and generalizations to filled systems are necessary.

\section{Select Figures}

Tires are Highly Engineered Multicomponent Blends

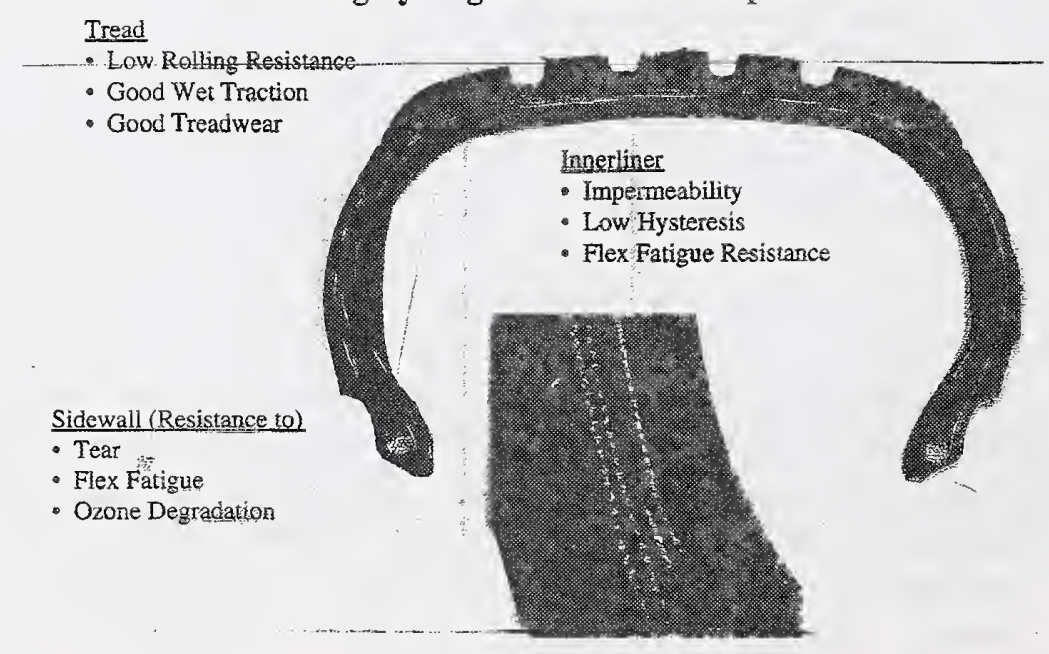

Fig. 1 


\section{Predictable Vulcanization and Performance for Elastomers}

Fig. 2

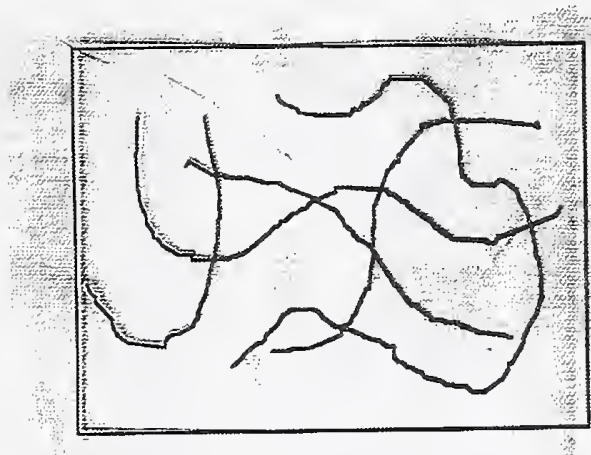

Curattros

Fille:

\section{Poly frer Type \\ Filler Type and Content Eurative Type and Content}

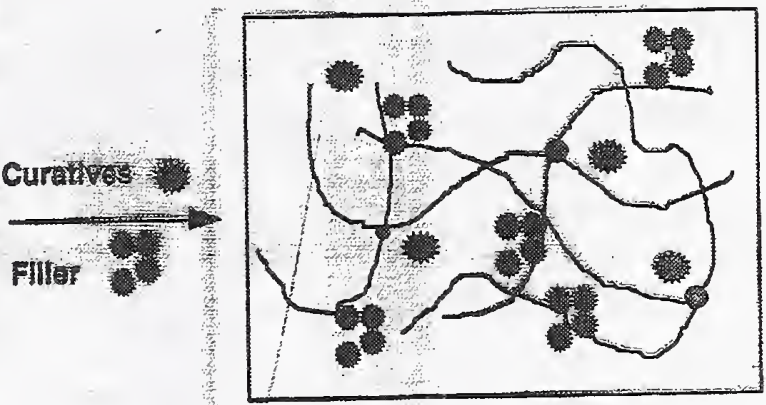

Vulcanizate Propertles

Crossilink Denstty Distrlbution

Filler Distribution : Polymer Interaction

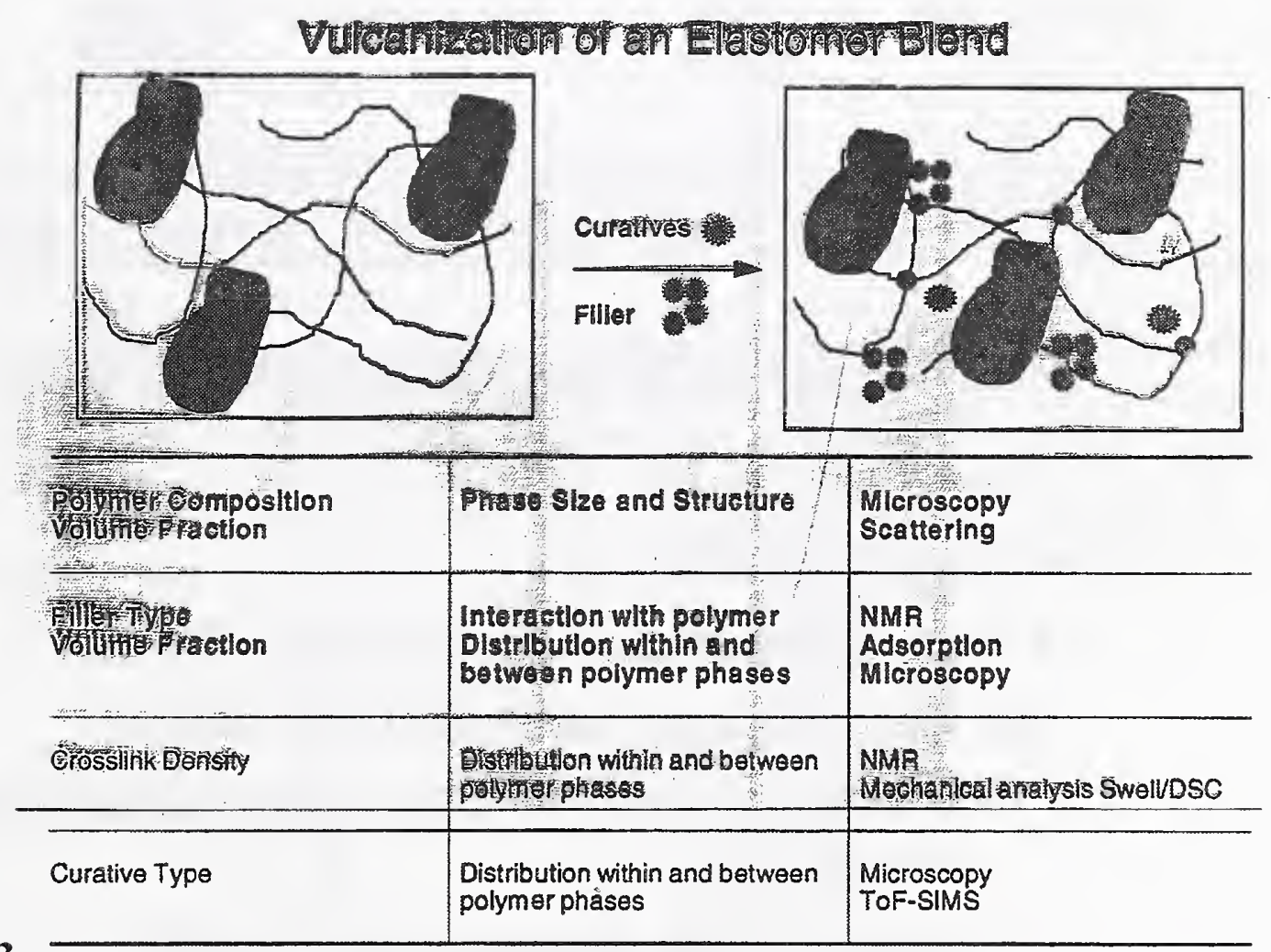

Fig. 3 


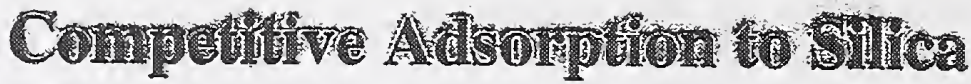

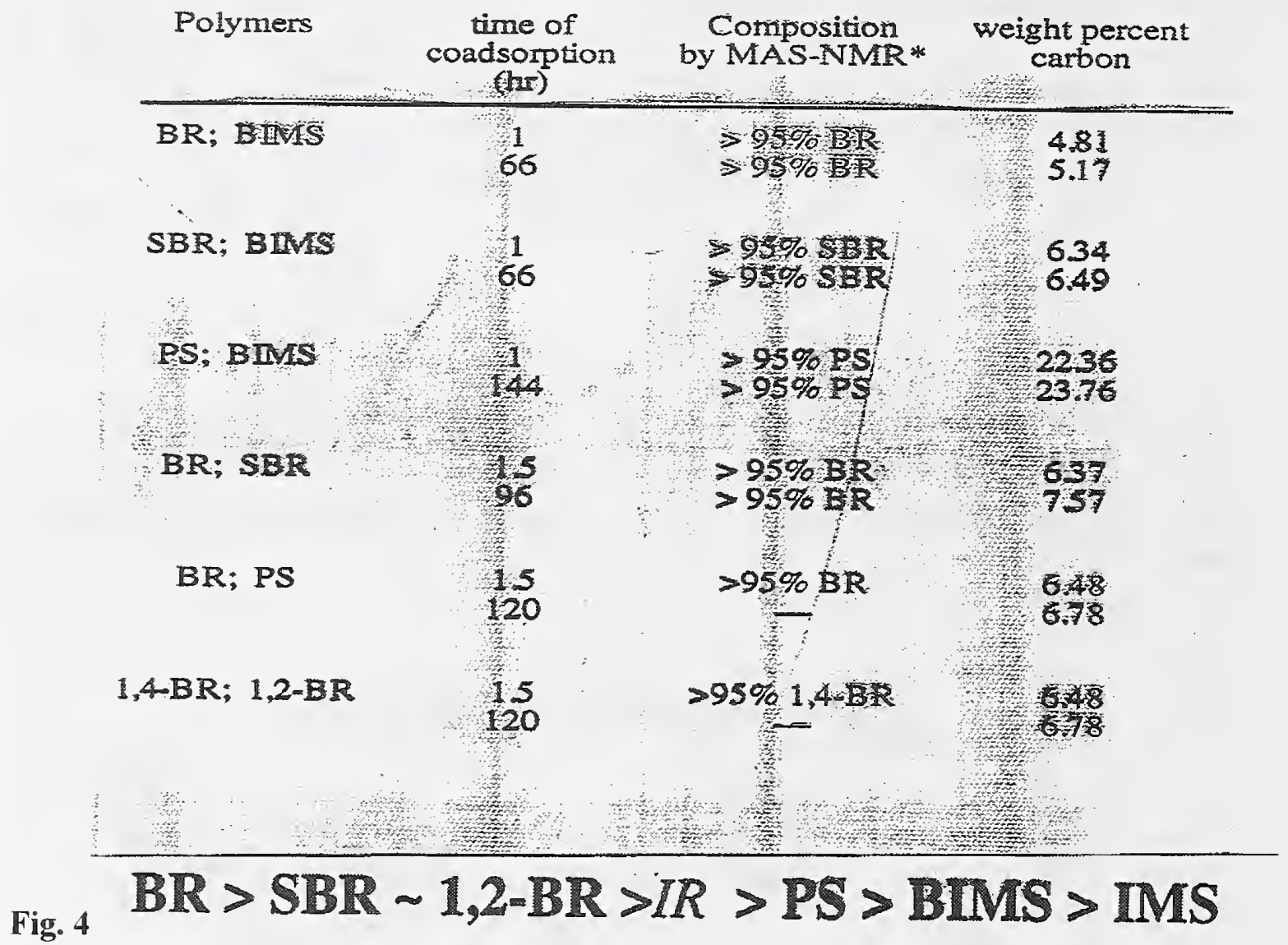

Difusfon of Chains Intwitced by Surface

- Neutron Iefleetivesy

- Chain diffusion slows near an lntertace

- BIMS - dBR layer interdiffusion studies

- Interdiffusion slows down dramatically in thin ( $20 \mathrm{~nm}$ ) films

- Carbon black angears to also inhibit

Fig. 5 
"Evolving Structure/Property Relationships for Precipitated Silica", Jo-Ann Bice, PPG Industries, Inc., Monroeville, PA

This talk was focussed on precipitated silicas rather than fumed silicas. The motivation for the studies were that recent studies indicated that silica particles in rubber improved properties of tire-wear resistance and moves forward in the step towards "green" technology. The processing conditions of filled systems dictate final properties, but the final properties are difficult to predict a priori. For these processes, in situ analysis techniques are therefore preferred. Determination of the microporous structure can be done by mercury porosimetry or oil (DBP) absorption. Determination of contact angle is however a more difficult problem. Residual porosity is found to affect the density measurements, and the poor determination of density is a big problem. Precipitated silica surface area can be determined by adsorption techniques, as enumerated by other speakers.

Surface preparation is important, since the chemistry of the surface determines the nature of the interactions with polymers as well as other additives. This is also related to wettability issues. Titration and spectroscopy are not useful in this regard. Other techniques give average values, but are not geometry specific (Same as with the density problem). Impurities are found to have a profound influence on surface chemistry.

Discussion- Any quantitative measure for energy required to disperse filler? (A: Not really).

\subsection{Nanocomposites Session}

"Structure and Dynamics of Polymer Nanocomposites", Emmanuel P. Giannelis, Dept. of Materials Science and Engineering, Cornell University, Ithaca, NY

Composites with dimensions in the range of $1 \mathrm{~nm}$ to $100 \mathrm{~nm}$, so-called nanocomposites, are the subject of intense current research and development. In particular, nanocomposites synthesized by intercalation of polymers in layered silicates exhibit many advantages including improved mechanical properties, outstanding diffusional barrier properties as well as flame resistance and self-extinguishing characteristics. The talk reviewed the physical and mechanical properties of nanocomposites and discussed them in terms of their static (neutron scattering and computer simulations) and dynamic (including NMR and dielectric relaxation) properties.

Select Figures (Next Page) 


\section{Nanostructures}

Fig. 1

i

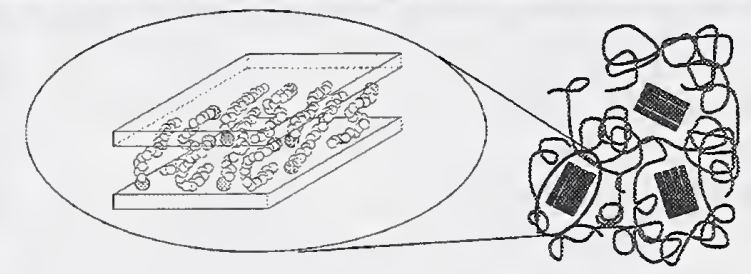

(n)
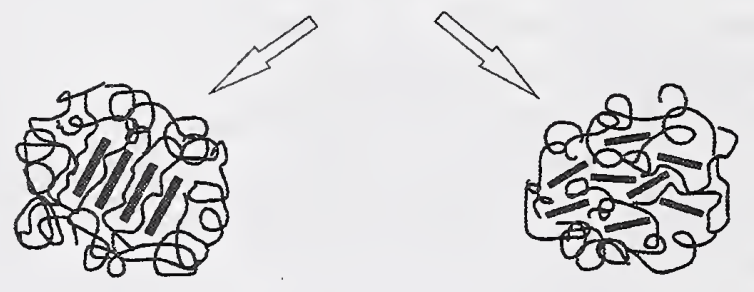

\section{Polymer / Silicate Nanocomposites TEM Viewgraphs}

Fig. 2

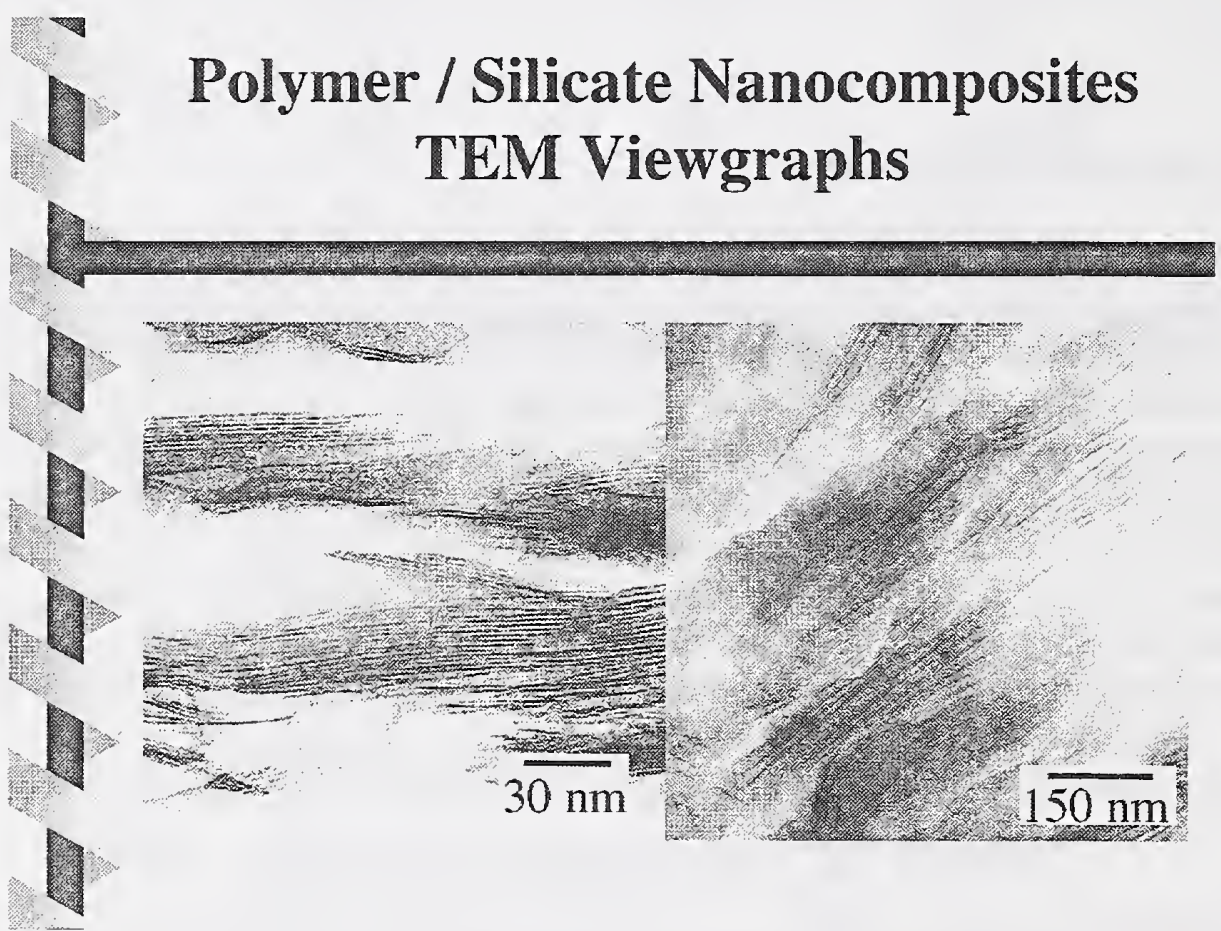




\section{Synthetic Approaches}

Fig. 3

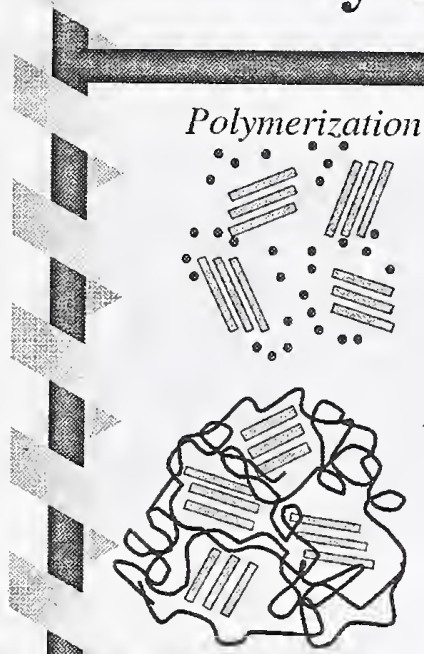

Immiscible

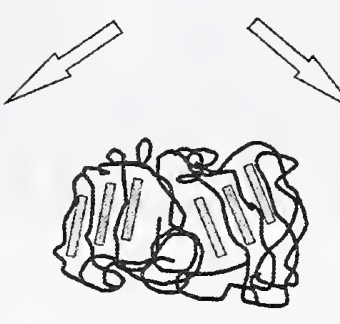

Intercalated
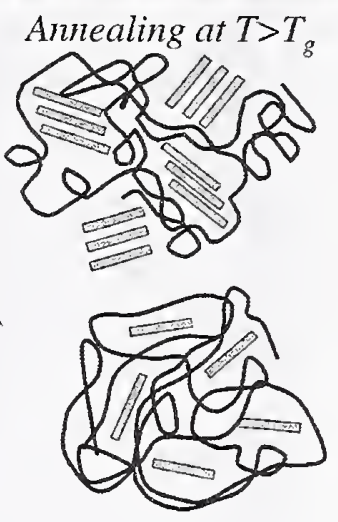

Exfoliated

\section{Properties of Nylon=6 / Nanocomposites}

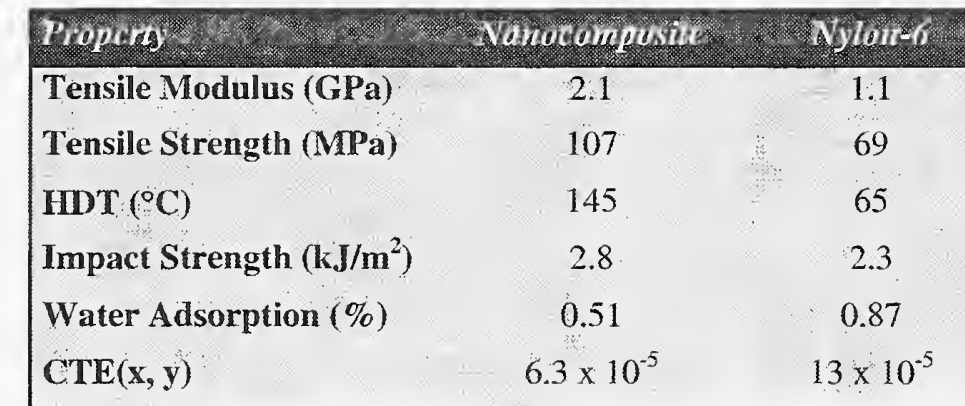

Fig. 4 


\section{Computer Modeling}

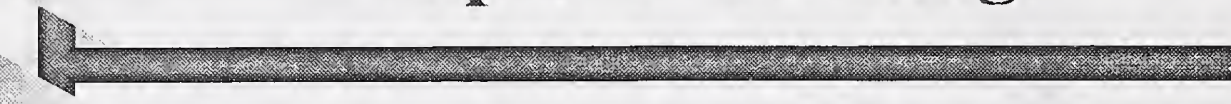

(1)

留

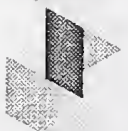

20

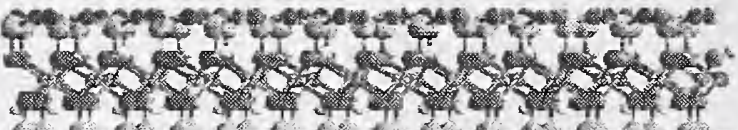

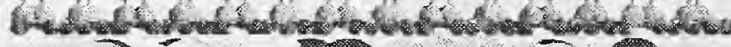

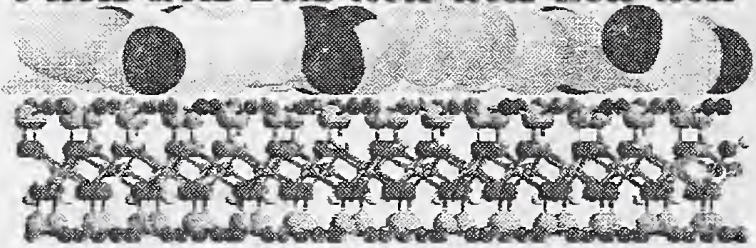

Hackett, Manias and Giannelis,

J. Chem. Phys. 108, 7410 (1998).

Fig. 5

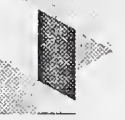

\section{Computer Modeling}

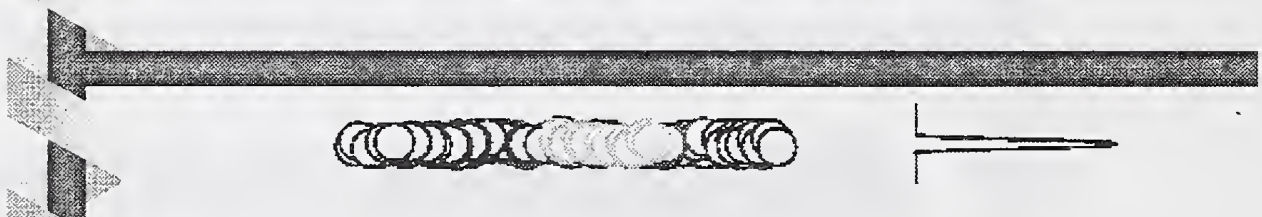

Fig. 6
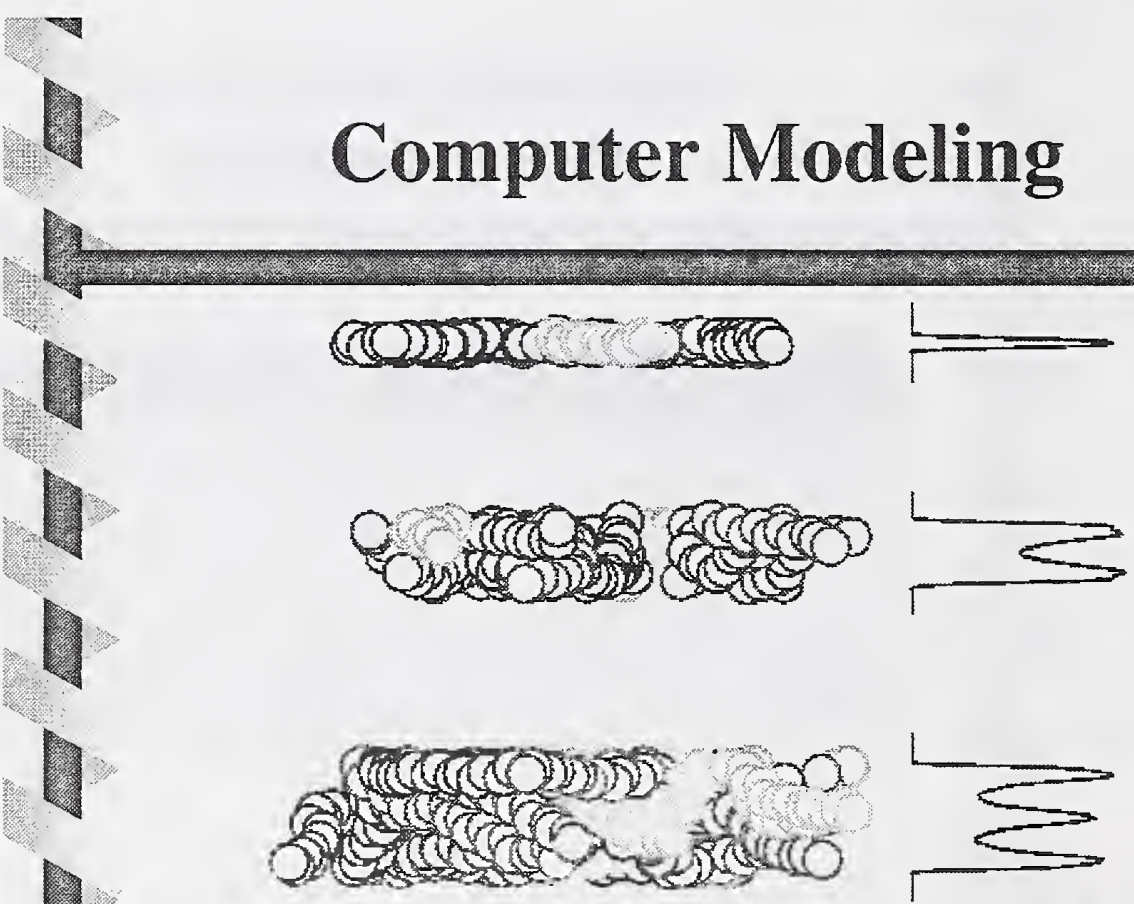

J. Chem. Phys. 108, 7410 (1998) 
"Montmorillonite Clay Structures and Intercalation Chemistries Based on Dipole Moment Interactions", Gary Beall and Karl Kamena, Nancore, Inc., Arlington Heights, IL

A new approach to montmorillonite clay surface modification has been developed to compatibilize clays with polymers to prepare nanocomposites. Dr. Beall explained that this new technology was referred to as ion-dipole treatment. The treatment method was described in some detail as well as its implications for nanocomposites. Two issues were discussed that have exhibited significant effects on nanocomposite properties and performance. The first involves the issue of clay purity. Data indicated that clay purity has a strong effect on engineering properties of nanocomposites, especially elongation and impact resistance. The second concerns the effect of clay on permeability. The traditional explanation for the improved barrier of nanocomposites is one of tortuous path. The effect of clay purity level was examined as well as intercalation chemistries that complicate permeability predictions and permanent properties and long term behavior.

"Dispersion in a Clay Nanocomposite; Application of Radiation Scattering", Chris D. Muzny, B.D. Butler and H.J.M. Hanley, NIST, Boulder, CO

The potential of using clay as the filler in a polymeric organic/inorganic composite is well understood and appreciated. The properties, however, of the resulting composite are most influenced when the largest possible clay surface area is presented to the polymer matrix. Ideally, then, the clay should be fully dispersed (exfoliated) into its constituentsnegatively charged platelets about $1 \mathrm{~nm}$ thick and $20 \mathrm{~nm}$ to $200 \mathrm{~nm}$ in diameter - and bonded to the matrix using an appropriate cationic organic intermediary. Unfortunately, clay platelets tend to form large aggregates in the presence of organics, so they normally will not disperse. A proposed route to prevent clay aggregation by forming plateletsurfactant micelles was presented. The procedure is based on performing a cation exchange reaction between the clay and a surfactant monomer and then adding sufficient excess monomer to give clay-micelle complexes. From chemical analyses of the samples, combined with light and small angle neutron scattering, the estimated excess monomer corresponded to four cation exchange equivalents. In the preliminary work, the complex was then polymerized with acrylamide. Dispersion of the clay was verified by following the synthesis using dynamic light scattering, X-ray scattering, and electron microscopy. It was argued that proof of dispersion is well demonstrated from dynamic light scattering data, thus indicating the potential of the technique of dynamic light scattering as a tool to monitor a synthesis process involving particulates. Problems arising from dispersing a nanometer scale clay mineral in a polymer matrix were discussed.

Some of the issues which needed to be addressed were: 1) Can clay be dispersed in organic solvents? 2) Which is preferred for better properties - homogeneous dispersion or delamination? 3) How can clay content be increased in solvent? 4) How to prove covalent bonding to the surface of the clay occurs? 5) Is crosslinking important?

Discussion- Crosslinking is important for compressive strength in composites, therefore, it is probably an important issue here. 
"Nanocomposites from Polymers and Layered Minerals", Leon H. Gielgens, H. R. Fischer, T. P. M. Koster, Tno-Tpd Institute of Applied Physics, Materials Division, P.O. Box 595, 5600 AN Eindhoven, The Netherlands

In his talk, Dr. Gilgens discussed block copolymer modified clays. He introduced nanocomposite materials as consisting of polymeric matrix materials and natural or synthetic layered minerals like clays prepared by using special compatibilizing agents between the two intrinsically non-miscible materials. In their approach, these compatibilizers were block- or graft copolymers, with the idea of combining one part of the polymer identically and/or completely miscible with the organic polymer (matrix compound) and another part compatible/miscible with the natural mineral. The interaction between the first part of the compatibiliser is preferentially an ionic interaction or an interaction via H-bonds. This interaction leads to a separation of the mineral into single sheets and a subsequent homogeneous incorporation of these sheets into the polymer matrix material. The aim of the investigation was to provide a general process for the manufacturing of nanocomposite materials consisting of polymeric matrix materials and homogeneously dispersed layered crystalline inorganic materials. He stated needs in mechanical property evaluation, diffusion data, chemical resistance, high temperature behavior and needs in cost and safety evaluation.

Discussion- Comments include emphasis on cost and the balance between increased modulus but decreased toughness. Suggestion that traditional rubber toughening methods should be successful in these systems to improve brittleness and that complete exfoliation is not always needed.

\section{Select Figures}

\section{TPD Schematical Structure of the with Block Copolymers modified Clays}

Fig. 1

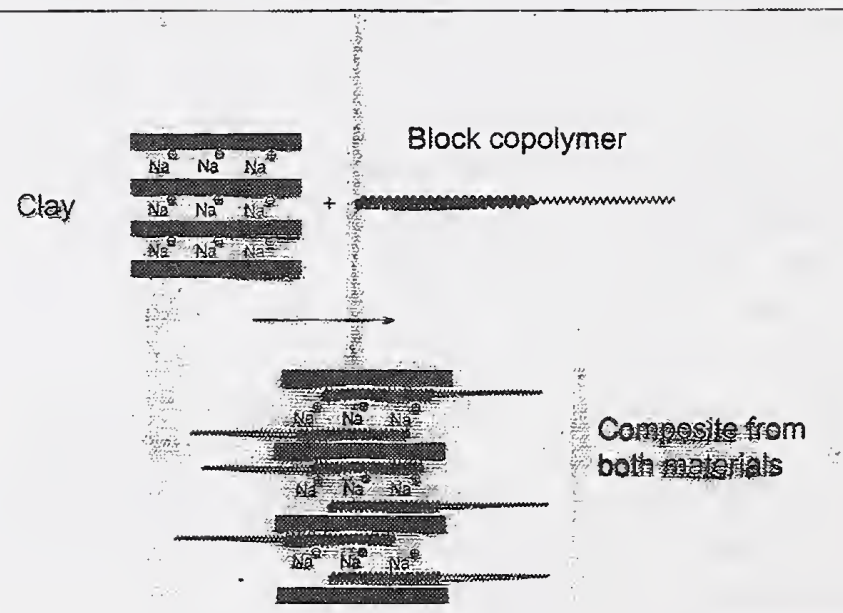




\section{TPD Clay Nanocomposites - general concept}

block copolymer

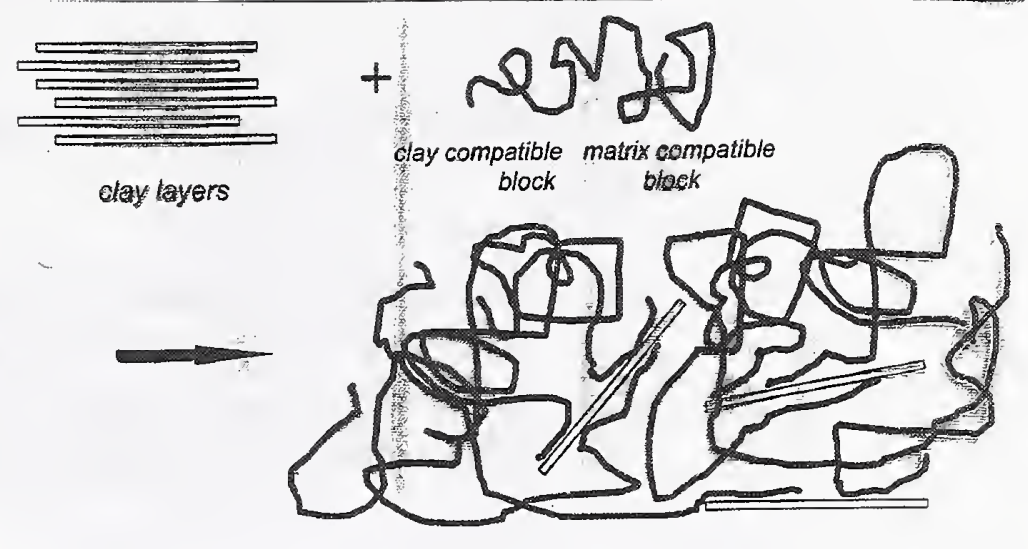

exfoliated clay layers

Fig. 2

\section{TPD Structure of the Block Copolymers used for the Modification of the Clays}

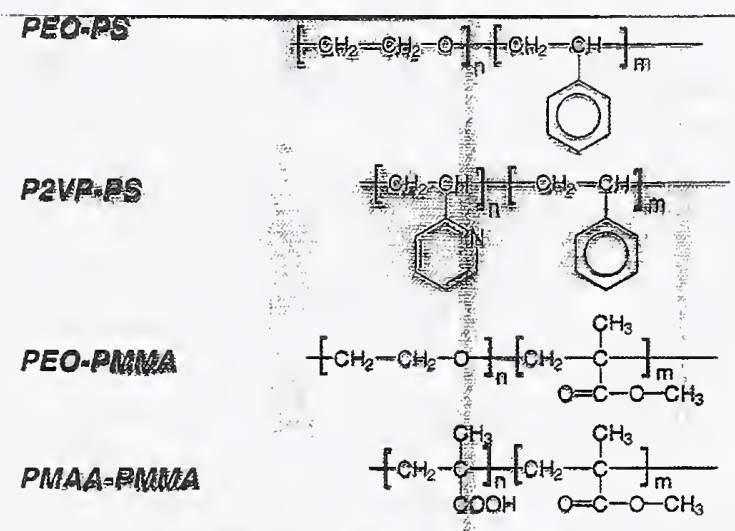

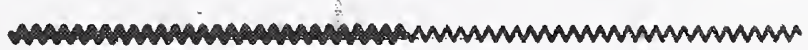

Fig. 3 
- General Coneept of Block Copolymers Warks

- Complete Exfoliation Not Almays Needed Good adhesiontinteraction between small stacks of sheets of the nano-panticles and the matrix also sumplises whancement of nectianical and thermal properies.

Fig. 4

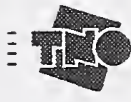

"Rheological Study of Macro- and Nano-Composites", Ramanan Krishnamoorti, University of Houston, TX

Dr. Krishnamoorti reported on the rheological behavior of composite materials containing filler particles that led to macro and nanocomposites. The rheological properties of intercalated and exfoliated nanocomposites of a homopolymer were examined using oscillatory shear and the terminal regime flow characteristics were found to be distinctly different - the exfoliated nanocomposites exhibited liquid like behavior while the intercalated nanocomposites exhibited characteristics intermediate between a liquid and a solid. Dr. Krishnamoorti also reported on the linear viscoelastic, alignment characteristics and non-linear oscillatory shear behavior of an end-tethered nanocomposite. These were shown to be model melt-brush systems and exhibited extraordinary strain hardening characteristics. Finally, Dr. Krishnamoorti reported on structural and viscoelastic characteristics of a block copolymer based nanocomposite. The rheological properties in the terminal regime were found to be pseudo-solid like and consistent with the response from a "hairy-disc" object.

Select Figures (Next Page) 
Polymer - Layered Silicate Nanocomposites

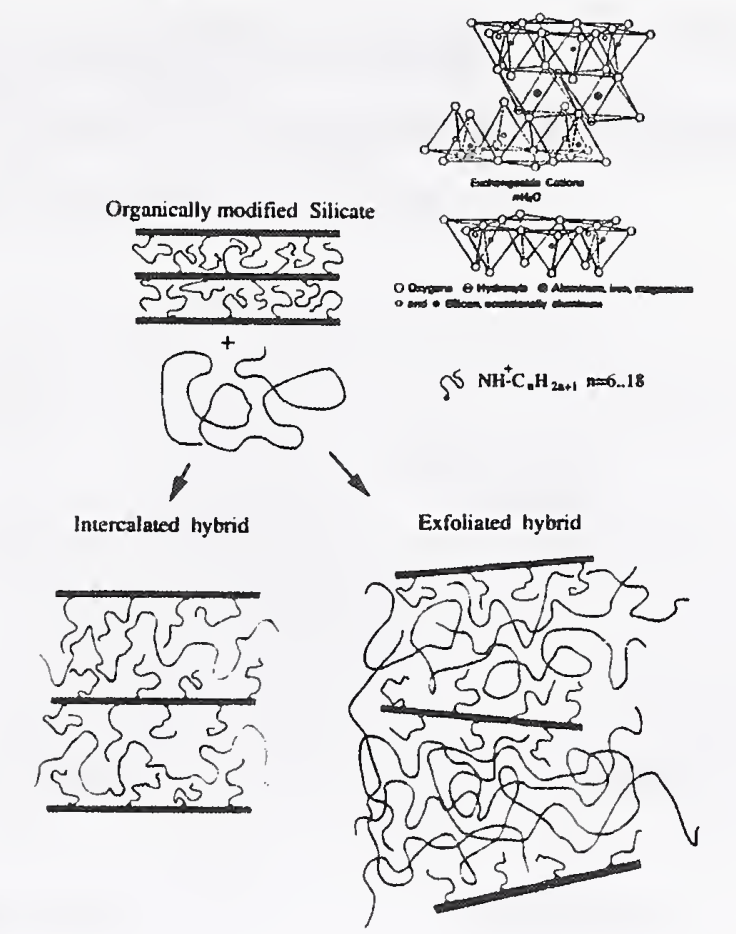

Fig. 1

- Nanocomposites

» Intercalated

» Exfoliated

»End-Tethered

» Structured Polymers

- Macrocomposites

» Carbon Black + BIMS

Fig. 2 


\section{Melt Rheology}

\section{Dynamic Oscillatory Shear}

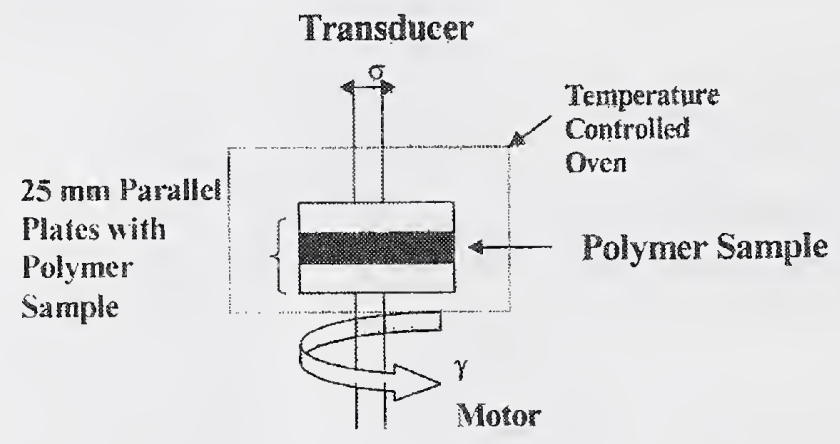

Apply

Fig. 3

$$
\gamma=\gamma_{0} \sin (\omega t)
$$

\section{Measure}

$$
\sigma=\gamma_{0}\left(G^{\prime} \sin (\omega t)+G^{\prime \prime} \cos (\omega t)\right)
$$

Fig. 4

- Melt State Rheology suggests a Correlation Between

Flow Properties and Interaction Strength.

- Templating Nature of Silicate Layers.

- End-Grafted Nanocomposites similar to Polymer

Brushes

"Flammability Studies of Polymer Layered Silicate Nanocomposites", Jeffrey W. Gilman, Takashi Kashiwagi, Sergei Lomakin", National Institute of Standards and Technology, Gaithersburg, MD; Emmanuel P. Giannelis, Evangelos Manias Cornell University, Ithaca, NY; ${ }^{\dagger}$ Guest Researcher at NIST from the Russian Academy of Sciences, Moscow, Russia.

Dr. Gilman reported on the enhanced thermal properties and improved flammability properties of polymer-layered silicate (clay) nanocomposites. He showed that both delaminated and intercalated nanostructures have improved flammability properties. His collaborative research program with Dr. Giannelis at Cornell University has focused on demonstrating the generality of the flammability behavior and on studing the mechanism of the flame retardant effect of the nano-dispersed clay. XRD and TEM analysis was used to identify a nano-reinforced silicate/carbon-like char from the combustion residue. Dr. Gilman felt the presence of this high-performance char supports a physical rather than a chemical mechanism of flammability control. A NIST-Inductry Consortium has been formed to further study the flammability properties of nanocomposites. 


\section{Presentation Outline}

\section{-1. Background}

2. PA-6 clay Nanocomposites

a) Synthesis, structure and properties

b) Flammability properties

\section{Intercalated clay Nanocomposites}

a) Thermoplastics

b) Thermosets

Fig. 1

\section{Radiative Gasification}

Fire Retarded Polymers by Enhanced Char Formation

- Increased char yield

- Increased rate of char formation

- Lower density char

- $T_{\text {Process }} \ll T_{\text {Charring }} \sim T_{\text {Decomp }}$

Fig. 2

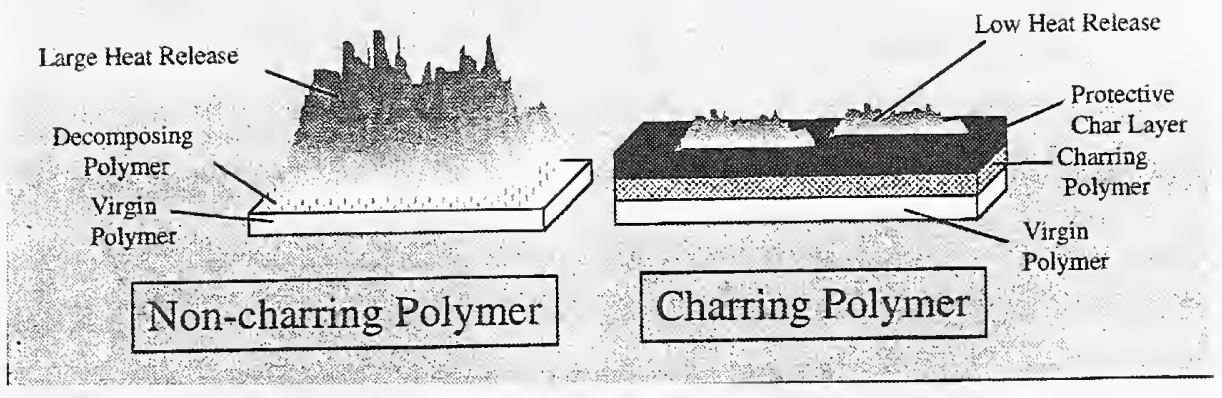



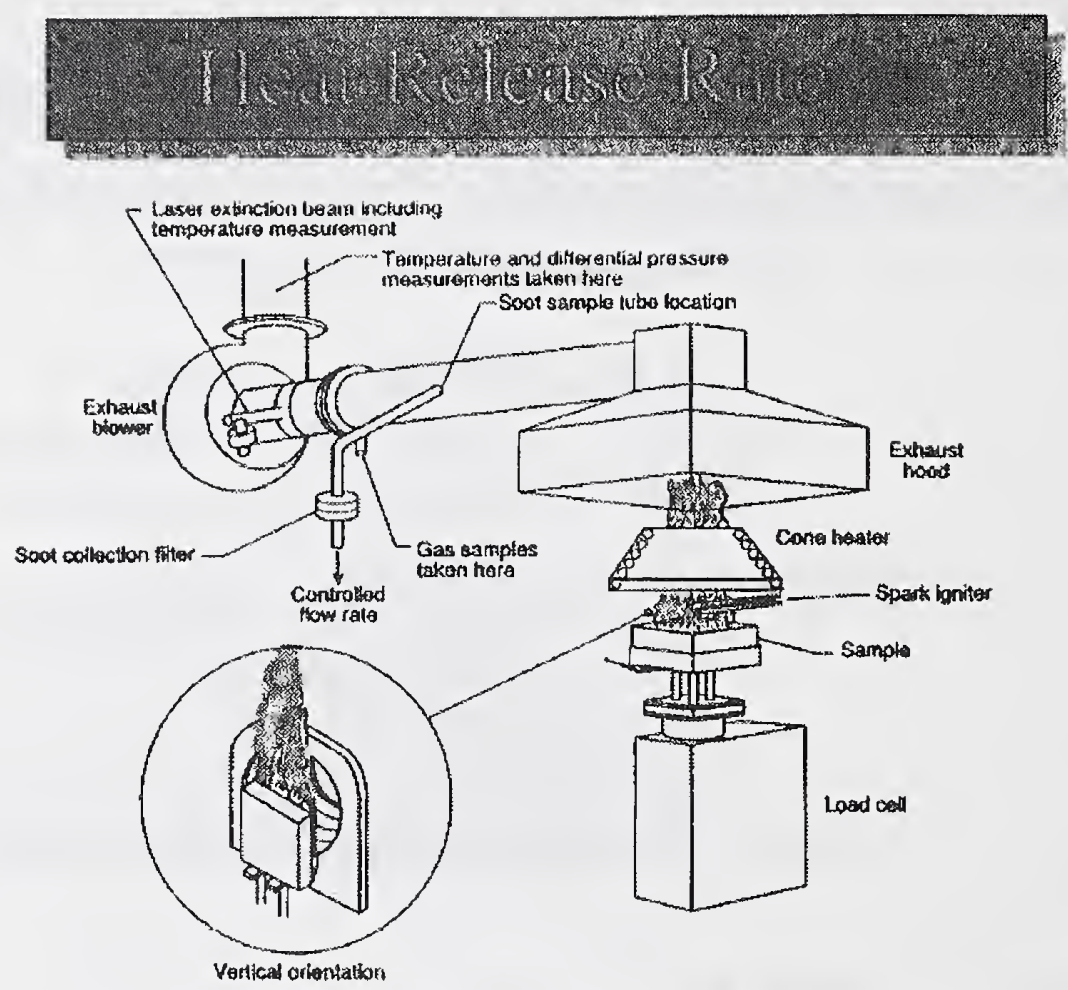

A schematic view of the cone calorimeter.

\begin{tabular}{|c|c|c|c|c|c|}
\hline \multicolumn{2}{|c|}{ Scenario } & & $\begin{array}{c}\text { Time to } \\
\text { incapacitation } \\
\text { (s) }\end{array}$ & \multicolumn{2}{|c|}{$\begin{array}{c}\text { Time to death } \\
\text { (s) }\end{array}$} \\
\hline \multirow{4}{*}{\multicolumn{3}{|c|}{$\begin{array}{l}\text { Base case } \\
\text { Double heat release rate } \\
\text { Double material toxicity } \\
\text { Halve ignition delay }\end{array}$}} & 180 & \multicolumn{2}{|c|}{$>600$} \\
\hline & & & 160 & \multicolumn{2}{|c|}{180} \\
\hline & & & 180 & \multicolumn{2}{|c|}{$>6(0)$} \\
\hline & & & 140 & \multicolumn{2}{|c|}{$>6000$} \\
\hline \multirow[t]{2}{*}{ Products } & \multirow{2}{*}{$\begin{array}{l}\text { Test } \\
\text { no. }\end{array}$} & \multicolumn{2}{|c|}{ Fire hazard condition } & \multicolumn{2}{|c|}{ Predictive variable } \\
\hline & & $\begin{array}{c}\text { Total toxicity, } \\
\text { exprexsed as } \\
\text { (CO equiv. } \mathrm{kg})\end{array}$ & $\begin{array}{c}\text { Time to } \\
\text { reach } \\
\text { untenable } \\
\text { conditions in } \\
\text { burn room } \\
\text { (s) }\end{array}$ & $\begin{array}{c}\text { CO } \\
\text { yield } \\
(\mathrm{kg} / \mathrm{kg})\end{array}$ & $\begin{array}{l}\text { Peak theat } \\
\text { release rate } \\
(k W)\end{array}$ \\
\hline Ion-FR & N1 & 21 & 110 & 0.22 & 1590 \\
\hline 10n-FR & NX0 & 17 & 112 & 0.18 & 1540 \\
\hline nOn-FR & NX1 & 16 & 116 & 0.14 & 1790 \\
\hline EW & $F 1$ & $2 \cdot 6$ & $\infty$ & 0.22 & 220 \\
\hline 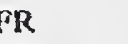 & FXo & $5 \cdot 5$ & 1939 & 0.23 & 370 \\
\hline $\mathrm{FR}$ & FX1 & $6 \cdot 1$ & 2288 & 0.23 & 350 \\
\hline FR & FXla & $5 \cdot 6$ & 1140 & 0.23 & 450 \\
\hline
\end{tabular}

Fig. 3

Vytenis Babrauskas, Richard D. Peacock 


\section{Inorganic Materials as New Flame Retardants}

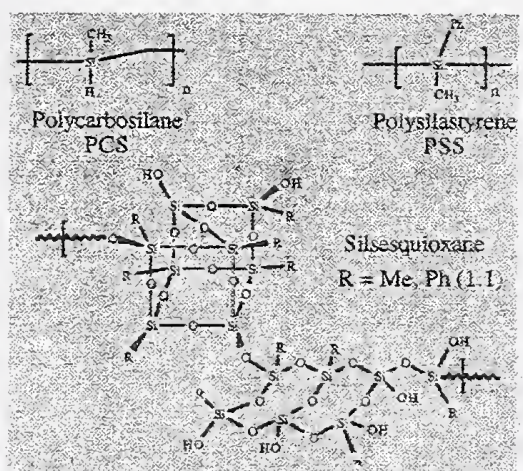

Preceramic Blends and Grafts

Low meling Glasses

$\mathrm{ZrO}_{2}$ in Borate salts

Fig. 4
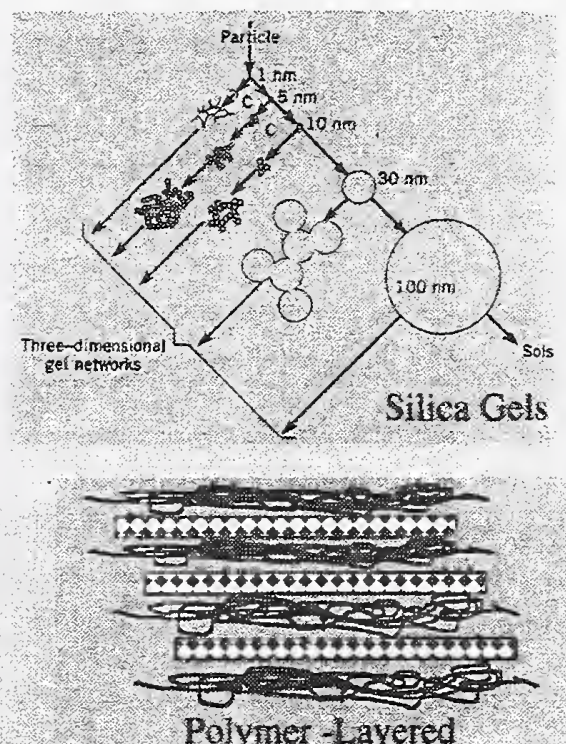

Polymer-Layered

Shicate Nanocomposites

$\mathrm{Na}+$ Montmorillonite Structure

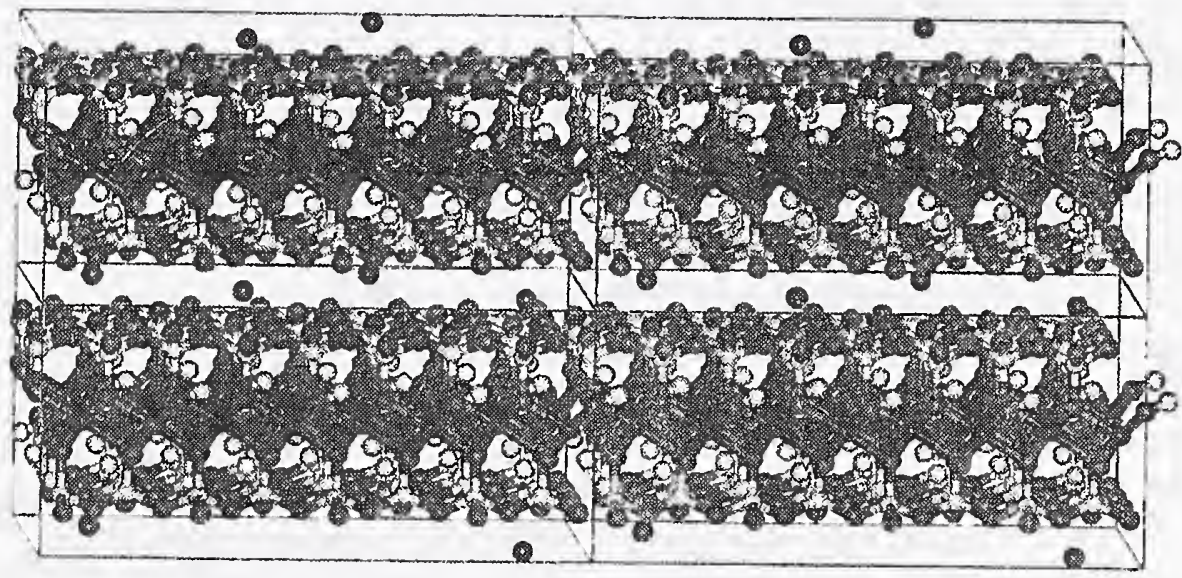

18 Chem. Mater., Vol. 6, No. 7, 1994

Vaia et al.

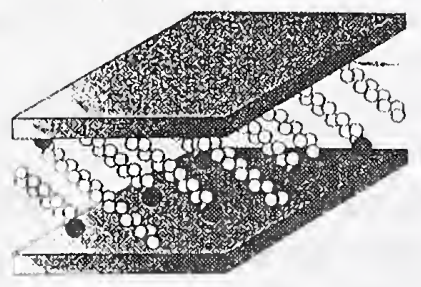

a)

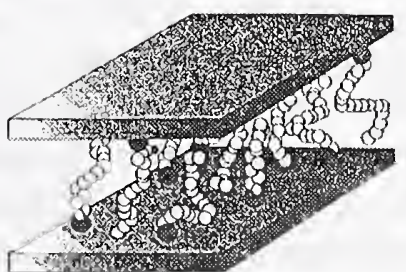

b)

Fig. 5

Nyden (NIST). (ilandlis. Manias (Cornell) 
- The HRRs of thermoplastic and thermoset polymer layered silicate nanocomposites are reduced by $40 \%$ to $60 \%$ in delaminated or intercalated nanocomposites containing a silicate mass fraction of only $2 \%$ to $6 \%$. Furthermore, this system does not increase the carbon monoxide or soot produced during the combustion.

- Not only is this a very promising new method for flame retarding polymers, but it does not have the usual drawbacks associated with other additives. That is, the physical properties are not degraded by the additive (silicate); instead they are improved.

- The nanocomposite structure of the char appears to enhance the performance of the char layer. This layer may act as an insulator and a mass transport barrier slowing

Fig. 6 the escape of the volatile products generated as the polymer decomposes.

"Dynamics of polymers in confined geometries: Neutron studies of intercalated polymer-clay nanocomposites", Robert Ivkov, A. Karim, E. Amis, N. Malizsewskyi, P. Gehring, NIST; R. Krishnamoorti, Dept. of Chemical Engineering, Univ. of Houston, Houston, TX

Dr. Ivkov discussed the use of neutron scattering methods to characterize the structure and dynamics of polymers such as polyethylene oxide (PEO) intercalated into fluorohectorite clay. He described the filter-analyzer spectroscopy technique to characterize the high energy dynamical features, and neutron time-of-flight and spin-echo spectroscopy to characterize the low energy, larger spatial features of these materials. Intercalated materials were prepared by melt intercalation of $100,000 \mathrm{M}_{\mathrm{w}}$ polyethylene oxide (PEO) into fluorohectorite $(\mathrm{FH})$ clay. Several samples were made with varying amounts of polymer mass fraction, $18 \%, 25 \%$, and $30 \%$. The extent of intercalation was characterized by $\mathrm{x}$-ray diffraction, and all samples were stored in a dessicator under vacuum until use. The samples were loaded into aluminum sample holders sealed with indium wire in an inert (dry He) atmosphere in a glove box immediately before use.

Neutron filter-analyzer spectra were obtained at a temperature of $10 \mathrm{~K}$ for all samples described above, and were compared with those obtained from bulk PEO and pure clay. The data reveal only subtle differences among the intercalated materials and the bulk PEO, suggesting that the vibrational motions of the hydrogens in the polymer do not experience a significantly different environment upon intercalation. Neutron time-offlight data taken at $20 \mathrm{~K}$ below the glass transition of PEO $(213 \mathrm{~K})$ reveal significant differences between the intercalated materials and the bulk polymer. Bulk PEO displays several peaks that result from vibrational modes of the crystalline regions of the polymer. These features diminish with intercalation. Another prominent feature observed in the bulk PEO is the low energy plateau $(-2 \mathrm{meV}$ to $-8 \mathrm{meV})$ common to the glassy state. With $30 \%$ intercalation, the plateau becomes a shoulder and almost completely disappears in the $18 \%$ PEO sample, suggesting that the intercalated polymer chains are not in the glassy state. 
Discussion-Comment that extension of studies to examine slower molecular motion modes might be enlightening for fatigue and failure studies and long term stability of filled polymers.

\section{Select Figures}
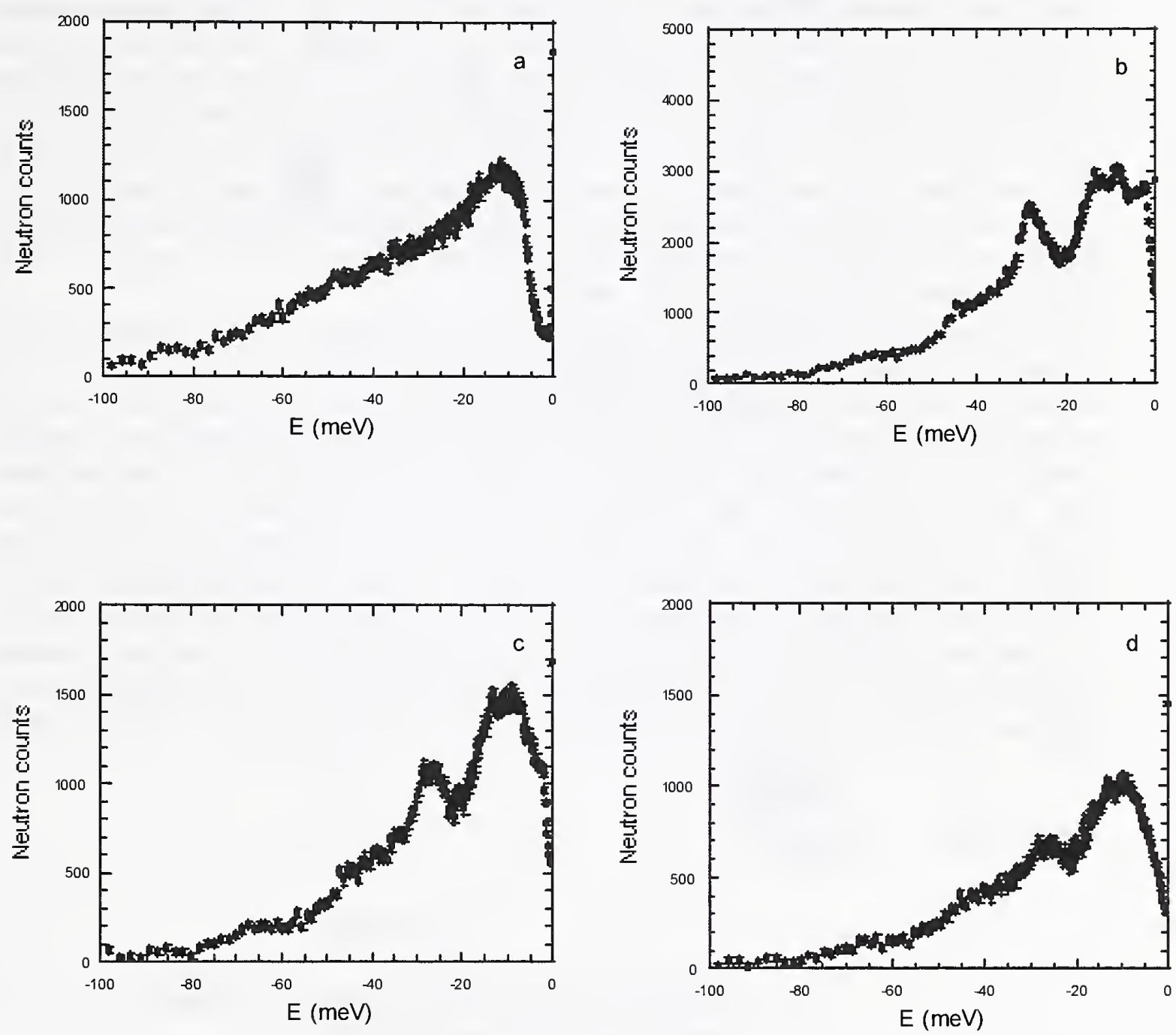

Fig. 1: Plots of neutron time-of-flight data obtained from samples at $193 \mathrm{~K}$ ( $20 \mathrm{~K}$ below the glass transition of bulk $\mathrm{PEO}):$ a) pure fluorohectorite clay, b) pure polythylene oxide (PEO); c) $30 \%$ PEO intercalated with fluorohectorite clay, and d) $18 \%$ PEO intercalated with fluorohectorite clay. These reveal significant differences between intercalated materials and bulk polymer. Several features seen in bulk PEO get suppressed with intercalation. Together, the results suggest that intercalation of PEO into clay galleries significantly reduces interchain interactions to the point that the chains no longer retain their macroscopic properties. 


\subsection{Theory and Modeling Session}

"Effect of fillers and their distribution on composite properties," C.K. Hari Dharan, Dept. of Mechanical Engineering, University of California, Berkeley, CA

Dr. Dharan stated the needs for gathering knowledge of local properties of the filler, elastic yield properties, interface strength, friction coefficients, and in-situ properties. Using homogenization techniques, certain effective properties of polymer composites can be derived from the volume fraction, distribution and properties of the reinforcing phase. Such approaches are useful for "designing" the composite so that desired properties can be obtained at desired locations. For these approaches to be useful, however, one needs to take a systems view, particularly a knowledge of the overall requirements of the structure. Thus, while so-called micromechanics approaches are used to homogenize the composite, the utility of the material depends upon component and application constraints which must be specified, requiring the materials designer to be cognizant of the application before the material can be designed.

This approach is illustrated by investigating the problem of an axisymmetric body subjected to thermal gradients. The desired distribution and properties of the reinforcement phase to minimize thermal stresses are obtained through the use of a homogenization scheme. Effective inhomogeneous material properties are obtained through the use of distribution functions that relate the concentration of the second phase with the coordinates of the structure. Using these properties, inhomogeneous eigenstrained media analyses are conducted for such axisymmetric bodies, and in this fashion, the desired shape and material properties of the reinforcement phase, and its close-optimal distribution, are determined. A similar approach was outlined for the case of a structure subjected to both internal and external pressure and to thermal gradients. Discussion- Areas requiring additional research, particularly the characterization of interfaces and in-situ properties in polymer composites, such as with a tensile stage for TEM.

\section{Select Figures}

Fig.1

\section{Approach}

- Derive "local" effective properties using homogenization techniques

- Define distribution functions for filler

- Determine performance parameters (stress, CTE, conductivity, transmission loss, etc.) for each specific application

- For yielding, fracture, and slip, we must resort to numerical techniques 


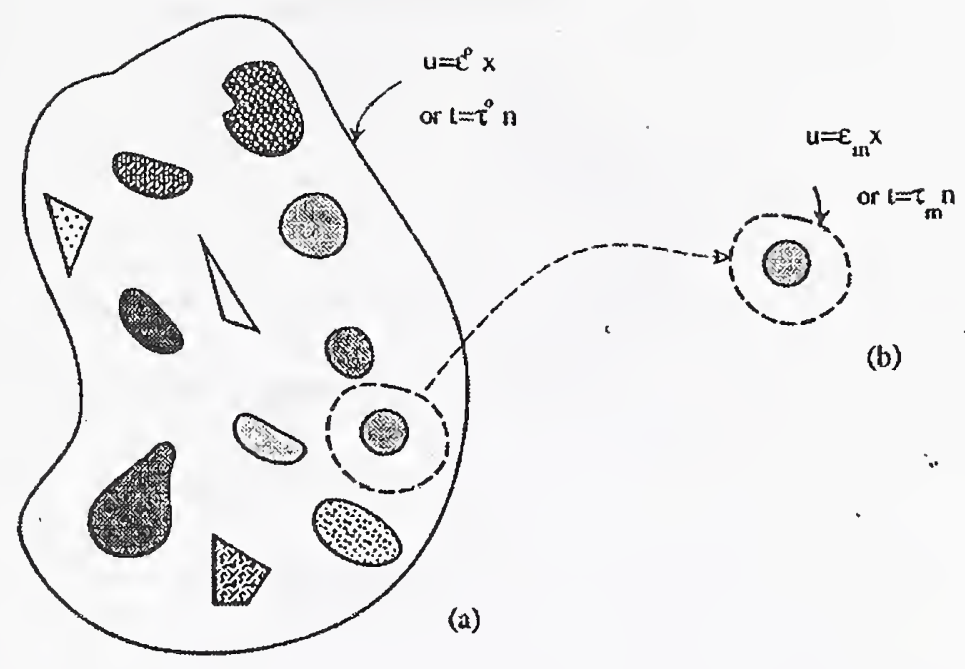

Figure I(a): Scluematic of a general composite material:

Figure 1(b): A single inclusion surrounded by the matrix phase

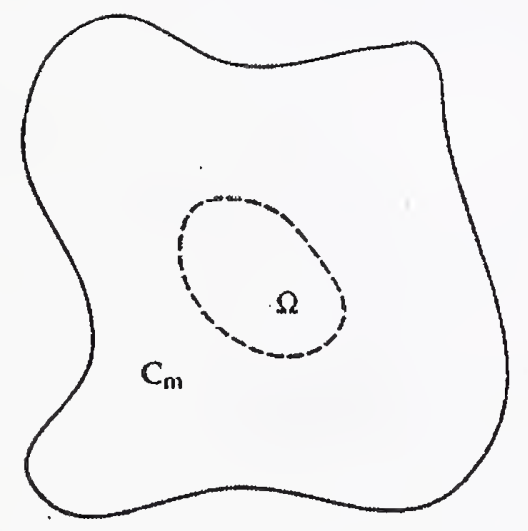

(a)

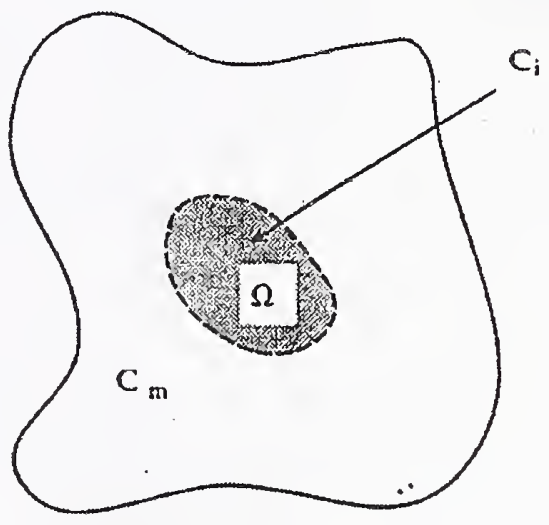

(b)

Fig. 2

Figure 2: Eshelby's equivalent inclusion method 
Effective Stiffiness Tensor

$$
C_{\text {efr }}=C_{m}+v\left(C_{i}-C_{m}\right) A_{i}
$$

Where

$$
\begin{aligned}
& \Lambda_{i}=T[(1-v) I+v T]^{-1} \\
& T=\left[I+E S_{m}\left(C_{i}-C_{m}\right)\right]^{-1} \\
& C_{m}=\text { Matrix Stiffness Tensor } \\
& S_{m}=\text { Matrix Compliance } \\
& C_{i}=\text { Inclusion Stifiness } \\
& v=\text { Volume Fraction } \\
& E=\text { Eshelby Tensor (See Mura, 1987) }
\end{aligned}
$$

CTE (Coefficient of Thermal Expansion)

$$
\alpha_{c T}=\alpha_{m}+\left(\alpha_{i}-\alpha_{m}\right) \mathbf{B}_{1}
$$

\section{Where}

$$
B_{i}=\left(S_{i}-S_{m}\right)^{-1}\left(S_{e f t}-S_{m}\right)
$$

\section{Fig. 3}

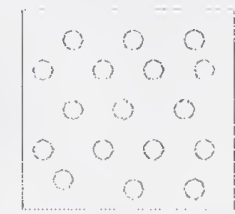

Vol. Fracion, $v$, is Fixed

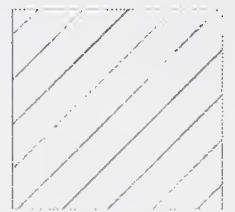

Hornogenized for Givell (\& Constituents)

\section{However}

In composites, we (ought to) have the ability to tailor properties to meet requirements at different locations.

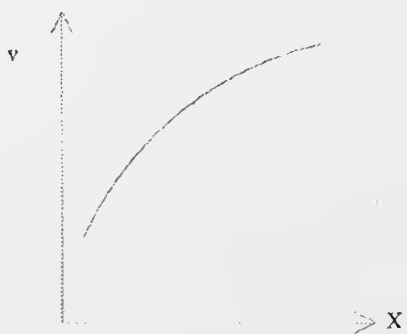

Fig. 4 


\section{Examples}

\section{Tube with internal}

\& external pressure \& heat flux

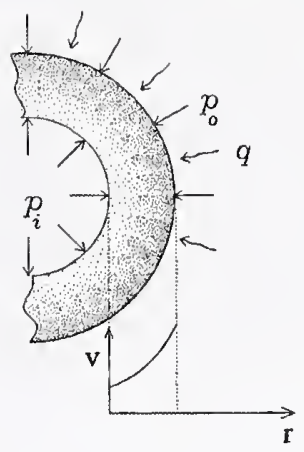

2. Beam under bending

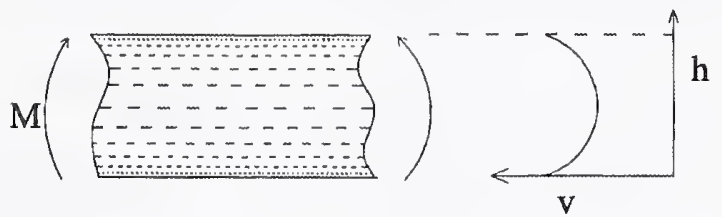

Fig. 5

3. Tube under torsion
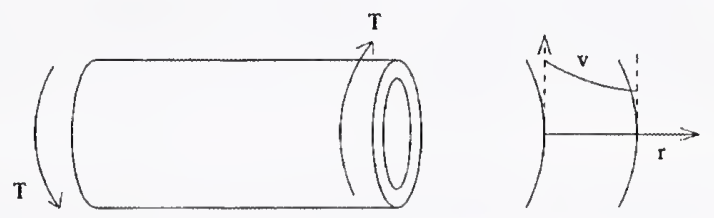

Maximize torque capacity

\section{Bearing surface}
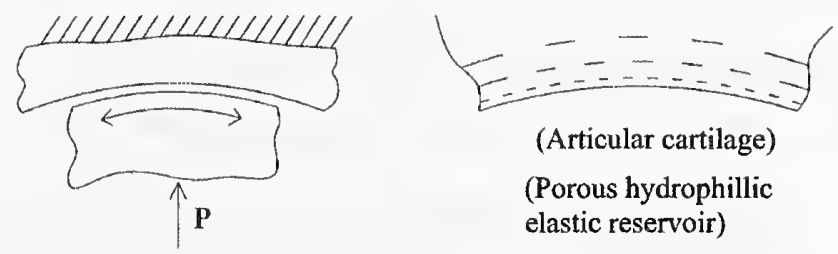

(Articular cartilage)

(Porous hydrophillic elastic reservoir)

Fig. 6
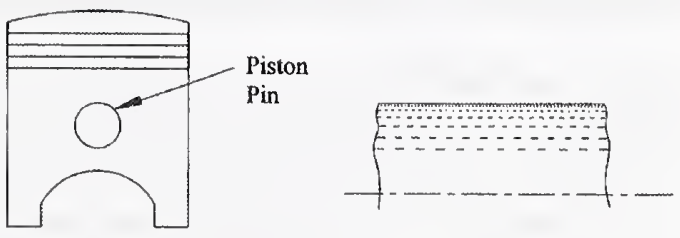

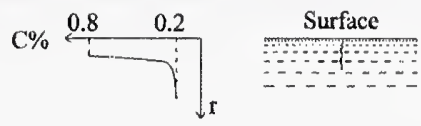

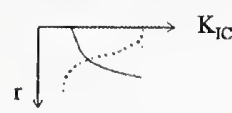


5. Combine fuctions

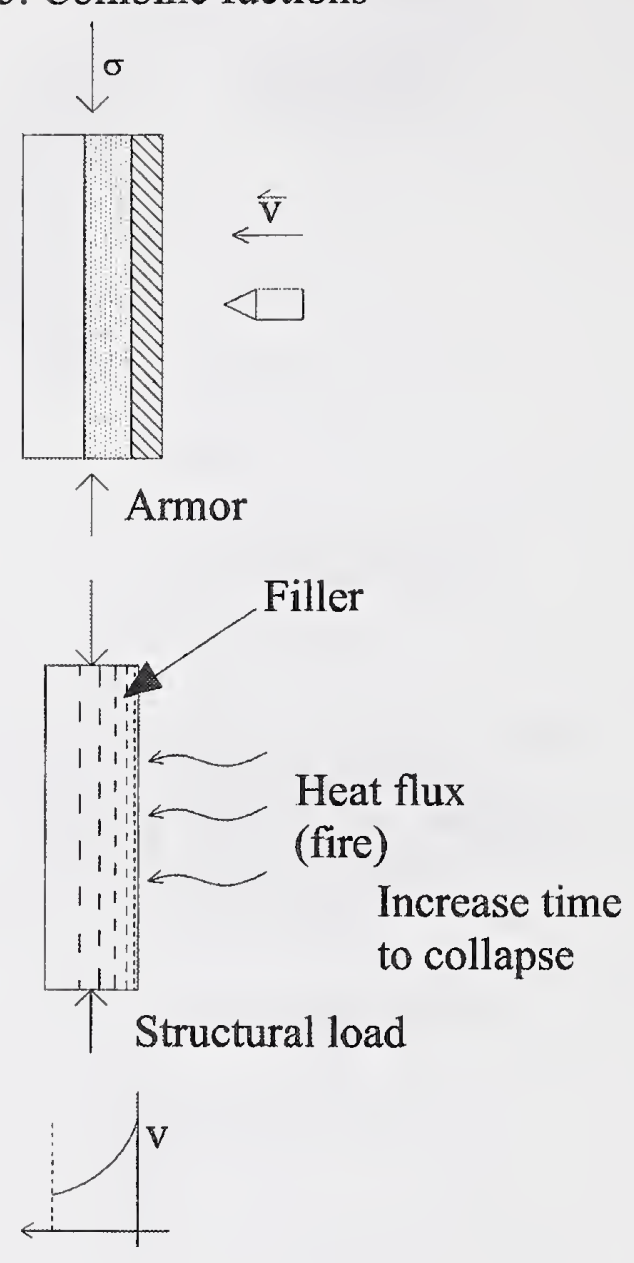

Fig. 7

\section{What is needed}

- Knowledge of local properties

- Filler elastic and yield properties

- Interface strength, friction coefficient

- Matrix and interphase in-situ properties

- Define high potential applications/processes

- Multi-disciplinary research teaming

-Polymer synthesis chemist, physical chemist, physical modeling, experimental models, instrumentation

Fig. 8 
"Model for dispersion rheology", Jozef Bicerano', Jack F. Douglas ${ }^{2}$ and Douglas A. Brune ${ }^{1}$; Dow Chemicals, Midland, MI; ${ }^{2}$ Polymers Division, NIST, Gaithersburg, MD

A simple quantitative predictive model was developed for the shear viscosity $\eta$ of dispersions of solids in liquids. The model is based on the fundamental physical concepts of universality and scaling. It does not involve empiricism; that is, calculations using the model do not require any pre-existing data for $\eta$ (dispersion), either for calibration, interpolation, or for extrapolation. The model allows the calculation of $\eta$ (dispersion) as a function of particle volume fraction, shape, polydispersity, fractal aggregation and flexibility, dispersing fluid viscosity, and shear rate and temperature.

\section{Select Figures}

\section{OUTLINE}

- Dilute regime (intrinsic viscosity [ๆ] versus particle shape).

- Tull volume fraction $\$$ range $(\eta)$.

- Percolation threshold $p_{c}$ versus particle shape.

- Maximum packing fraction $\Phi_{\mathrm{In}}$ as key parameter.

- Effects of particle shape for monodisperse rigid solid particles.

- Shear rate (SR), absolute temperature (T), and flocculation effects.

- Examples of viscosity calculations as a function of:

- Particle shape.

- Shear rate (SR).

- Absolute temperature (T).

- Viscosity of dispersing fluid.

- Number of particles $(\mathrm{N})$ and fractal dimensionality (d) of aggregates in flocculated systems.

- When one finds a finite yield stress (with example).

- Polydispersity, flexibility, and "slip" or "plasticization" effects.

- Comparison with experimental data of Krishnamoorti et al.

Fig. 1

- Summary and conclusions. 


\section{$A_{\mathrm{f}}$ DEPENDENCE OF $[\eta]$}

- Isotropic average of [ $\eta]$ for biaxially symmetric ellipsoids.

- $A_{f}=($ length of major axis $c$ )/(length of minor axes $a=b$ ).

- $A_{f}>1$ for fibers, $A_{f}=1$ for spheres, $A_{f}<1$ for platelets.

- Squares indicate exact solutions of constitutive equations.

- The curve represents a fitting equation:

$[\eta] \approx \frac{1012+2904 \mathrm{~A}_{\mathrm{f}}-1855 \mathrm{~A}_{\mathrm{f}}^{1.5}+1604 \mathrm{~A}_{\mathrm{f}}^{2}+80.44 \mathrm{~A}_{\mathrm{f}}^{3}}{1497 \mathrm{~A}_{\mathrm{f}}+\mathrm{A}_{\mathrm{f}}{ }^{2}}$

Fig. 2

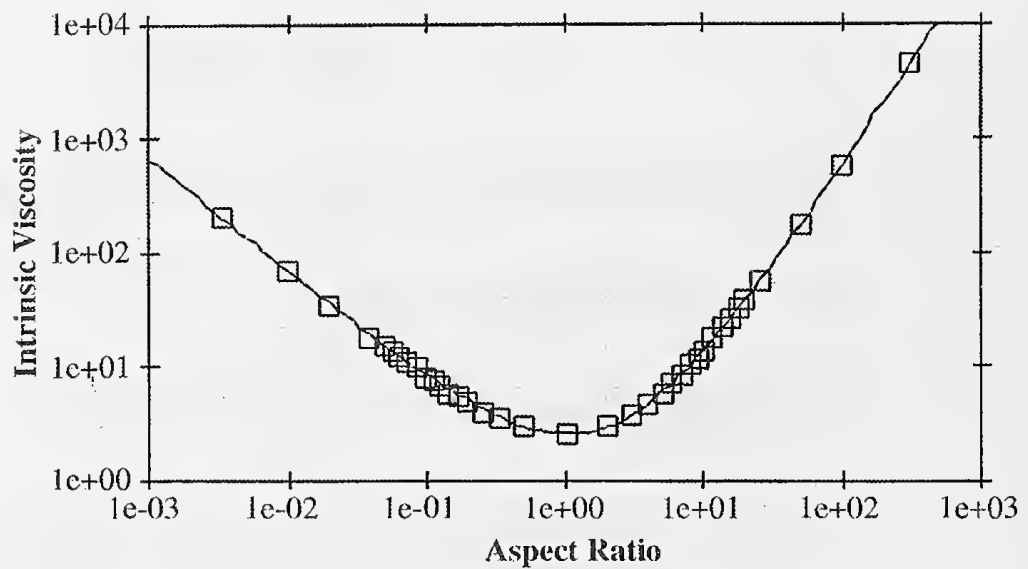

$\mathrm{A}_{f}$, SHEAR RATE AND T DEPENDENCE OF [ $\left.\rceil\right]$

$A_{\mathrm{f}}$ affects $[\eta]$ at all SR values, while SR and $T$ dependences may occur for nonzero SR via dependence of $[\eta]$ on Pe.

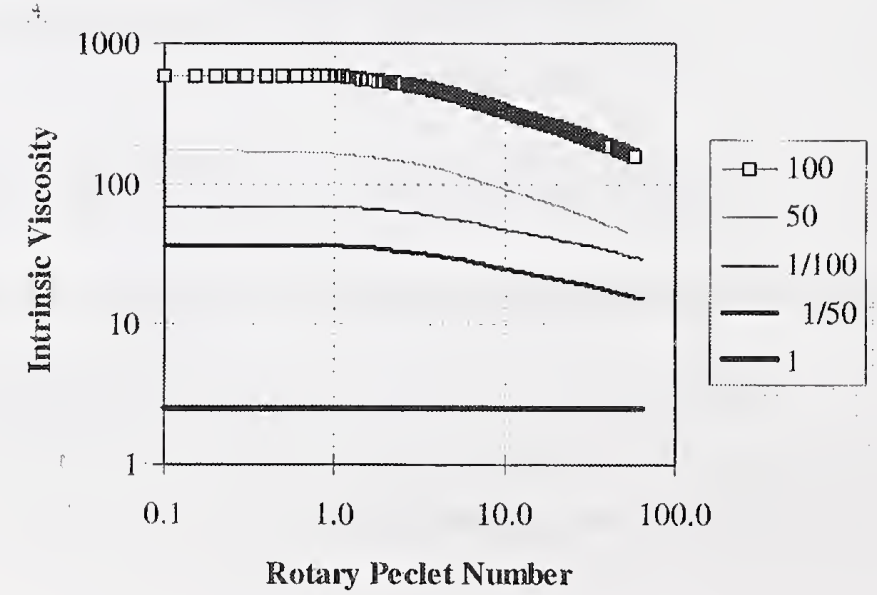

Fig. 3 
- Dilute dispersion described by a "virial expansion":

$$
\eta(\text { relative }) \equiv \frac{\eta(\text { dispersion })}{\eta(\text { dispersing fluid })} \approx 1+[\eta] \Phi+\mathrm{k}_{H} \cdot \Phi^{2}+\ldots
$$

- Concentrated dispersion described by the Maron-Pierce equation (a good semi-empirical expression), where k 1.

$$
\eta(\text { relative }) \approx \mathrm{k} \cdot\left(1-\frac{\Phi}{\Phi_{\mathrm{m}}}\right)^{\cdots 2}
$$

- Our new "universal" expression is valid over full range of $\Phi$ values, and goes to following limits:

* Second-order virial expansion in dilute regime.

- Maron-Pierce equation with $k=0.94$ in concentrated regime.

Fig. 4

$$
\eta \text { (relative }) \approx\left(1-\frac{\Phi}{\Phi_{\mathrm{m}}}\right)^{-2} \cdot\left[1-0.4 \cdot \frac{\Phi}{\Phi_{\mathrm{m}}}+0.34 \cdot\left(\frac{\Phi}{\Phi_{\mathrm{m}}}\right)^{2}\right]
$$

\section{"UNIVERSAL" $\eta$ EXPRESSION VERSUS DATA}

- Representative data from work of de Kruif et al., for sterically stabilized hard silica spheres in cyclohexane.

- Also good agreement with data from many other sources, for particles of different shapes in different types of fluids.

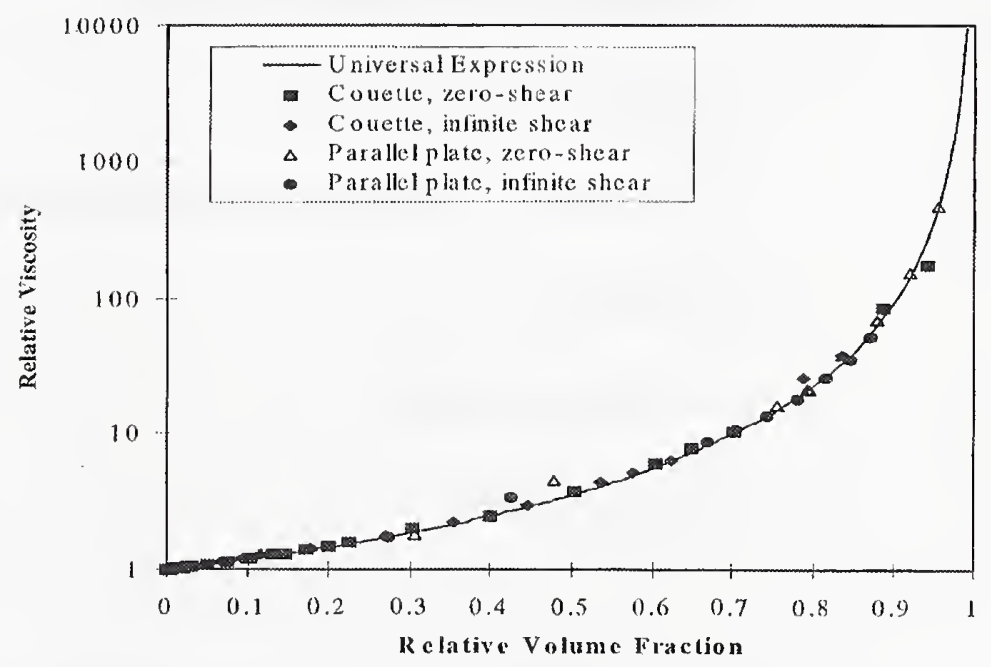

Fig. 5 


\section{$A_{f}$ DEPENDENCE OF $p_{c}$}

- Isotrojically placed biaxially symmetric ellipsoids.

- $A_{f}=($ length of major axis $c$ )/(length of minor axes $a=b)$.

- $A_{p}>1$ for fibers, $A_{f}=1$ for spheres, $A_{f}<1$ for platelets.

- Squares indicate results of Monte Carlo simulations.

- The curve represents a fitting equation:

$$
\mathrm{p}_{\mathrm{c}} \approx \frac{9.875 \mathrm{~A}_{\mathrm{f}}+\mathrm{A}_{\mathrm{f}}^{2}}{7.742+14.61 \mathrm{~A}_{\mathrm{f}}+12.33 \mathrm{~A}_{\mathrm{f}}^{1.5}+1.763 \mathrm{~A}_{\mathrm{f}}{ }^{2}+1.658 \mathrm{~A}_{\mathrm{f}}{ }^{3}}
$$

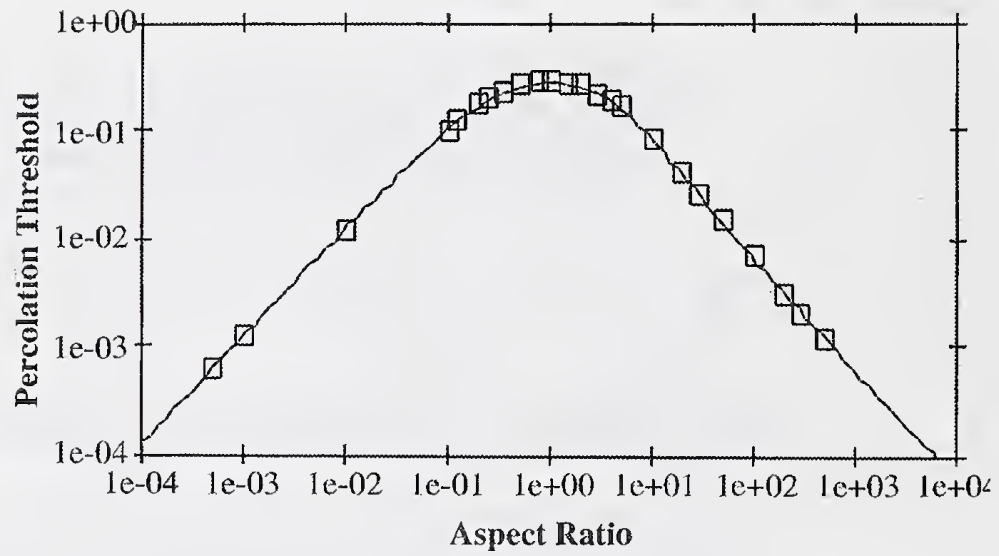

Fig. 6

\section{Aspect Ratio}

- A quantitalive predictive model was developed for dispersion shear viscosity relative to dispersing fluid, as a function of:

Volume fraction of dispersed particles.

- Shape of dispersed particles.

- Flocculation (size and fractal dimensionality of aggregates).

- Shear rate.

- Absolute temperature.

- Particle flexibility.

Fig. 7

- A computer program and a major manuscript were prepared. 
"Modeling the Behavior of Polymer/Clay Nanocomposites", Anna C. Balazs, Chemical Engineering Department, University of Pittsburgh, PA

Dr. Balazs discussed the paucity of knowledge regarding thermodynamic properties of polymer/clay nanocomposites. It is well known that polymer-clay nanocomposites exhibit dramatic increases in tensile strength, heat resistance, and barrier properties as compared to the pure polymer matrix. Insights into these phenomena, and a better understanding of the properties of polymer/clay nanocomposites may by obtained by modeling their thermodynamics. By deriving the free energy for the system, phase diagrams for polymer/clay and polymer/solvent/clay mixtures were constructed. Dr. Balazs's results provided guidelines for fabricating thermodynamically stable nanocomposites with the desired morphology. Dr. Balazs also focussed on the interactions between surfactant-modified clay surfaces and a polymer melt. Using selfconsistent field calculations, the various characteristics of the surfactants, polymers and clay surfaces were varied. From the calculations, the optimal conditions for promoting the penetration of the polymer between the organically-modified interfaces were isolated. 


\section{ATTENDEES RESPONSE}

Surveys were conducted by brainstorming all research and technical needs in the area of fillers and nanocomposites and then ranking the needs by a voting scheme.

\begin{tabular}{|c|c|c|}
\hline Rank & Compounding, Reinforcement and Toughening - Research Needs & Score \\
\hline 1 & Polymer/Filler Interactions & 16 \\
\hline 2 & Dynamics at Filler/Polymer Interface & 15 \\
\hline 3 & Surface chemistry of fillers (and silane coupling agents) & 10 \\
\hline 4 & Inter"phase" morphology & 6 \\
\hline 5 & What initiates fatigue? Where does it happen? & 6 \\
\hline 6 & Polymer blend thermodynamics in the presence of fillers & 5 \\
\hline 7 & Ideal Systems (e.g. bound versus excluded) & 4 \\
\hline 8 & Correlation between size scale and performance & 3 \\
\hline 9 & Durability and Heterogeneity & 3 \\
\hline 10 & Viscoelasticity measurements of filled polymers - bound fraction from high shear. & 3 \\
\hline 11 & Evolution of morphology related to stiffness/toughness & 2 \\
\hline 12 & Polymer/Filler Networks & 2 \\
\hline 13 & Equilibrium or non-equilibrium? How far away? Timescales. & 2 \\
\hline 14 & Role of crosslinking & 2 \\
\hline 15 & Role of fillers in crystalization & 2 \\
\hline 16 & Orientation/Aspect Ratio with interface at finite thickness & 1 \\
\hline 17 & Modulus interpretation of AFM data & 1 \\
\hline 18 & Thermal/shear effects & 1 \\
\hline 19 & Selectivity of pigments, flame retardant, etc... & 1 \\
\hline 20 & Filler mobility versus polymer mobility & 0 \\
\hline 21 & Chemistry of coupling agents & 0 \\
\hline 22 & Role of surface roughness & 0 \\
\hline 23 & Migration of additives to interfaces & 0 \\
\hline
\end{tabular}




\section{Compounding, Reinforcement and Toughening - Research Needs (85 responses)}

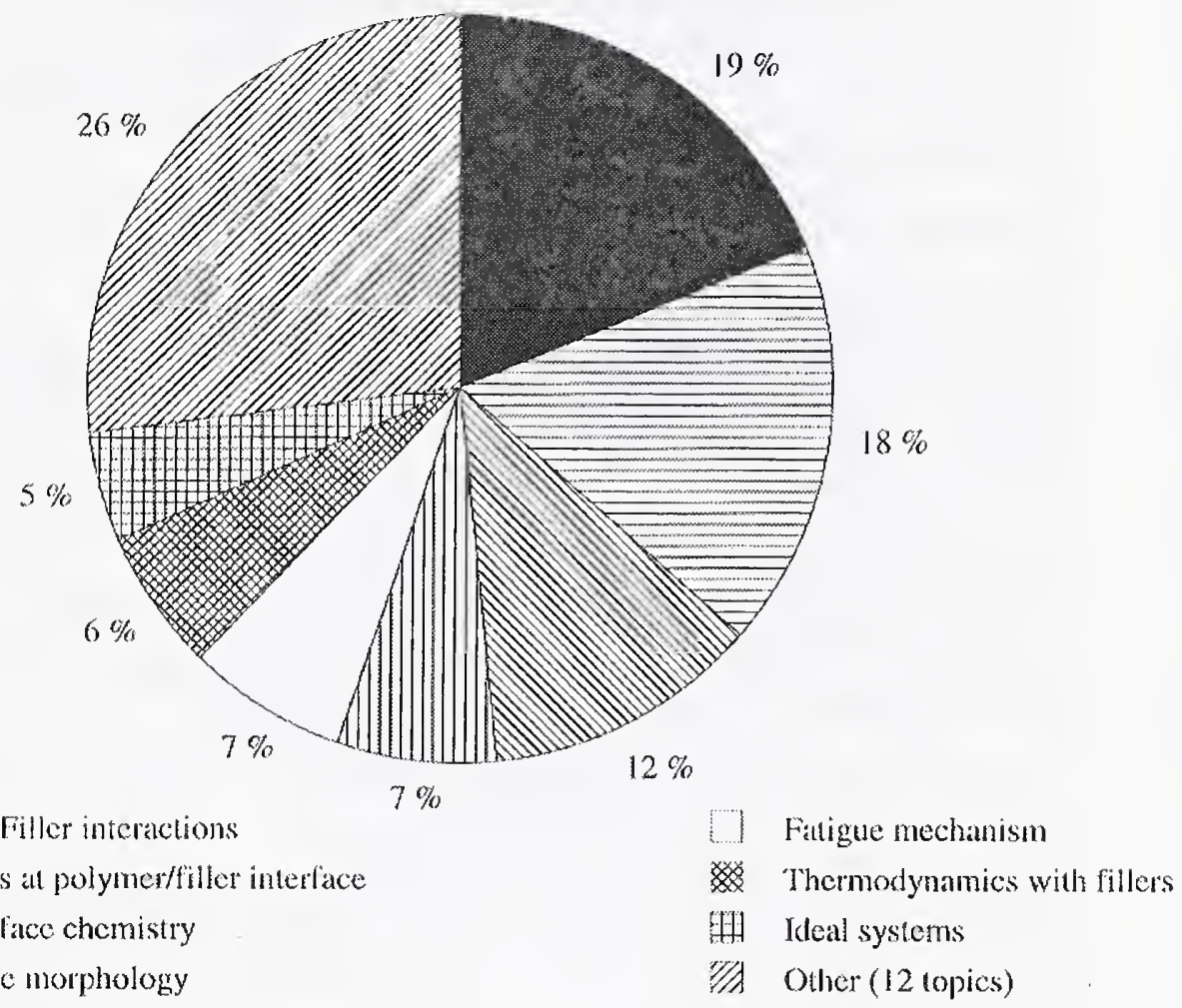




\section{Results of Survey (cont'd)}

\begin{tabular}{|c|c|c|}
\hline Rank & Compounding, Reinforcement and Toughening - Technological Needs & Score \\
\hline 1 & Measuring transient morphology & 10 \\
\hline 2 & Less expensive/less labor intensive technique for characterizing dispersion & 8 \\
\hline 3 & Online probes of distribution. Process monitoring & 7 \\
\hline 4 & AFM instead of TEM to look at filled systems (10nm resolution) & 4 \\
\hline 5 & Resistivity Measurements/Lumped Impedance & 4 \\
\hline 6 & Mobility at interface in high temperature systems & 3 \\
\hline 7 & Measuring Exchange with Scattering & 2 \\
\hline 8 & $\begin{array}{l}\text { New Visualization Techniques for seeing networks. Magnetic Resonance Imaging } \\
\text { (MRI) }\end{array}$ & 1 \\
\hline 9 & Low temperature atomic force microscope (AFM) & 1 \\
\hline 10 & Mechanical-optical & 0 \\
\hline 11 & Online probes of dispersion & 0 \\
\hline 12 & Filler migration & 0 \\
\hline 13 & In-situ nanoscale probe (cheap, portable, etc...) & 0 \\
\hline 14 & How to measure fatigue. Real-time, in-situ & 0 \\
\hline 15 & Measuring small strains at small length scales & 0 \\
\hline 16 & post-processing evolution & 0 \\
\hline 17 & Understanding and eliminating "skin" effects & 0 \\
\hline 18 & High frequency measurements in cured state & 0 \\
\hline 19 & Entanglement with bound fraction & 0 \\
\hline
\end{tabular}




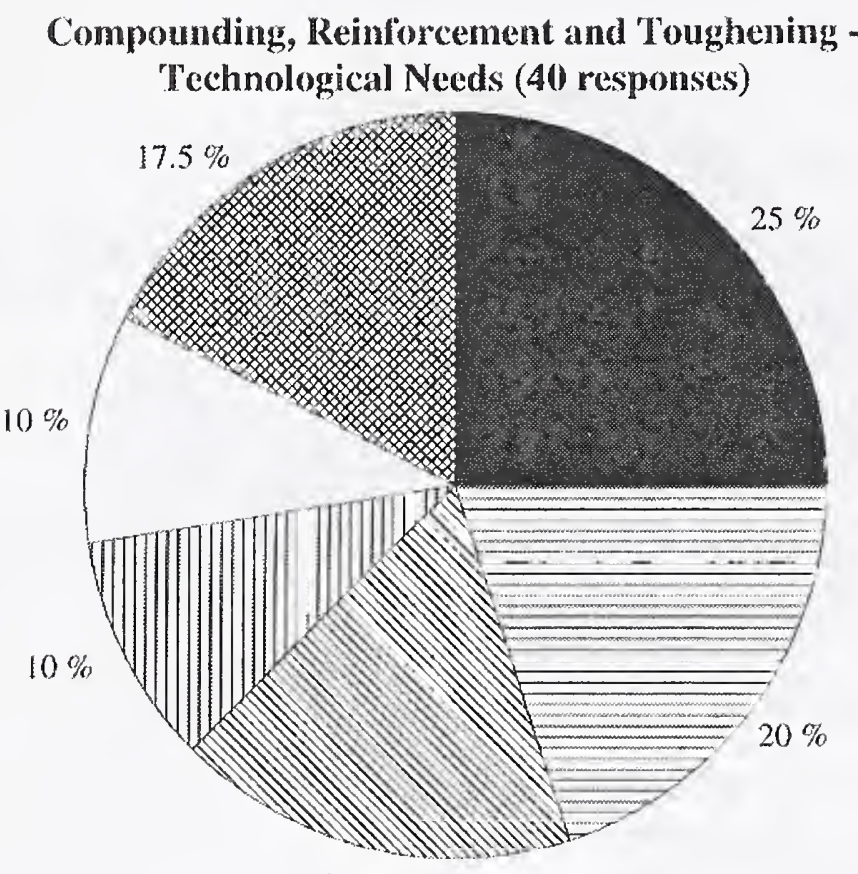

$17.5 \%$

Measuring transicnt morphology

Easicr dispersion characterization

AN Online process monitoring
1II) AFM vs. TEM

1... Electrical measurements

Other (14 topics) 


\section{Results of Survey (cont'd)}

\begin{tabular}{|l|l|l|}
\hline Rank & Nanocomposites - Research Needs & Score \\
\hline 1 & Structure/dynamics in confined media & 8 \\
\hline 2 & Characterization method for degree of intercalation & 4 \\
\hline 3 & Characterization of thin film mechanics & 4 \\
\hline 4 & exfoliation - mechanism & 3 \\
\hline 5 & dielectric spectroscopy for nanocomposites & 3 \\
\hline 6 & Measure barrier properties/transport & 3 \\
\hline 7 & Define length scales of morphologies relating to known physical properties & 2 \\
\hline 8 & Positron annihilation & 2 \\
\hline 9 & Mechanics of nanocomposites & 1 \\
\hline 10 & Intercalated models based on capillary theories & 1 \\
\hline 11 & Method to monitor/characterize degredation during processing & 1 \\
\hline 12 & Polydispersity on intercalation & 0 \\
\hline 13 & Characterization of interphase layer in semi-crystalline & 0 \\
\hline 14 & Comparison of same volume loading of fillers (e.g. Si, CB) & 0 \\
\hline 15 & NMR for nanocomposities & 0 \\
\hline 16 & SANS for nanocomposites & 0 \\
\hline 17 & Replacement/addition to TEM & 0 \\
\hline 18 & Examine purity issue & \\
\hline & & 0 \\
\hline
\end{tabular}




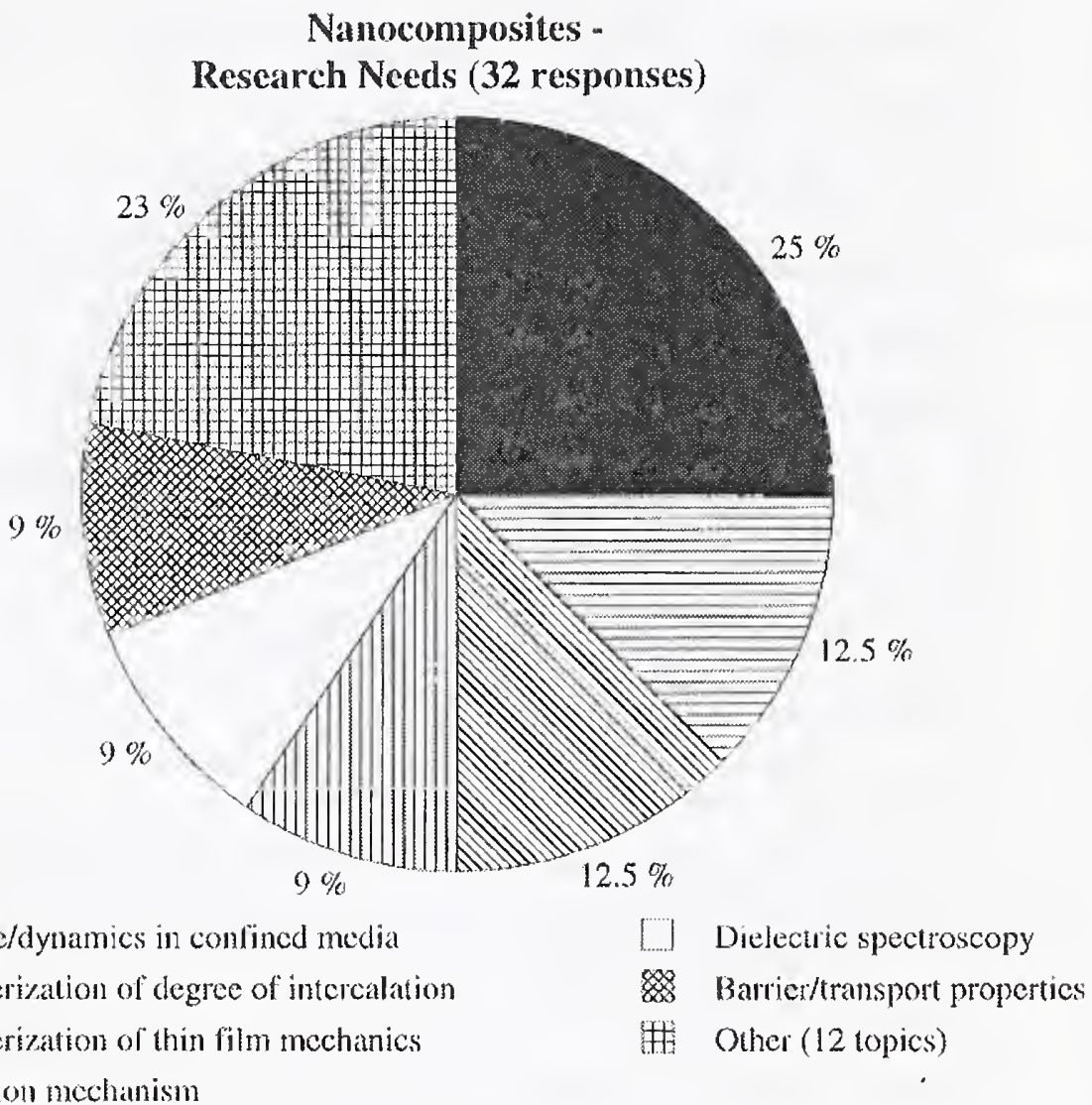

III Exfoliation mechanism 


\section{Results of Survey (cont'd)}

\begin{tabular}{|l|l|l|}
\hline Rank & Nanocomposites - Technological Needs & Score \\
\hline 1 & Characterize degree of exfoliation & 6 \\
\hline 2 & Functionalized AFM tips & 4 \\
\hline 3 & Nanomechanics - real-time measurements of fracture, toughness & 4 \\
\hline 4 & Enthalpy measurements - microcalorimetry & 3 \\
\hline 5 & How to probe dynamics at different time scales? & 3 \\
\hline 6 & Technique that combines global probe (SAXS, XRD) with local (TEM) that is fast & 3 \\
\hline 7 & Standard sampel preparation method for XRD & 2 \\
\hline 8 & Measure anisotropy - dielectric, etc. & 2 \\
\hline 9 & Methods to characterize starting material - different length scales relate to properties & 1 \\
\hline 10 & Synchtron x-ray & 1 \\
\hline 11 & Take advantage of clay flourescence to image & 0 \\
\hline 12 & SIMS area result (scanning) & 0 \\
\hline 13 & Surface force aparatus & 0 \\
\hline 14 & Catalytic degredation - measure and compare with conventional fillers & 0 \\
\hline 15 & Torsional measurements & 0 \\
\hline 16 & Simulation of Tg & 0 \\
\hline 17 & Control orientation/structure & 0 \\
\hline 18 & Measure mechanism/extent of exfoliation & \\
\hline & & 0 \\
\hline
\end{tabular}




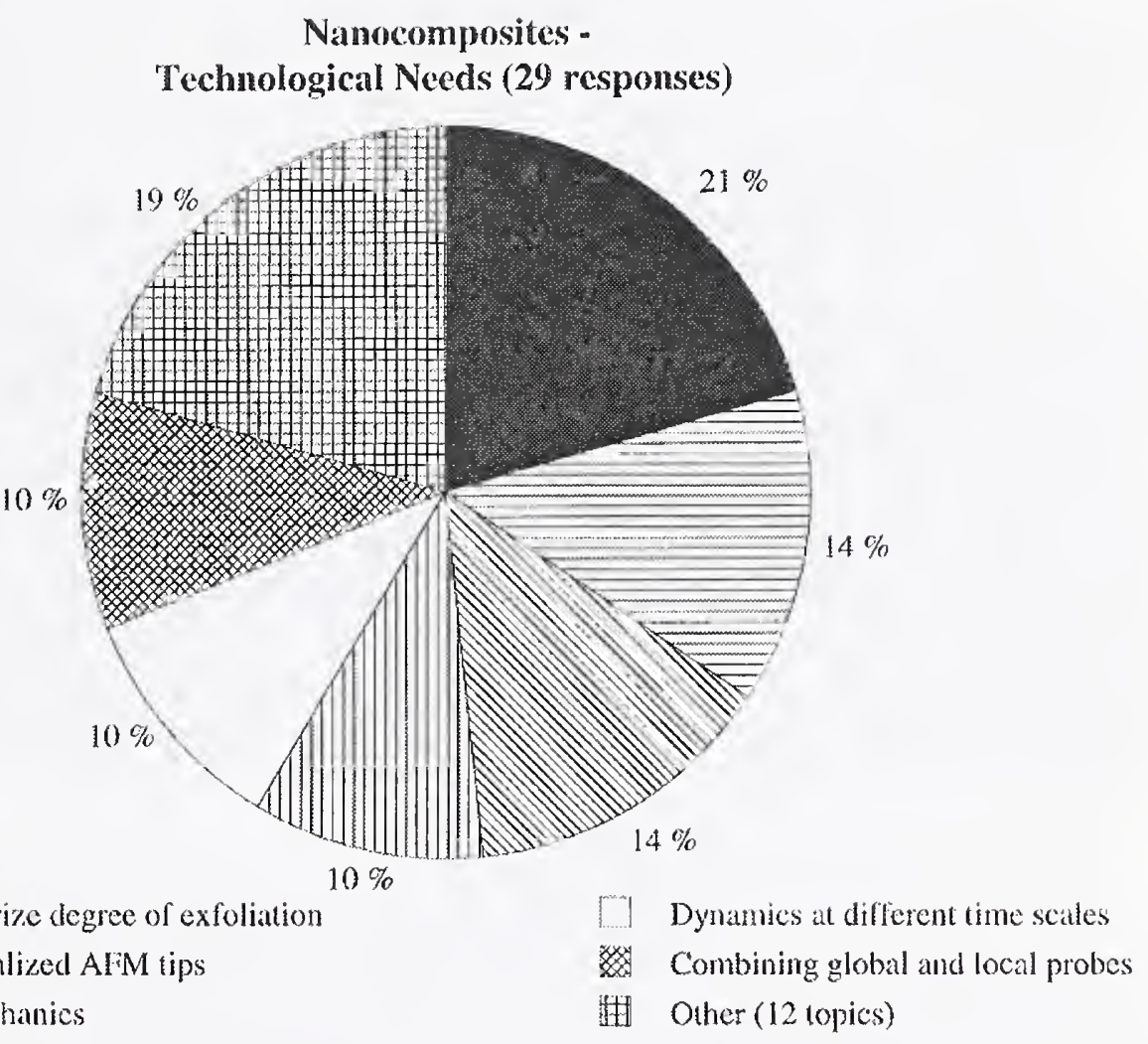

III Microcalorimetry 


\section{CONCLUSIONS}

\subsection{Research and Technology Needs}

The most important research and technological needs are summarized in the pie charts identified in the previous section. Some general observations are drawn from these results.

\section{Research Needs}

\section{Filled Polymers}

\section{Characterizing Polymer/Filler Interactions}

The polymer/filler interactions play an important role in the binding and adsorption of molecules at the filler surface, and these interactions determine many of the ultimate properties of filled materials. Control of interaction parameters can be therefore be vital for many filled systems. However, the nature of the polymer/filler interactions is illcharacterized in most filled polymeric systems. This is primarily because of the difficulty in applying measurement techniques suitable for filled polymer systems. Studies on model filler surfaces may be useful in this regard. Studies of blend phase separation in the presence of fillers using scattering and rheology is an approach being tested by the Blends and Processing Group at NIST. Results indicate that this can be used to characterize relative polymer/filler interactions in multicomponent filled systems. Absolute characterization of polymer/filler interactions is considerably more difficult, yet all important; an issue that should be addressed in future meetings and workshops.

\section{Dynamics at Filler/Polymer Interface}

While a number of rheological studies exist on measuring the bulk properties of filled systems, there is a paucity of information at the molecular level on dynamics of the polymer chains in filled systems. The volume in the vicinity of the filler is especially important in this regard. As with the polymer/filler interactions, these measurements suffer from technical difficulties in applying straight forward methods to measure local chain dynamics. Nuclear Magnetic Resonance (NMR) is perhaps the most successful technique to date. Inelastic neutron scattering is an equally promising technique for exploring the local chain dynamics in filled systems, especially since the measurements do not require costly deuterated polymers. This program was initiated by the Polymer Blends and Processing Group at NIST for investigating dynamics in nanocomposite materials, and is being extended more generally to filled materials in collaboration with industry.

\section{Surface Chemistry of Fillers (and Silane Coupling Agents)}

Control and characterization of filler surface chemistry is an important industrial approach for modifying polymer/filler interactions. For instance, silane coupling agents are widely used in many applications of filled polymers and therefore of significant interest to the filled polymers industry. Much of the knowledge on the modification and its effect is however at the empirical level. Development of characterization techniques for probing the chemical nature, homogeneity and roughness of the modified surface is deemed important. In addition, the effect of the surface modification in altering 
polymer/filler interactions may be key to predicting properties of polymer materials containing surface modified fillers.

\section{Technological Needs}

\section{Measurements of transient morphology}

Most current measurement techniques involve measuring only the final state morphology of the filled polymer. However, in order to better control the final state morphology in a typical processing or extrusion, it is important to understand the morphological changes occurring during the different stages of processing. Advances in measurement technology for rapidly measuring transient morphologies is therefore important for the goal of reduction of industrial product development cycles.

\section{Low cost automated technique for dispersion characterization}

Development of an inexpensive technique for characterizing state of dispersion in filled polymers was a unanimous request by the fillers workshop participants. This would involve not only measuring the sample in its dispersed state, but also to quantify it in terms of useful parameters such as loading level, particle anisotropy, aspect ratio, etc. Development of advanced image analysis techniques in two and three dimensions is expected to be a necessary component to quantify dispersion as well. Mathematical tools and concepts such as Fourier transform of images, already in use by the Blends and Processing Group for quantifying morphology and kinetics during phase separation may possibly be applied to more generally characterize filler particle dispersed state. Due to the large number of parameters characterizing the dispersed state of a typical filler, developing a universal parameter defining dispersion is expected to be a non-trivial task.

\section{Online probes of filler distribution and process monitoring}

Related to the problem of measuring transient morphologies is the more general problem of measuring the in-situ state (such as dispersion, morphology, monitoring coupling agent level, etc.) of the filled polymer. Such in-situ measurements will enable incorporation of more efficient adaptive techniques for on-line process corrections. The use of on-line probes for process monitoring has been an ongoing project within the Blends and Processing Group using ultrasonic probes, and more recently using optical temperature probes with success on regular blends. An extension of these measurements to filled polymer systems would be a useful logical step. The monitoring of opaque filler particles is expected to place constraints on the applicability of the optical probe technique, however.

\section{Nanocomposites}

\section{Research Needs}

\section{Structure and dynamics in confined media}

The effects of confinement on polymer structure (such as chain dimensions, radius of

gyration, isotropy, density etc.) can be significant given that the interlayer gallery spacing between clay sheets has the same order of magnitude dimensions as small molecule 
polymer chains. Measurements of the polymer structure in confined media and how their dynamics are affected in intercalated and exfoliated clays versus bulk polymer should eventually be related to the ultimate material properties. Inelastic neutron scattering capabilities are expected to be exceptionally promising in accomplishing this goal. To this end, collaborative efforts are currently being forged with filler producers and manufacturing industries involved in this area of research.

\section{Characterization method for degree of intercalation}

The current most commonly used technique for demonstrating the degree of intercalation of polymer into the clay is transmission electron microscopy (TEM) and to a lesser extent, scattering methods. One of the problems with a technique such as TEM is that it does not readily yield the three dimensional (3-D) structure, but instead only a 2-D slice through an arbitrary plane. The results are therefore often dependent on sample preparation and slicing conditions. A more universal method for characterizing the degree of intercalation in nanocomposites in 3-D would be beneficial to obtain more complete structural information on dispersion in clays, especially since the clay sheets are not necessarily planar but mostly undulating.

\section{Characterization of thin film mechanics}

Many nanocomposite applications are expected to be in the area of thin film coatings, and thus an effort is required to characterize their novel mechanical properties. These novel mechanical properties should arise from the strong degree of anisotropy induced in the system due to the high aspect ratio clay platelets. Their orientation and degree of intercalation may strongly affect the mechanical integrity and stability of the coating. The use of atomic force microscopy (AFM) in conjunction with thin film shearing devices may be required for such characterization.

\section{Technological Needs}

\section{Characterize and control degree of exfoliation}

An understanding of the factors (e.g. enthalpic, entropic and geometric) controlling the degree of exfoliation is an important technological requirement for preparing nanocomposites with well defined degree of exfoliation. The importance arises from potential applications that may have requirements from nearly unintercalated state, to intermediate intercalated state, and finally to being in the exfoliated state. Characterization of the degree of homogeneity of the dispersed platelets in macroscopic samples is an additional requirement to fully predict and estimate the properties of bulk nanocomposites.

\section{Nanocharacterization utilizing functionalized AFM tips}

Measurements of interactions of clays with differently functionalized polymers may be simulated by performing AFM studies using tips with attached surface groups of different chemical functionality. Local modulus, friction and surface roughness are some of the measurable properties using the AFM. Development of theoretical models to predict such behavior would have to be developed as part of such an effort. 


\section{Nanomechanics-real time measure of fracture, toughness}

The real-time measure of fracture and toughness on a local scale at the size of the clay platelets would yield useful insights into the mechanism governing macroscopic mechanical failure in nanocomposites, and means by which it can be avoided. Since the fracture typically occurs very quickly, measurement techniques such as AFM cannot be applied to do real time studies of fracture mechanics. Localized ultrasonic probes and dielectric spectroscopy approaches may be potentially more useful in this regard.

\subsection{Summary and Future Outlook}

The workshop discussions clearly suggest that there are significant technological and scientific opportunities in extending our knowledge of filled polymers and nanocomposites at a more fundamental scientific level of description. A steady increase in the demand for filled polymeric materials, yet with flexible or finely tunable and predictable properties, makes it imperative to understand key factors governing filled polymer behavior. Control of molecular level interactions and polymer dynamics at the filler interface have been identified as the most critical issues in filled polymers and nanocomposites in our workshop. Other important issues relate to developing inexpensive methods for characterizing online and in-situ processing studies, better dispersion control, developing a more universal definition for characterizing dispersion, and nano-characterization of filled material properties. The Polymer Blends and Processing Group at NIST has developed a program to study filled polymer and nanocomposites to address some of the most critical issues, in collaboration with industrial partners. Future efforts will focus on some of the other important issues identified through the workshop. 


\section{APPENDICES}

\section{Appendix I Workshop Program Agenda}

Thursday June 18, 1998

8:30 Registration, Refreshments

9:00 Welcome and Introduction- Leslie Smith, Director, MSEL

9:10 Outline and Introductions - Eric Amis and Alamgir Karim, NIST Polymers Division

Morning-Compounding, Reinforcement and Toughening (I)

9:30 Gary Burns (Dow Corning)- Concepts in Rubber Chemistry: The Role of the Filler Particle

10:15 Break

10:30 Henry Yang (Sid Richardson) - Filler-Filler, Polymer-Polymer and Filler-Polymer interactions: Effects on Rubber Compounds Physical Properties

11:00 Saad Khan (NC State)- Flow-induced Microstructural changes in Filled Polymeric Liquids

11:30 Moshe Narkis (Technion, Israel)- Recent Industrial Developments: From Anti-

Static Polymers to Artificial Marble

12:00 Discussion

12:30 Lunch Break (NIST Cafeteria)

\section{Afternoon-Compounding, Reinforcement and Toughening (II)}

1:45 Albert Yee (U. of Michigan) - A Comparative Study of Microstructure and Fracture Behavior of a Conventional Filled Polymer and a Nanocomposite: Possible Roles of Interfacial Constraint

2:30 Rose Ryntz (Ford) - Effect of Metallocene Impact Modifiers on Cohesive Strength of Thermoplastic Olefins

3:00 Break

3:15 Mun Fu Tse (Exxon) - BIMS Elastomer/Filler Interactions

3:45 Jay Dias (Exxon) - Investigations of Filler Polymer Interactions

4:15 Jo Ann Bice (PPG) - Evolving Structure/Property Relationships for Precipitated Silica

4:45 Discussion of Needs and Priorities

Friday June 19, 1998

Morning -Nanocomposites

8:30 Emanuelle Gianellis (Cornell U.)- Structure and Dynamics of Polymer Nanocomposites

9:00 Karl Kamena (Nanocor) - Montmorillonite Clay Structures and Intercalation Chemistries based on Dipole Moment Interactions

9:30 Howard Hanley (NIST) - Dispersion in a Clay Nanocomposite; Application of Radiation Scattering

10:00 Break

10:15 Leon Gilgens (TNO netherlands) -Nano-Composites from Polymers and Layered Minerals 
10:45 Ramanan Krishnamurthy (U. Houston) - Rheological Study of Macro and Nano Composites

11:15 Jeffrey Gilman (NIST) - Flammability Studies of Polymer Layered Silicate Nanocomposites

11:40 Robert Ivkov (NIST) - Dynamics of Polymers in Confined Geometries: Inelastic

Scattering

12:00 Discussion

12:30 Lunch (NIST Cafeteria)

\section{Afternoon-Theory and Simulations}

1:45 C.K.H. Dharan (U. Berkeley) - Effect of Fillers and their Distribution on Composite Properties

2:15 Josef Bicerano and Jack Douglas (NIST) - The "Effective" Properties of PolymerFiller Mixtures

2:45 Coffee Break

3:00 Anna Balazs (U. Pittsburg) - Modeling the Phase Separation of Polymer Clay Nanocomposites

3:30 Discussion of Needs, Priorities and Future Plans 


\section{Appendix II}

Final Participants List

\section{Workshop on'Interactions of Polymers With Fillers and Nanocomposites}

June 18-19, 1998

National Institute of Standards and Technology

Gaithersburg, MD

Eric Amis

NIST

Bldg. 224, Rm. 13210

Gailliersburg, MD 20899-0001 USA

Telephone: $301 / 975-6681$

Fax: 301/975-4924

Email: eric.amis@nist.gov

Anna Andrews

Ferro Corp.

7500 E. Pleasant Valley Rd.

Techanical Center

Independence, OH 44131 USA

Telephone: $216 / 641-8580 \mathrm{ext} / 7912$

Fax: 216/524-0518

limail: andrewsa@ferro.com

Joseph Antomucei

NIST

Bldg. $224, \mathrm{Rm} . \mathrm{A} 143$

Gaithersburg, MD 20899-0001 USA

Telephone: 301/975-6726

Ama Balars

University of l'ittsburgh

Chem. Ling. Dept.

Pittsburgh, I'A 15219 USA
Mike Balogh

$\mathrm{GM}$

30500 Mound Rd.

Warren, MI 48090

Telephonc: 810/986-0862

Fax: 810/986-0817

Kathleen Bames

NIST

Bldg. 224, Rm. B210

Gailhersburg, MD 20899m0001 USA

Telephone: $301 / 975-4671$

Fax: 301/975-4924

Email: kathlecn,barnes@nist.gov

Joerg Baschnagel

Mainz University

Dept. of Physics

Mainz, GERMANY

Email: baschnag@flory.physik.uni-mainz..de

Gary Beall

NANOCOR Inc.

$1500 \mathrm{~W}$. Shore Dr.

Arlington lleights, IL, 60000 USA

Telephone: $847 / 394-8844$

Fax: 847/394-9040

Email: gbeal(a)nanocor.com 
Charles Beally

University of florida

Dept. of Material Science

Gainesville, H 32611 USA

Telephone: $352 / 392 m 1574$

Fax: $352 / 846-2008$

Fmail: cbeatumscull.edu

Tia bienson-lolle

Air Force Research Lab.

2941 P.St., Ste. 1

AFRLALBC B. 654

WPAFB, OH 45433 USA

Telephone: 937/255-9065

Fax: $937 / 656-4706$

Imail: bensonth(o)ml.wpafb.at.mil

Jo Am Bice

$\mathrm{PPG}$ Industries, Inc.

440 College Park Dr.

Monrocville, PA 15146 USA

T'elephone: 724/325-5368

Fax: 724/325 5255

Fimail: bice appg.com

Jozef Bicerano

Dow Chemical Company

1702 Building

Midland, MI 48674 USA

Telephone: 517/636-6980

Fax: $517 / 638-9623$

Email: biccranoj@glow.com

Thomas Blinka

Sealed Air Corporation

7500 Grace Dr.

Columbia MO 21044 USA

Telephone: $410 / 531-4483$

Fax: 4J0/5,31-4462

Email: thomas.ablinka(o) sealedair.com
Dr. Robert M. Briber

Inniv. Of Maryland

Dept. Of Materials and Nuclear Ing.

2100 Marie Mount Hall

College Park, MD 20742-2155

Telephone: $301 / 405-7313$

Fax: 301/314-9601

Email: rbriber(eng.umd.edu

Janis Brown

AFRL/MLBC

2941 P St., Ste. 1

Bldg. 654

Dayton, OH 45433 USA

Telcphone: 937/255-0968

Fax: 937/656-4706

Email: brownjm@ml.wpafb.af.mil

Ken Brown

Ferro Corporation

5001 O'Hara Dr.

Evansville, IN 47711 USA

Telephone: $812 / 435-2166$

Fax: 812/435-2169

Gary Burns

Dow Coming Comporation

Pare Industriel

Zone C

Senelfe B-7180, BELGIUM

Tclephone: (32) 64-88-84-30

Fax: (32)64-88-85-58

Email: gtburns@dern.c-mail.com

Forest Busby

The Dow Chemical Company

4.33 Building

Midland, MI 48667 USA

Telephone: 517/636-8229

Fax: 517/636-059]

Email: fbusby@dow.com 
Brent Butler

NIST Boukler

325 Broadway - Mail Code 838.08

Boulder, CO 80303 USA

Telephone: 303/497-3952

Email: brent butler (a) nist.gov

Walter Chappes

DAMILIC Corporation

14670 Southlawn Lane

Ruckville, MD 20850 USA

Telephone: $301 / 251.2960$

Fax: 301/251-8591

Email: walter.chappas@damilic.com

Martin Chiang

NIS'"

Bldg. 224, Rm. A209

Gaithersburg, MD 20899-0001 USA

Telephone: 301/975-6752

Jim Chou

Dow Chemical Company

2301 Brazosport/ B1470A

Freeport, TX 77541 USA

Telephone: $409 / 238-2601$

Fux: 409/238 0047

Email: choulodow.com

Deen Chundury

Ferro Corporation

5001 OHara Dr.

Evansville, IN 47711 USA

Telephone: 812/435-2166

Tax: 812/4.35-2169

Stephen Craig

Dulomil

Experimental Station/E328-131

Wilmington, 101: 19880 USA

Telephone: 302/695-2331

Fax: $302 / 695-8412$

Email: stcphen.l.craig@usadupont.com
David Curliss

Air Force Rescarch Lab.

2941 P St., Ste. 1

Bldg. 654

WPAIB, OH 45433 USA

Telephone: 937/255-9078

Fax: 937/656-4706

Email: curlisdb@ml.wpafb.mil

Chris Debbaut

Raychem

8000 Purfey Rd.

Fuquay Varina, NC 27526 USA

Telephone: $919 / 557-8688$

fax: $919 / 557-8595$

Email: cdebbatt@raychem.com

Hari C.K. Dharan

University of California

Dept. of Mech. Eng.

Berkeley, CA 94720 USA

lelephone: $510 / 642-4933$

Fax: 510/643-5599

Email: dharan(a)me.berkeley,edu

Beibei Diao

DuPont

Rt $141,13174 / 205 B$

DuPont Exper. Station

Wilmington, DE 19880 USA

Telephone: $302 / 695-8055$

Fax: $302 / 695-4855$

Email: diaob@BSVAX.email.dupont.com

Jay Dias

Exxon Chemical Company

5200 Bayway Dr.

Baytown Polymer Cli.

Baytown, TX 77520 USA

Telephone: $281 / 834-5255$

Fax: 281/834-2678

Email: ajdias(g)erenj.com 
Jack Douglas

NIST

Bldg. 224, Rm. B210

Gaithershurg, MD 20899-0001 USA

Telephone: $301 / 975-6779$

Fax: $301-975-4924$

Email jack.douglas@inist.gov

Cymthia Ebner

Scaled Air Corporation

7500 Grace Dr.

Columbia, MD 21044 USA

Telephone: $410 / 531-4596$

Fax: 410/531-4462

Emait: cynthail.chner@scaledair.com

Yoma lickstein

Bl'Goodrich Co.

9021 Brecksville $\mathrm{Rd}$.

Brecksville, OH 44141 USA

Telephone: $216 / 447-7520$

Fax: 2]6/447-7335

Email: cckstein@brk.bfg,com

Bruce lichinger

Molecular Simulations Inc.

9685 Scranton Rd.

San Diego, CA 92121 USA

Telephone: 619/546-5540

Fax: 619/458-0136

Email: bruce(ansi.com

Tom lillis

General Molors R\&D

Polymers irept.

M/C 480.106.216

Warten, MI 48000 USA

Teleplane: 810/986-1233

Fax: $810 / 986-8859$

Email: lclis(b) cmsa.gmr.con
Brett Ermi

NIST

Bldg. 224, Rm. B210

Gaithersburg, MD 20899-0001 USA

Telephone: 301/975-4356

lax: 301/975-4924

Email: brett.ermi(unist.gov

Ken Farminer

Dow Corning Corporation

2200 Salzburg Rd.

$\mathrm{CO} 2404$

Midland, MI 48686 USA

l'elephone: $517 / 496-1693$

Fax: $517 / 496-4511$

Yi Feng

Goodycar Tire \& Rubber Co.

142 Goodyear Blvd.

Rm. 360, Research

Akron, OH 44305 USA

'Telephone: $330 / 796-2235$

Fax: 330/796-7060

Email: yi.feng@goodycar.com

James Fishburn

GL Corporate R\&D

1 Research Circle

K. 4A26

Niskayuna, NY 12309 USA

Telephone: $518 / 387-4095$.

Fax: $518 / 387-5812$

Email: fishburn(OCRD.GE.com

Emmanucl Giannclis

Cornell University

Materials Science \& Engineering Dept.

Ithaca, NY USA 
Leon Gielgens

TNO

P.O. $130 \times 595$

Eindhouen, $5600 \mathrm{AN}$.

THE NITHERLANDS

Telephone: +31-40-265-0152

Fax: $+31-40-244-8350$

Email: gielgens $(0)$ fpd.tno.nd

deftry Cilman

NIST

Bldg. 224, Rm. B256

Gaithershurg, MD 20899-0001 USA

Telephone: $301 / 975-6573$

Fax: 301/975-4052

Fnail: jefrey.gilman@nist.gov

Sharon Giloter

NIST

Bldg. 223, Rm. A.309

Gaithersbury, MD 20899-0001 USA

Telephone: $301 / 975-5729$

Fax: 301/975-5008

Email: sharon.glotzer@nist.gov

John J. Godfrey

Aristech Chenical Corp.

1000 Tech. Center Dr.

Monroeville, PA 15146 USA

Telephone: 412/825-3433

Fax: 412/825-3495

Email: godfeyij@istechchen.com

Michael Grah

Michelin R\&D Corporation

515 Michelin Rd.

P.O. Box 1987

Grecnville, SC 20602 USA

Telephone: $864 / 422-4735$

Fax: $864,422-3505$

Email: mike.gralıo,michelin.com
Richard Harris

NIST

Bidg. 224, Rm. B258

Gaithersburg, MD 20899 USA

Telephone: 301/975-6688

Fax: 301/975-4052

Email: dick.hamis@nist.gov

\section{Erik Hobbic}

NIS'T

BIdg. 224, Rm. B210

Gaithersburg, MD 20899 -0001 USA

Telephone: 301/975-6774

Fax: 301-975-4934

Email: erik.hobbic@nist.gov

Alex Hsich

Army Research Laboratory

AMSRL-WM-MA

Aberdeen Proving Grd., MD 21005 USA

Telephone: 410/306-0698

Fax: 410/306 0676

Limait: ahsieh(a)arl.mil

Robert Ivkov

NIST

Bldg. 224, Rm. 13210

Gathersburg, MD 20899-0001 USA

Telephone: $301 / 975-4348$

Fax: $301 / 975-4924$

Email: robert.ivkov@nist.gov

Krishnamunthy Jayaraman

Michigan State University

Dept. of Chemical Eng.

Enginecring Bldg.

East Lansing, MI 48824 USA

Telephone: $517 / 355-5138$

Fax: 517/432-1105

Emai1: jayarma@egr.msu.edu 
Karl Kamenat

Nanocor, lnc.

1500 W. Shure Dr.

Arlington Heights, II, 60004 USA

Telephone: $847 / 394-8844$

Alamgir Karim

NIS'I

Bldg. 224, Rm. 3210

Gaithersburg, MD 20899-0001 USA

Telephone: $301 / 975-6588$

Fax: $301 / 975-4924$

Email: alamgir.karim(anist.gov

Chates Kenney

Aristech Chenical Corp.

600 Grant St.

Rm. 1034

Pittsburgh, PA 15219 USA

Telephone: $412 / 433-1033$

Fax: $412 / 433-7932$

Email: kenneyck@aristechchchem.com

Satad Kham

North Carolina State Univ.

Dept of Chem. ling.

Raleigh, NC 27695 USA

Fax: 919/515-3465

Email: khanócosnesu.com

Ramanan Krishnamoorti

University of Houston

Dept of Chem. ling.

Houston, TX 77204-4792 USA

Telcphone: $713 / 743-4312$

Fax: 713/743-4323

Emait: ramanan(ebayou.uh.edu
Sai Kumar

Anoco Polymers

4500 McCinnis ferry Rd.

Alphaketta, GA 30005 USA

Telephone; $770 / 772-8987$

Fax: 770/772-8547

Email: kumar(o)amoco.com

Benjamin Lee

NIS'Y

BIdg. 224, Rm. B210

Gaithersburg, MD 20899-0001 USA

Telephone: $301 / 975-2113$

Fax: 301/975-4924

Email: benjamin.lec@nist.gov

Yeong Ching Lin

Integral Chemical Corp.

17 Jen-Chen Rd.

Ilsiu-Chiu Industry

Hsiu-chu, TAIWAN

Telephone: $88-635 \times 978-599$

Fax: $88-635-978762$

Da-Wuiliu

NIST

Bldg. 224, Rm. 13210

Gaithersburg, MD 20899-0001 USA

Telephone: 301/975-6735

Fax: 301/975-4924

limail: da-weiliu@nist.gov

Robert Lochead

University of S. Mississippi

Hardy St.

Dept. of Polymer Science

Hatticsburg, MS 39406 USA

Telephone: 601/266-4868

Fax: 601/266-5504

Email: robert. lochhead@usm.cdu 
Kevin Lyons

Symyx lechnologies . 3100 Central Express

Santa Clara, CA 95051 USA

Telephone: 408/7642040

Fax: 408/748-0334

Email klyons@symyx.com

Debora Massonda

DuPont

Experimental Station E323/30313

Wilmington, DE 19880 USA

Telephone: $302 / 695-8751$

Michael McBrenty

CEP

705 Yorklyn Rd.

Hockessin, DE 19707 USA

Telephone: $302 / 234-8206$

Fax: 302/239-4677

Email: mm@cep-corp.com

Nornan Moll

Dow Chemical Company

677 Building

Midland, MI 48667 USA

Telephone: $517 / 636-3748$

Fax: $517 / 638-7347$

Email: normmollowdow.com

David Moll

Dow Chemical Corponation

1702 Building

Midland, MI 48674 USA

Telephone: $517 / 636-9413$

Fax: $517 / 638-9623$

Fimail: dimoll@dow com
Cal Moreland

Michelin R\&D Corporation

515 Michelin $\mathrm{Rd}$.

P.O. Box 1987

Greenville, SC 29602 USA

Telephone: $864 / 422-4300$

Fax: 864/422-3505

Chris Munzy

NIST Boulder

325 Broadway

Boulder, CO 80303 USA

'lelephone: 303/497-5549

Fax: 303/497-5224

Email: chris.munzy(anist.gov

\section{Alan Nakatani}

NIST

Bldg. 224, Rm. B210

Gaithersburg, MD 20899-0001 USA

Telephone: $301 / 975-6782$

Pax: 301/975-4924

Email: alan.nakatani@nist.gov

Moshe Narkis

Israel Institute of Tech.

Dept of Chem. Eng.

Technion City, ISRAEL

Telephone: $972 / 48232937$

Fax: 972-4-823-0476

Email: narkis@tx.technion.ac.il

Diep Nguyen

PPG Industries, Inc.

4325 Rosanna Dr.

Allison Park, PA 15101 USA

Telephone: 412/492-5459

Iax: 412/492-5588

Email: dnguyen(appg.com 
Tinh Nguyen

NISI

Bldg. 226 Rm. B348

Gaithersburg, MD 20899-0001 USA

Telephone: 301/975-6718

Email: tinh.nguyen(o)nist.gov

Marc Nyden

NIST

Bldg. 224. Rm. B258

Gaithersburg, MD 20899-000 USA

Telephone: 301/975-6692

Fax: $301 / 975-4052$

Email: marc.nyden@nist.gov

Don Rivin

U.S. Army

Natick RD\&E Center

Natick, MA 01760 USA

Telephone: 508/233-4392

Fax: 508/233-5223

Email: drivin(a)natick-amed02.army.mil

Rose Ryntz

Ford Motor Company

401 Southield Rd.

$\wedge 103$

Deaborn, MI 48121 USA

Telephone: 313/621-7648

Fax: $313 / 621-7648$

Email: myntzoford.com

Dan Siand

Eastman Chemical Company

P.O. Bow 1955

Kingsport, TN 37662 USA

Telephone: 423/229-6808

Fax: $423 / 229-4558$

Email: dansandobeastman.com
Nigel Sanders

Speciatty Minerals

9 Highland Ave.

Bethlehem, PA 18017 USA

Telephone: 610/861-3457

Fax: 610/861-3412

Thomas Seery

University of Connecticut

97 N. Eagleville Rd., U-136

Storrs, CT 06269 USA

Telephone: 860/486-1337

Iax: 860/486-4745

Email: seery@mail.ims,uconn.edu

Willian Simendinger

Raychem

8000 Purley Rd.

Fuquay Varina, NC 27526 USA

Telephone: 919/557-8688

lax: 919/557-8595

Email: tsimendi@raychem.com

Demis Simpson

PPG Industries, Ine.

4325 Rosanna Dr.

Allison Park, PA 15101 USA

Telephone: 412/492-5224

Anant Singh

Triton Systems, luc.

200 Tumpike Rd.

Chelmsford, MA 01824 USA

Telephone: 978/250-4200

lax: 978/250-4533

Email: anant@tritonsys.com 
Diane Steeves

U.S. Arny Soldier Systems,

Science \& Tech Dir.

Natick, MA 01760-5020 USA

Telephone: $508 / 233-4320$

Fax: $508 / 233-5521$

Email: dsteevesionatick-amed02.amy.mil

Benjamin Tang

DOT/FIWW

$400711 \mathrm{St}, \mathrm{SW}$

Washington, DC 20590

Telephone: 202/366-4592

Fax: $202 / 366-3077$

Martin lant

Fastman Chemical Company

P.O. Box 1972

Kingsport, IN 37662 USA

Telephone: $423 / 229-2147$

Fax: $423 / 22944558$

Enail: Lanlateastman.com

Ed lownsend

Aristech Chemical Corp.

1000 Tech. Center Dr.

Monroeville, PA 15146 USA

Telephone: $412 / 825-3356$

Fax: $412 / 825-3495$

Email: townsende(a) aristechehem.com

Isung Yen Tsai

I'IRI

321 Kuang I'U Rd.

Section 2

Hsinchu 300,TAW

Telephone: $886-3-573-2479$

Fax: $886-3-573-2519$

lmail: 850335 ancl.itriorg.tw
Mun Tse

Exxon Chemical Company

5200 Bayway Dr.

Baytown, TX 77522 USA

Telephone: $281 / 834-2457$

Fax: 281/834-2395

Email: mun.ftse@exxon.sprint.com

Mark VanLandingham

NIST

Bldg, 226, Rm, B350

Caithersburg, MD 20899-0001 USA

Telephone: $301 / 975-4686$

Fax: 301/990-6891

Email: mark,vanlandingham@nist.gov

Brent Viers

University of Cinncinnati

P.O. Box 210172

Dept. of Chemistry

Cincinnati, OH 45221 USA

Telephone: 513/556-9290

Fax: 513/556-9239

Lmail: viersbd(@email.uc.edu

Paul Winston

Michelin R\&D Corporation

515 Michelin Rd.

P.O. Box 1987

Greenville, SC 29602 USA

Telephone: 864/422-4090

Fax: 864/422-3505

Email: paul.winston( 0 us.michelin.com

Willian Winter

SUNY ESF

121 Edwin C. Jahn Lab

Syracuse, NY 13210 USA

Telephone: $315 / 470-6876$

Fax: $315 / 470-6856$

Lmail: wtwinter@syr.edu 
Kurt Wolske

Aristech Chemical Corp. .

1000 Tech. Center Dr.

Monroeville, PA 15146 USA

Telephone: $412 / 825-3469$

Fax: 412/825-3495

Email: wolskeka@aristechchem.com

Henry Yang

Sid Richardson Carbon Co.

4825 N. Freeway

f1. Worth, 'TX 76021 USA

Telephone: 817/626-3711

Fax: 817/624-9920

Email; sidrich $(\omega)$ metronet.com

Albert Yee

University of Michigan

2300 llayward St., MSE

Ann Arbor, MI 48109 USA

Telephone: 734/763-2445

Fax: $734 / 763+4788$

Email: afyee(o)engin.umich.edu 

